\title{
SHELL PERSONAL ORNAMENTS CRAFT AT THE SITE OF THA KAE, LOPBURI PROVINCE, CENTRAL THAILAND. TRACING THE SOUTHWARD DISPERSAL OF THE DRILLING TECHNIQUE
}

\author{
R. Ciarla ${ }^{1}$, F. Rispoli ${ }^{2}$, P. Yukongdi ${ }^{3}$ \\ 1'Giuseppe Tucci' National Museum of Oriental Art, Rome; ${ }^{2}$ International Association of Mediterranean and Oriental Studies, Rome; \\ ${ }^{3}$ Fine Arts Department of Thailand, Ministry of Culture, Bangkok.
}

\begin{abstract}
The collection of mollusk remains excavated at Tha Kae has been recently re-analyzed and identified as to genera or family level. Out of 5 main fresh/salt-water mollusk families, only Conus and Tridacna were used to make personal ornaments and, for Tridacna, small adzes, during the local Bronze Age (BA) (c. 1100-500 BCE). The study of $100 \mathrm{~kg}$ of production debris and of whole/fragmentary ornaments demonstrated the manufacturing cycle consisted of two main steps: 1) Procurement of the raw material; 2) Transformation in a sequence of six stages of the raw material into the base material for luxuries that arguably entered inter-regional exchange circuits. The manufacturing cycle, possibly part of a system organized at the community level, implied procurement expeditions and skilled craftspeople able to organize and use the relevant tool kit, whose origin can be traced back to the lower Yangtze valley (late fourth millennium BC). The shell-craft cycle also sheds light on the cognitive processes of the craftsmen, who had to make a choice in order to maximize the output of their work. The study provides newly organized data of direct archaeological interest to the field of Southeast Asian pre-protohistory, as well as to those of social and cultural anthropology, cognitive science, marine palaeobiology and to palaeogeography.
\end{abstract}

\section{INTRODUCTION}

Tha Kae (TK) is a pre-protohistoric site (1450’38' N $\left.100^{\circ} 37^{\prime} 10^{\prime \prime} \mathrm{E}\right)$, c. $6 \mathrm{~km}$ north of Lopburi city, on the eastern side of the lower Central Plain of Thailand (Figure 1). In 1945 and 1953 aerial photographs it was recognizable as a double-moated settlement on an ancient river terrace (1015 m.a.s.1.). A circular enclosure (c. 13 ha) was constructed on this terrace during the Iron Age (IA), later to be incorporated within an oval enclosure, formed by a moat and ditch system (c. 220 ha), of which only faint traces survived in 1988 (Figure 2). In the 1960s, quarrying for the extraction of the carbonatic bedrock (caliche), used in building constructions for soil stabilization, start to eat away the terrace.
Looters soon joined the commercial exploitation of the site, being attracted by the presence of prehistoric graves furnished with items much sought by antique collectors (Figure 3). Destruction ended in the mid-1990s with the complete loss of the site (Ciarla and Rispoli 2016).

Officers of the Fine Arts Department of Thailand (Thai FAD) first visited TK in 1979; in 1980 and 1983, the Thai FAD carried out excavations, respectively conducted by Surapol Natapintu and Ratchanie Thosarat. In 1988 the Thai-Italian 'Lopburi Regional Archaeological Project-LoRAP' resumed investigations at what remained of the site until 1993. Preliminary reports of these excavations and several studies of the excavated materials have been published in English and Thai (Bhumadhon 1984; Ciarla 1992, 1994; Ciarla et al. 1989; Cremaschi 1990; Cremaschi et al. 1992; Hanwong 1985; Natapintu 1984a, 1984b, 1995; Rispoli 1992, 1997a, 1997b, 2004, 2005, 2006; Rispoli et al. 2013; Siripanish 1985).

The abundance of shell jewellery manufacturing debris is one of the main features of this site, throughout five cultural phases spanning the Neolithic to the early Ayutthaya period. A preliminary study of the shell industry assigned it to the Neolithic until the mid-BA (1800-700 BCE) (Ciarla 1992).

In this paper, we present the results of our analysis of the shell industry at TK. Our study included four blanks, c. 4000 primary flakes, c. 200 circlet fragments at different stages of manufacture, c. 30 complete and fragmentary artefacts (e.g. bangles, rings, beads and ear-studs) and 88 (including fragmentary ones) sandstone polishers.

\section{WATER SHELL AND LAND SNAIL SPECIES FOUND AT TK}

The remains of the ubiquitous marine and fresh water gastropod shells and land snail shells have been identified to genus and/or family level, including:

- Pila ampullacea (apple snail) (Linnaeus, 1758), relatively abundant at TK, it is an edible freshwater snail endemic in the marshy environments of Southeast Asia.

- Anadara (Tegillarca) granosa (Linnaeus, 1758) (ark shell) is a marine shell adapted to shallow muddy bottoms. Together with the fresh water shell Corbicula Fluminea (golden clam) (Muller, 1774), entered the diet of local inhabitants. At TK both bivalve species 


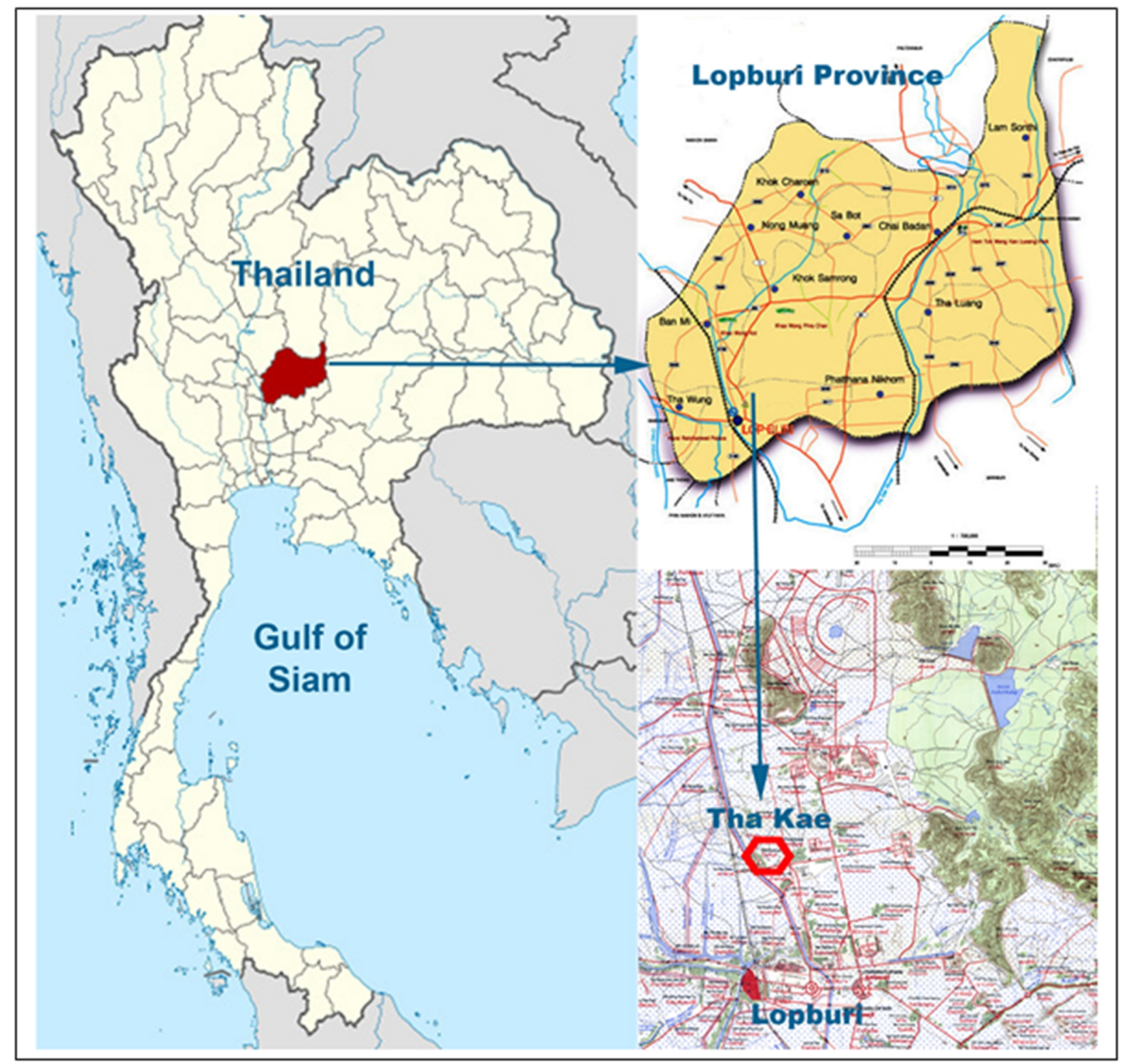

Figure 1: LoRAP study area and location of Tha Kae site.

were used to make beads and pendants in the Neolithic period (c. 1800-1100 BCE).

- Unionidae (freshwater mussel) (Fleming, 1828) is a large edible bivalve, used as mortuary offerings from the Neolithic to the IA (500 BCE-600 CE) at TK and neighbouring sites, as well as at several other sites in Mainland Southeast Asia (MSEA) (Ross and Oxenham 2017).

- Tridacna maxima (Bruguière, 1797) (sub-family Tridacnidae of the Cardiacea family), or 'small giant clam' (on average $20-30 \mathrm{~cm}$ in length), is an edible species ubiquitous in shallow coral reefs of the South Pacific and Indian Oceans; at TK T. maxima was the main raw material used to make personal ornaments and small adzes.
Few complete shell and stone ornaments were found in mortuary contexts from the Neolithic, BA, IA graves, or as finished artefacts in manufacturing waste disposals. Therefore, our typology of the shell jewellery is essentially based on fragments of finished artefacts. An exception is a complete shell bangle (TK\#2258) from Grave 19 in the IA cemetery. The shell bangle, attributable to the BA on typological ground, lay near the right upper arm of the skeleton, associated to a serpentine triangular pendant and, stuck inside the bangle, to a parallelepiped serpentine bead and a bone annular ear-stud, whose twin was, also on the right side, close to the ear region (Figure 4).

We suggest that IA occupants of TK discovered the bangle by chance when disturbing older archaeological deposits. Arguably the new owner attributed to the old shell bangle 


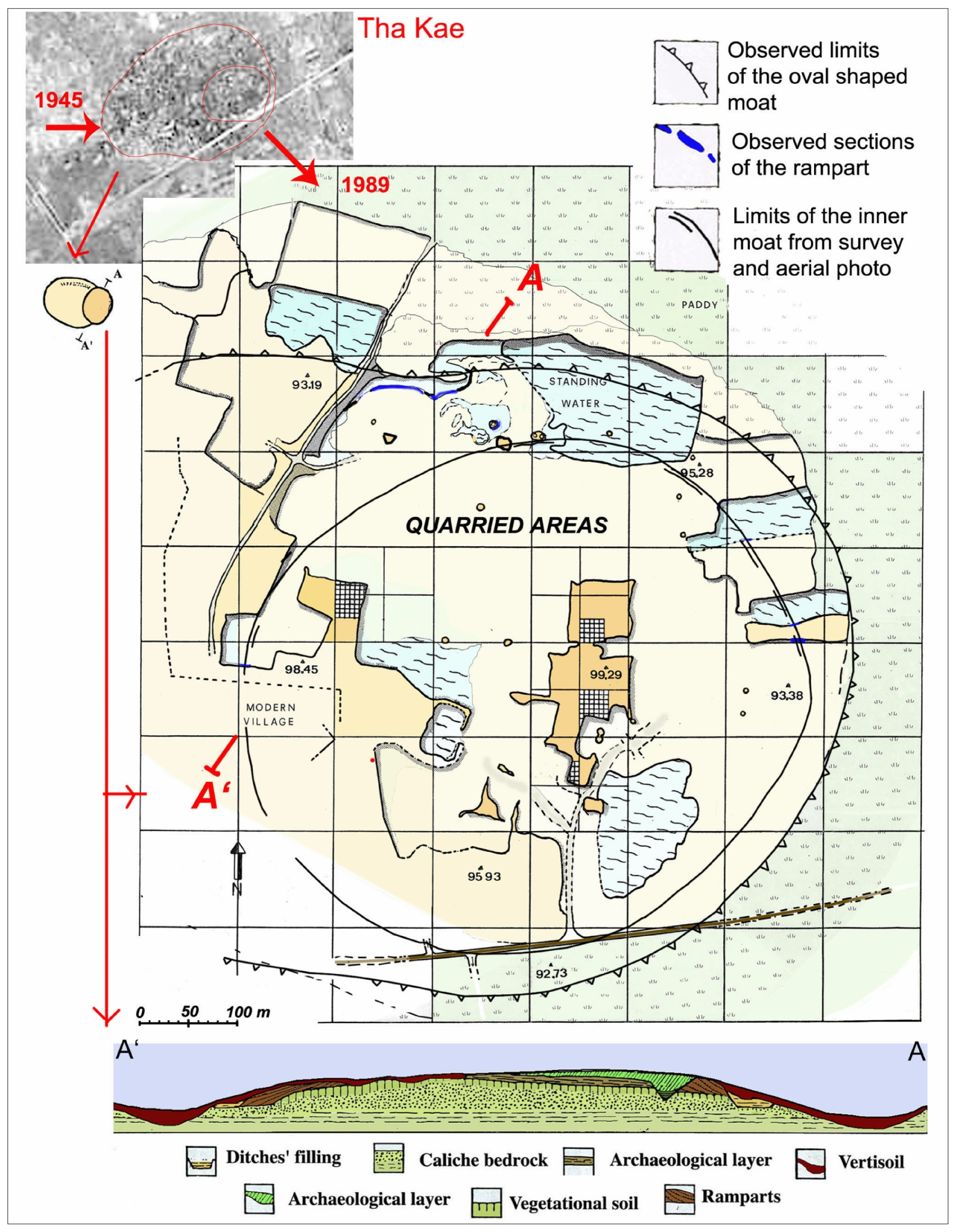

Figure 2 -Tha Kae moated site original extension in a 1945 aerial photograph (upper left) compared to its remnants mapped in 1989 $A-A$ ' geomorphologic section showing archaeological deposit, the moat and rampart of the large enclosure and the ditch of the smaller one. 


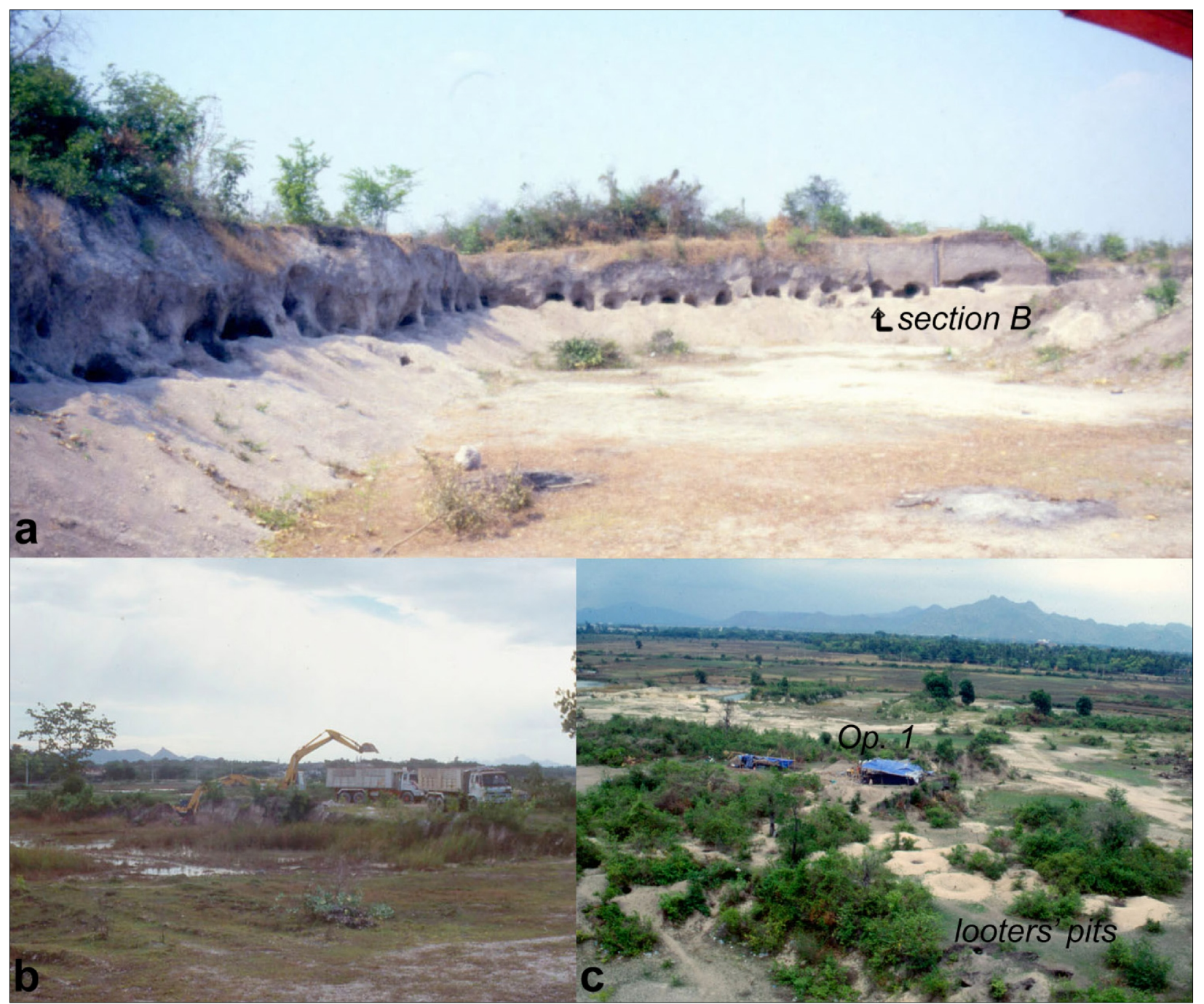

Figure 3 - Tha Kae: a-1988: looted graves along the SE quarry front of the 'Central Island' at the beginning of LoRAP investigations; $b$ - 1989: Backhoes at work in the Northern margin of the site; $c$ - 1993 Cluster of looters' pits and Op. 1 excavation trenches (in the foreground).

a value or meaning, possibly imbued with ideational implications, different from the original one, but still used it as a valuable personal ornament, if not a charm emerged from the earth, although not worn on the arm, the wrist or the anklet.

Similar "antiquarian" re-use of older artefacts is exceptionally documented in China by the discovery of Neolithic jades laid in the grave furniture of early historic burials: e.g., an 'amulet' of the Hongshan culture (c. 3500-2500 BCE) found in the grave of a Zhou aristocrat (Burial 1) at Shangguodian site dated to the Spring and Autumn Period (722-481 BCE) (Fengxiang 2005: Figure 1.7).

That IA disturbance on the underlying archaeological layers took place at TK is evidenced by the widespread presence of shell working waste in the filling of the IA graves, including Grave 19 itself.

We have approached the techno-typological study of the shell industry from the preliminary identification of the materials with which the artefacts were made. However, we appreciate that the distinction between shell and stone ornament manufacture at TK is misleading. Personal ornament types of tridacna shell, limestone, coarse and fine grained marbles are in fact recurrently coincident, and the manufacturing traces observed on the ornaments of tridacna, limestone and marble are basically the same, suggesting that for these materials the same suite of techniques was used (as of Chang 2001:35). Each valve of living individuals of the Tridacnidae family has an outer organic layer (the periostracum) that envelops the calcified exoskeleton that consists of a double layer of aragonite. According to the classification of shell structure types (Kobayashi 1969), the outer layer of a tridacna shell has a crossed-lamellar structure, while the inner layer has a complex prismatic structure. The structure of the two layers contributes to the hardness of the aragonite shell, which measures approximately 3 on the MOHS scale. This is similar to limestone and marble. The same hardness as limestone, marble and aragonite probably offered the prehistoric craftsmen the possibility to work one or the other material with the same suite of techniques. 


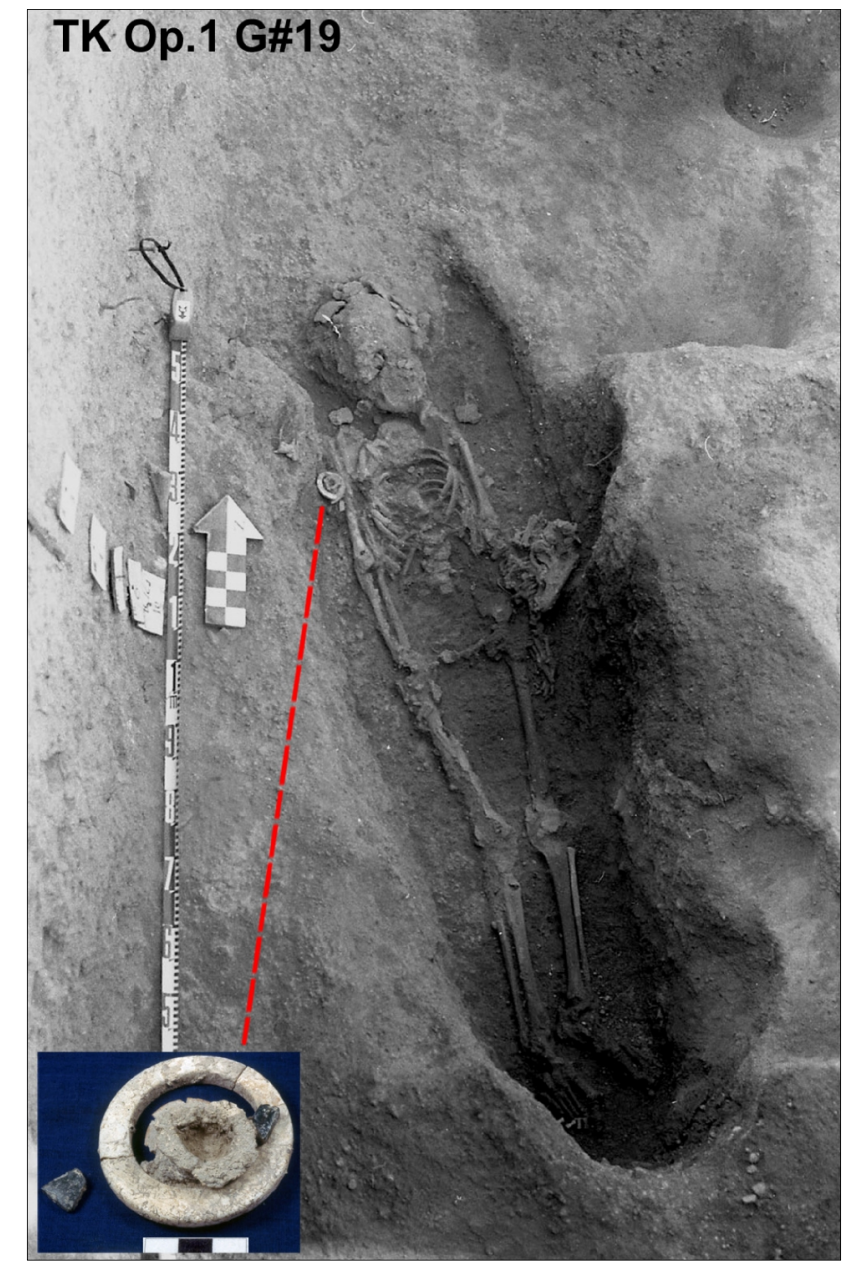

Figure 4 - Tha Kae Op. 1 Sq. A: G\#19 (ca. 200 BCE-300 CE) $N W$ oriented inhumation of a sub-adult individual (ca. 12-15 years old) showing the location of the shell-bangle associated to a bone-ear-stud and two serpentine beads (lower left).

In any case, T. maxima dominates the production debris representative of different stages of manufacture, as well as whole and fragmentary personal ornaments. Nacreous Conus and Trochus shells are also found either as very eroded bangle fragments or as truncated conical microcores possibly from reworked artefacts. We therefore assume that personal ornaments made of shells other than tridacna were imported. The same could be said for the limestone and marble ornaments, which were also imported or worked in some area of the site destroyed before the Thai FAD and LoRAP excavations commenced. Manufacturing debris of yellowish marble ornaments in fact rarely occur in association with shell waste, the only exception being the very flat grey limestone circlets of our Type D, whose manufacturing waste outnumber the shell waste for the same circlet type (Plate $1 . \mathrm{BNG}$ - type D).

Therefore, in the present study we will focus our analyses on the shell craft, leaving the discussion of the personal ornaments made of stone to the forthcoming TK final excavation report.

\section{SHELL PERSONAL ORNAMENT TYPES AT TK}

We have considered three main attributes in analyzing the shell industry: material, class and shape type (the style in Chang 2001). However, a warning is necessary: "Each class, and style, of artefact may occur in a variety of materials and vice versa" as Chang clearly stated (2001:28), and to his Figure 4.1 that illustrates "the cross-cutting categories of 'material' and 'artefact class' that must be negotiated when considering personal ornaments", as well as to his definition of the classes of personal ornaments (Chang 2001:29-30) we refer to here.

Four main classes of shell personal ornaments have been recognized at TK: 1. Bangles; 2. Rings; 3. Earstuds; 4. Beads (Plates 1-4).

\section{Bangles}

Are closed circlets made of homogenous material that could be worn on the arm (Chang 2001: 30, 32). Some of the circlets in this class are large enough to be worn on the ankles or the arms, however in the absence of evidence provided by unequivocal findings in mortuary contexts, we provisionally maintain the term 'bangle' for all the circlets included in this class, of which six main profiles have been identified at TK:

Type A: circlet with 'D-shaped' radial section (height $[\mathrm{H}]$ equal or almost equal to its width $[\mathrm{W}]: \mathrm{H} \approx \mathrm{W}$ ) in which the straight side is formed by the inner edge (Chang 2001:33) (Plate 1.BNG type A). One of the earliest examples of this type is attested at the Neolithic site of Khok Phanom Di (KPD) (cat. 579) (Pilditch 1993:136); but it became popular only in the early BA (c. 1100-800 BCE), as indicated, in Central Thailand, at Nong Nor (NN) (cat. \#198, 394, 466, 741) (Chang 2001:59, 62), at Non Mak La (NML) (cat. \#32301, 32081, 19018) and Non Pa Wai (NPW) (cat. \#14262, 20121, 20123) (Chang 2001:269, 279), and Phromthin Tai (http://media.uow.edu.au/news/UOW189914.html; Lertcharnrit 2009, 2010, 2014); in Northeast Thailand at Ban Non Wat (BNW) (cat. \#18806) (Higham 2012a:65), Ban Lum Khao (BLK) (cat. \#179) (Chang 2004:219) and Non Pa Kluay (NPK) (cat. NPK-658-1 and 2) (Wilen 1989:57). These simple bangles represent a long-lived type: e.g. BNW in the IA 1 Mortuary Phase (420-100 BCE) (cat. \#19550, 19690, 19754, 18082) (Higham 2012g: 253).

Type Aa: it is a variant of type A, in this case the 'Dshaped' radial section is more 'flat' than type A (radial $\mathrm{W}>\mathrm{H})$ (Plate 1.BNG type Aa). Circlets with 'Flat Dshaped' section had a lesser circulation than type A; so far, comparisons have been encountered only at $\mathrm{NN}$ (cat. \#877) (Chang 2001:61), and KPD (cat. \#658d) (Pilditch 1993:135). At NPW, three Type Aa bangles were found on the right arm of the individual in Sq.B Burial 6 (cat. \#16978) (Pigott and Natapintu 1986: 20).

Type B: this is a 'band-shaped' bangle of rectangular radial section $(\mathrm{H}>2 \mathrm{~W})$ (Plate $1 . \mathrm{BNG}$ type $\mathrm{B})$. As with type A, the 'band-shaped' bangle had a wide circulation, particularly in Northeast Thailand. Abundant comparisons are present at BLK (cat. \#56, 65, 309, 746) (Chang 
2001:102, 106), and at BNW in burials of the BA Period 2 (1000-900 BCE) (cat. \#2266, 2377, 2345-2349, 2378, 2397, 2352-2358, 5826, 18832-18834, 1226512266) (Higham 2012a:86; 2012b:113-115), and BA Period 3 (900-800 BCE) (cat. \#12225 and 25495) (Higham 2012c:193, 218). Several of the dead at this site wore sets of band-shaped bangles, ranging from three to seven circlets on each arm, suggesting the presence of wealthy individuals.

Type Ba: the 'pseudo-double band' bangle is a variant of Type $\mathrm{B}$, characterized by a deep groove that divides the external surface into two halves, thus producing the visual effect of two superimposed band-shaped bangles (Plate 1.BNG type Ba). Type Ba is present in Northeast Thailand: e.g., 5 Ba type bangles (cat. \#12225) covered the arms of the individual inhumed at BNW in Burial 262 of the BA Period 3 (900-800 BCE) (Higham 2012c:193).

Type C: the trapezoidal radial section and the relatively small diameter are the main traits of this type (Plate 1. BNG type C). Comparisons are restricted to the Neolithic site of KPD (cat. \#533, 658, 2039) (Pilditch 1993:136).

Type D: the flat lenticular radial section $(\mathrm{H}<2 \mathrm{~W})$ characterizes this circlet, more properly a disc that "projects extensively from the arm" (Chang 2001:33) (Plate 1.BNG type D). Type D is preferably made of stone (mainly slate or limestone) and it is the only type, either of shell or stone, whose passing hole was drilled monodirectionally (monopolar drilling) (Figure 5). Comparisons for the shell bangles type D at KPD (cat. \#616, 997, 2039d) (Pilditch 1993: 135) suggest that Types C and D might represent a Neolithic novelty in the region.

Type E: It is a circlet with a rectangular radial section, characterized by scalloped edges that make its profile similar to a chain of small discs (Plate1. BNG type E). At $\mathrm{TK}$, this type is represented by a single fragment (TK\#2559) comparable to "Style 24 bands, all examples so far in bronze, with rectangular radial section ..." (Chang 2001:35). Chang's observation that "... all examples so far in bronze ..." and the provenience of the TK fragment from the IA upper deposit, suggest that it might be an IA shell-made imitation of a coeval copper-bronze scalloped bangle.

Type F: a heavy body characterizes this bangle type carved into thick pieces of tridacna shell or marble, in imitation of the natural helicoid architecture of a large gastropod shell (arguably Trochus). Few fragments of this type were found at TK, the radial section might be called ' $\mathrm{G}$ shaped' (see Styles 16-17 in Chang 2001:33) (Plate 1. BNG type F). A bangle of this type, but in marble (cat. \#16060) (Chang 2001:265, 270), was found associated to a bangle with 'Flat D-shaped' section, a stone polisher, three bone tools and the fragments of an oxidized copper-base tool in the furniture of Op.1 Burial 1 at NPW, datable to the early-middle BA (1000-700 BCE) (Pigott et al. 1997:122, Figure 6).

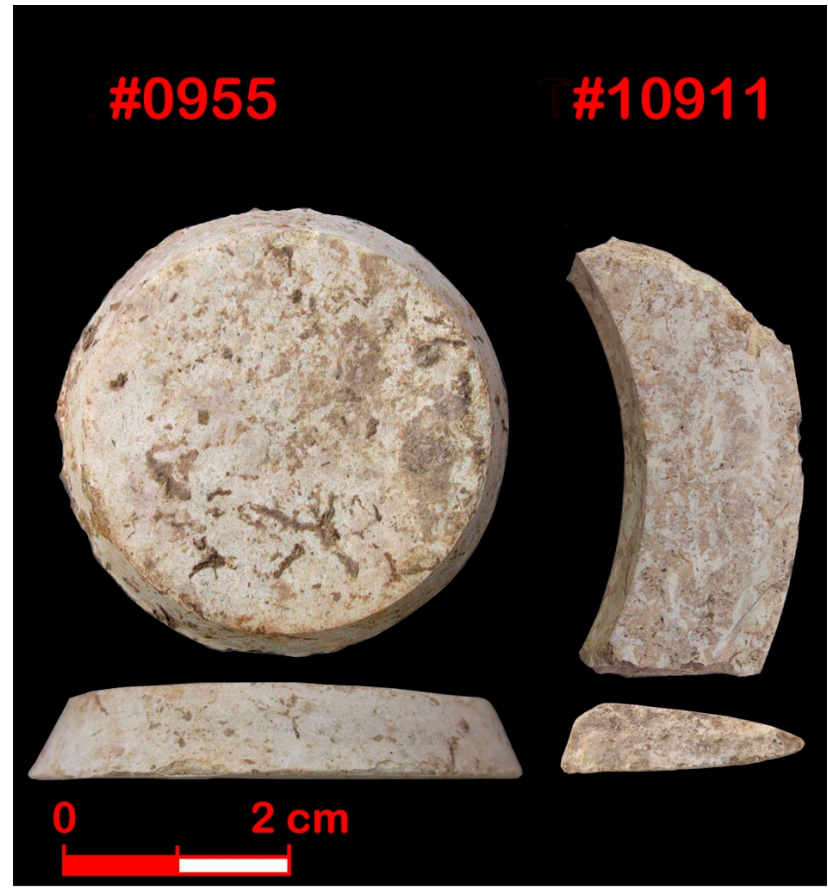

Figure 5 - Fragment of a limestone, flat bangle of type D and truncated conical limestone core, both evidencing the use of mono-polar boring.

Rings

Circlets made of homogenous material that can be worn on the fingers or toes (Chang 2001:30). Only two types have been identified at TK:

Type A: for general shape and for the 'D-shaped' radial section, these rings (TK\# 175, 10233) are miniature versions, due to their obvious function, of Type A bangles (Plate 2. Ring type A). This type of finger-ring finds comparison at BNW in late BA contexts (800-420 BCE) (cat. \#11709, 11593) (Higham 2012e:297; Higham 2012f:428).

Type B: rings obtained by 'slicing' the natural architecture of a gastropod mollusc (Plate 2. Ring type B). In Central Thailand these rather fragile finger-rings (TK\# 876.1-.3, 1706) were found at Khok Charoen (cat. SH19 possibly of Cyclophorus floridus Pfeiffer and SH20 identified as Conus), associated with BA contexts (1000-700 BCE) (Ho 1984: 291, Figure 11.28).

\section{Earplugs}

Any object, either of a homogenous material or of composite manufacture, which probably were inserted into the artificially modified earlobes (Chang 2001:30); at TK only two types are documented.

Type A: is a 'nail-shaped' earplug consisting of a cylindrical stem with more or less tapered end and flared, discshaped flathead seldom decorated by several incised lines radiating from a tiny hole pierced at the centre (Plate 3.EPG type A). At TK type A earplugs have been found (1984) in TT9-Grave 2 on both sides of the deceased's skull, associated with a necklace of 'I-shaped' and disc-shaped shell beads and to a ceramic vessel 
placed on the legs of the dead (Hanwong 1985/2528:97, 220-221, figure 30.3). TT9-Grave 2 is datable to the late Neolithic (c. 1400-1100 BCE), as also suggested by comparisons with the marble earplugs found at NML (e.g., cat. \#31118 in Chang 2001:280-281) and at Khok Charoen (cat. ST102 in Ho 1984: Figure 11.25). At TK three further examples, one of shell and two of fine grained white marble (TK\#2111, 10906, 10931) have been excavated from the layer coeval with the disturbances operated by the IA grave pits on the underlying Neolithic/BA layers.

Type B: also called 'drum-shaped' due to its similarity with Dongson kettledrums, is characterized by a marked circular flathead on a short truncated conical body (Plate 3. EPG type B). Four concentric incised circles decorate the flat disc, while two incised lines decorate the edge of the stalk to be inserted into the pierced earlobe. At TK the only pair of drum-shaped earplugs (TK\#2325), associated to a necklace of 4 cylindrical shell beads (TK\#2324), was found in situ on both sides of the deceased's skull in the IA Grave 27.

Beads

Any perforated object generally worn on a cord or a wire, or sewn onto clothing for personal ornament purposes (Chang 2001:30). In the pre- and protohistoric sites of MSEA beads represent the most frequent personal ornament and usually the most varied in terms of shape and materials. In central Thailand from the Neolithic to the IA shell and limestone were the raw materials preferentially used for making beads. Three main shell bead types are represented at TK:

Type A: Flat, centrally drilled circular beads with rectangular radial section are generally called disc-shaped beads (Plate 4. BD type A). Widespread in MSEA this is a long-lived type documented from the Neolithic to the IA (1800 BCE-600 CE). At TK ark shell, tridacna and undetermined nacreous shells were used to make beads variable in diameter from $5.5 \mathrm{~mm}$ (passing hole $\varnothing 1.5-1.8 \mathrm{~mm}$; thickness $1 \mathrm{~mm}$ ) to $1.9 \mathrm{~mm}$ (passing hole $\varnothing$ 0.7-0.8 mm; thickness 0.04-0.05 mm) (Figures 6-7).

Type B: includes beads with simple cylindrical body centrally pierced along its longer axis (Plate 4. BD type B). At TK this type is documented in situ only in the furniture of Grave 27 (TK\# 2324) finding comparisons at BNW (cat. \#20261, 19996, 12246, 15129) (Higham 2012a:56; 2012b:107; 2012c:187; 2012d:230), and at BLK (cat. \#1332) (Chang 2001:102), where they are dated c. 1000-700 BCE.

Type C: the slender cylindrical body of round to ovoid transverse section, is more or less constricted in its central part. When the height of the body exceeds the diameter of the flared ends we call this type $\mathrm{Ca}$ or 'Ishaped' bead (Plate 4.BD type C). When, on the contrary, the length of the flared ends exceeds the body height we call it type $\mathrm{Cb}$ or 'H-shaped' bead. At TK only type $\mathrm{Ca}$ is present (TK\#6743, 6792). Comparable beads are known from KPD, Burial 15, Mortuary Period 5 (Pilditch 1993: Figure 47), NPW (cat. \#6881) and NML (cat. \#30954) (Chang 2001:267, 277), all datable c. $2000-1500 \mathrm{BCE}$

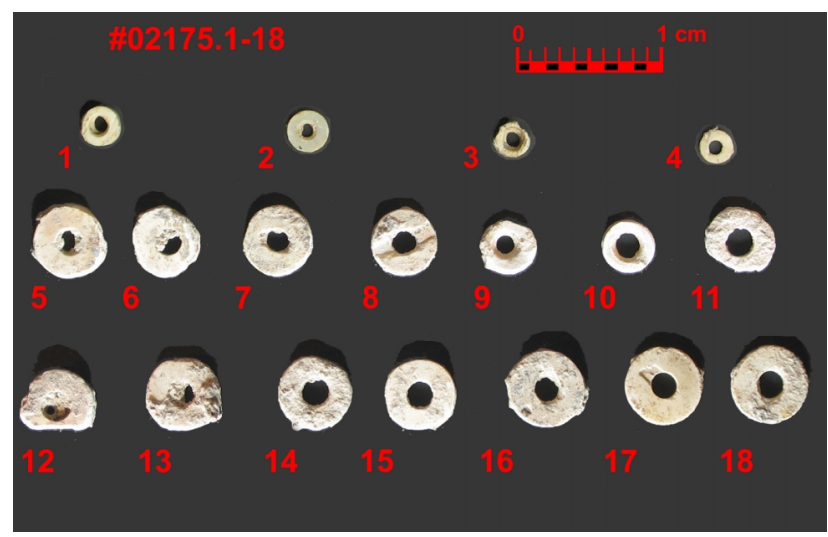

Figure 6-TK\#2175 diameter variability of disc-shaped beads (Type A) found in a cluster near a looted grave along Op. 1 western quarry front.

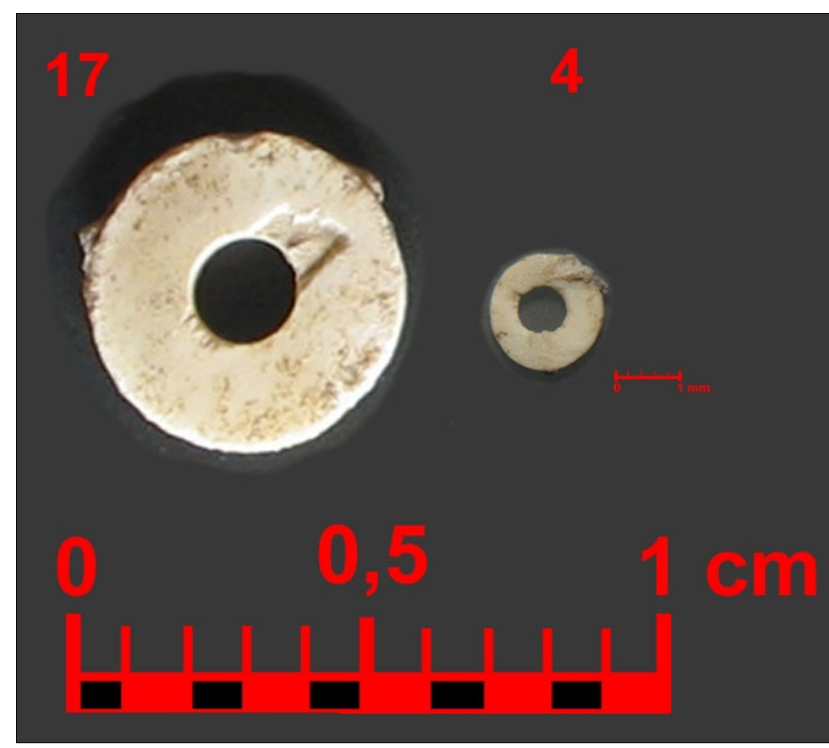

Figure 7 - TK\#2175: view of bead 4 (smallest in the series) and bead 17 (largest) under optical microscope. Note use wears on the edge of bead 17 passing hole.

The analysis of the stratigraphic contexts at TK and the typological comparisons, ascertained that the tridacna production of personal ornaments, a class of artefacts we might define as luxuries, or prestige 'commodities' (Sraffa 1963:7-8; Trubbit 2003:245-248), began in the late second millennium BCE (final Neolithic), flourished during the initial and middle BA (c. 1100-700 BCE) and ended around the mid-first millennium BCE (late BA-early IA). In the IA new jewellery types and materials (copper-bronze, iron, glass and semiprecious stones) were first found with, and then replaced, shell ornaments. Possibly, this re-orientation 
of the means of status display was consequent to not sporadic contacts with alien cultural environments (traceable to the Indian Subcontinent and China) and the ensuing localization of exotic ideas concerning personal adornment and the projection of status.

\section{THE MANUFACTURING CYCLE}

This research rests on the study of the morphology of individual production waste (Ciarla 1987: 487-88) in order to reconstruct their relative position within the manufacturing cycle. The study includes the analysis of discarded flakes and fragments of semi-finished and finished artefacts, as such or with morphological modifications aimed at or due to waste recycling (Schiffer 1972:158). Wherever possible we have distinguished between evidence relatable to a main, primary 'production line' and evidence pertaining to a secondary line of 'waste recycling', in order to ascertain eventual differences between the two lines either in the technology or in the artefacts produced.

We distinguish two main operational steps in the primary manufacturing cycle:

A) the procurement of the raw material;

B) the transformation of the raw material into base material by investment of a variable quantity of energy (that is the outcome of time plus labour).

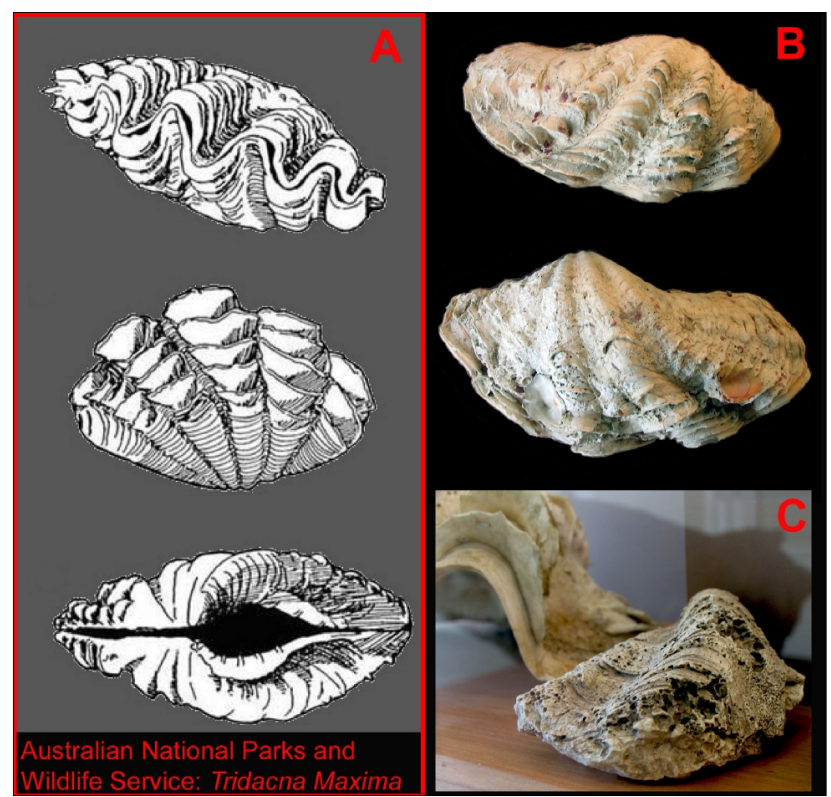

Figure 8-A. Morphology of a Tridacna maxima bivalve shell; $B$. Two valves of Tridana maxima recently collected on the shores of the Gulf of Thailand; C. Fragment of Tridacna shell from $T K$, note the dense distribution of sponge bore-holes, and the traces of encruster organisms. (B. and $C$. on display in the King Narai Palace National Museum).

The raw material

Out of the eight main Tridacnidae family members still distributed along the coasts of the Indo-Pacific Basin (Othman et al. 2010), we recognize the fragments of raw material under discussion as derived from T. maxima shells (Figure 8a-c). The valves of this sedentary species of subtidal habitats grow to considerable thickness (c. $1 \mathrm{~cm}$ per year), compatible with the thickest fragments $(<6-8 \mathrm{~cm}>)$ found at TK.

The highest number of fragments recovered from our excavations derives from shells that, judging from the thickness and the undulating, concentric growth-striae, should represent adult individuals. In general, the shell fragments in our sample are relatively well preserved, showing the protracted action of symbiotic organisms, sponge bore-holes, and traces of encruster organisms (mainly barnacles and tube worms) that usually develop post-mortem (Figure $8 \mathrm{c}$ ). Therefore, we assume that the shells selected for craft purposes belong to empty shells either embedded in their natural environment on the surface of reefs or sand beyond the low-water of the intertidal zone, or washed up on the tidal beach by powerful storms. For example, the $T$. gigas shells, a species now extinct in Thai waters, recently discovered on the coasts of Surin Islands are in fact beached valves of various individuals possibly transported at different times by heavy storms during the Southwest monsoon (Kittiwattanawong 2011).

Therefore, we are keen to consider the tridacna fragments recovered at TK as beached shells or 'semi-fossil' shells embedded in the ancient beaches of the Thai palaeogulf, which in the early first millennium BCE was much closer to Lopburi than it is today (Somboon 1990: 57-70; Negri 2009; Siripong 2010; Hutangkura 2014). This hypothesis is also supported by $\mathrm{C} 14$ dates of TK shell fragments analyzed by T. F. G. Higham. The calibrated dates span from the fifth to the mid second millennium BCE, witnessing individuals much older than the date of their actual use as raw material.

Radiocarbon age determination (AMS measurement) for the Tha Kae tridacna samples (The University of Waikato, Radiocarbon Dating Laboratory)

\begin{tabular}{|c|c|c|c|c|}
\hline No. & $\begin{array}{l}\text { Sample Descrip- } \\
\text { tion }\end{array}$ & $\begin{array}{l}\text { OxCal } \\
\text { No. }\end{array}$ & Result & $\begin{array}{l}\text { Calibrated } \\
\text { BCE }\end{array}$ \\
\hline TK1 & $\begin{array}{l}\text { fragment of raw } \\
\text { material }\end{array}$ & $\begin{array}{l}\text { Wk- } \\
37057\end{array}$ & $\begin{array}{l}3098 \pm 25 \\
\text { BP }\end{array}$ & $\begin{array}{l}\text { 1426-1292 } \\
\text { BCE }\end{array}$ \\
\hline TK2 & fragment of waste & $\begin{array}{l}\text { Wk- } \\
37058\end{array}$ & $\begin{array}{l}5788 \pm 25 \\
\text { BP }\end{array}$ & $\begin{array}{l}4709-4555 \\
\text { BCE }\end{array}$ \\
\hline TK3 & fragment of waste & $\begin{array}{l}\text { Wk- } \\
37059\end{array}$ & $\begin{array}{l}5835 \pm 25 \\
\text { BP }\end{array}$ & $\begin{array}{l}4782-4652 \\
\text { BCE }\end{array}$ \\
\hline TK4 & $\begin{array}{l}\text { fragment of unfin- } \\
\text { ished bangle }\end{array}$ & $\begin{array}{l}\text { Wk- } \\
37060\end{array}$ & $\begin{array}{l}3282 \pm 25 \\
\text { BP }\end{array}$ & $\begin{array}{l}1618-1504 \\
\text { BCE }\end{array}$ \\
\hline TK5 & $\begin{array}{l}\text { fragment of bore } \\
\text { core }\end{array}$ & $\begin{array}{l}\text { Wk- } \\
37061\end{array}$ & $\begin{array}{l}3880 \pm 25 \\
\text { BP }\end{array}$ & $\begin{array}{l}2464-2290 \\
\text { BCE }\end{array}$ \\
\hline TK6 & $\begin{array}{l}\text { fragment of unfin- } \\
\text { ished bangle }\end{array}$ & $\begin{array}{l}\text { Wk- } \\
37062\end{array}$ & $\begin{array}{l}3153 \pm 25 \\
\text { BP }\end{array}$ & $\begin{array}{l}\text { 1498-1392 } \\
\text { BCE }\end{array}$ \\
\hline
\end{tabular}

As for the procurement of the tridacna shells processed at Tha Kae we have avoided the proposition of abstract models, considering the paucity of relevant published data, both in Thai and foreign languages, apart from the few detailed studies focused either on purely biological aspects, or on actual economic aspects of tridacnids mariculture. In any case, we are not aware of ethno-anthropological studies on traditional molluscs harvesting patterns, of tridacnids in particular, along the coasts of MSEA. We would rather signal an anthropological study on the rural context 


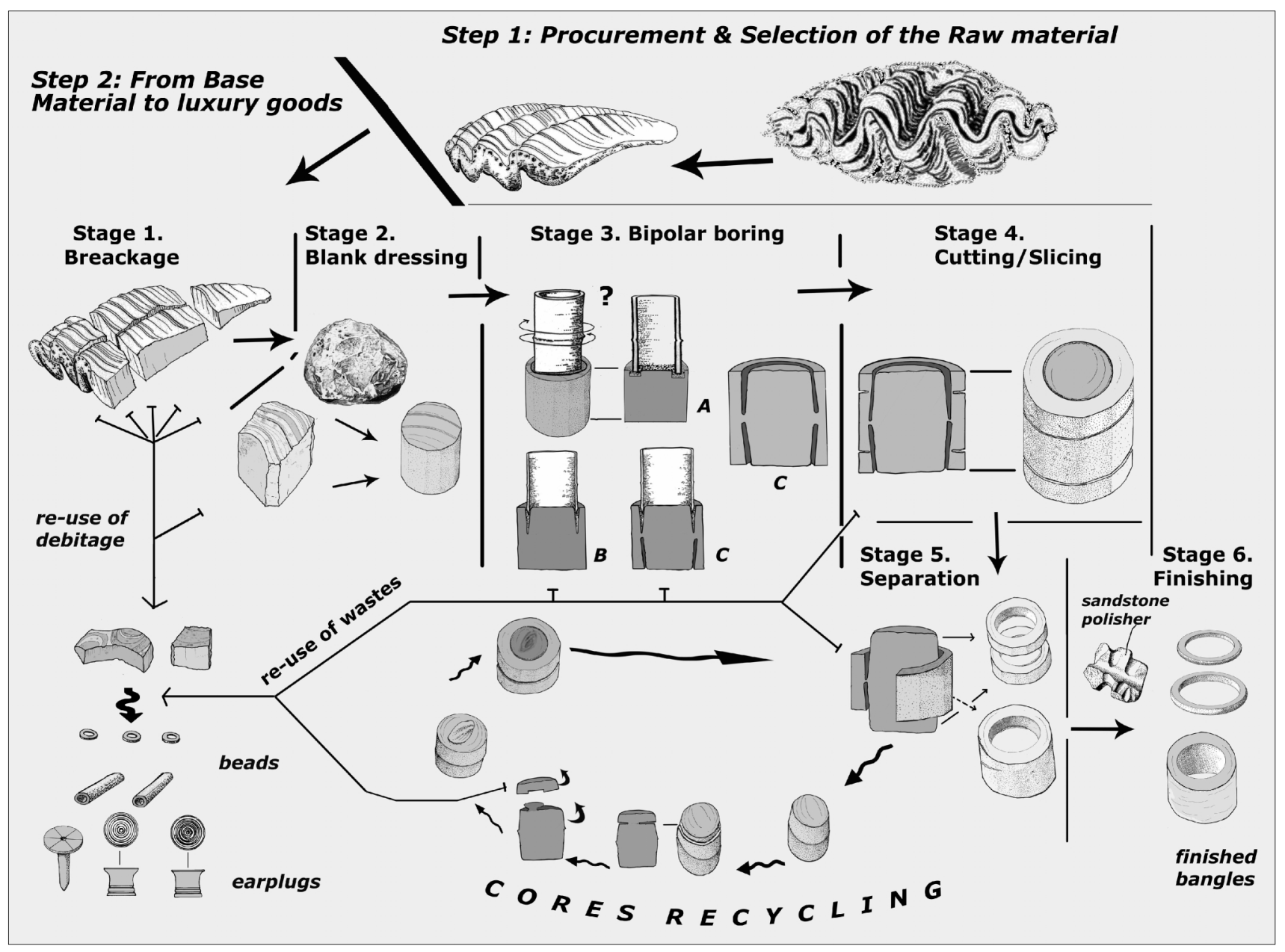

Figure 9 -Reconstruction of shell bangles and other personal ornaments production cycle at TK.

of giant clam mariculture in Solomon Islands particularly stimulating and suggestive (Hviding 1993:16-26). For example, in the case Hviding observed, the important role women play in the traditional shellfish gathering and reef gleaning, the seasonality of the annual patterns in the harvesting of molluses (particularly the annual shifts in tidal cycles), the relevant role that tridacna species had and have as protein rich food sources, or their relative importance in folk ideational constructions related to food, with the T. maxima ranking third in a decreasing order of most palatable tridacnids, followed by the T. gigas (4th). This latter is conversely considered the food 'number one' to be presented for the important occasions. Also illuminating, for the possible implications it might have with our case study, are the traditional post-harvesting methods, including the butchering and the selection of the giant clams' edible parts, and the ways they are cooked, while the actual shells are used for ceremonial and pragmatic purposes. In this case "T. gigas shells are undoubtedly the most widely used, owing to their size and to their suitability in fossilized condition for the artifact manufacture" (Hviding 1993:25). While this latter observation supports the hypothesis advanced in the preceding paragraph, the data Hviding pro- vides are extremely informative and suggestive, but not directly applicable to the reconstruction of the procurement of the tridacna shells treated at Tha Kae.

Therefore, we can only hypothesise on how the shells reached the manufacturing site in the Lopburi Plain. We cannot ascertain if the craftsmen organized regular gleaning expeditions from the working site to the coast or if the shells were moved from the coast to the working site within down-the-line local exchange circuits. In both cases, once the raw material reached the workshop(s) it entered the manufacturing cycle crossing the fundamental passage from raw material to base material.

From raw material to base material: the beginning of the manufacturing cycle

The transformation of a raw material into a base material is rather subtle in the context of a prehistoric craft. However, it is useful to discriminate the raw material in its original status of natural resource, from the raw material that, having acquired a value derived by the expenditure of energy to be extracted (selected, gleaned and transported), physically entered into the production cycle (Figure 9). 


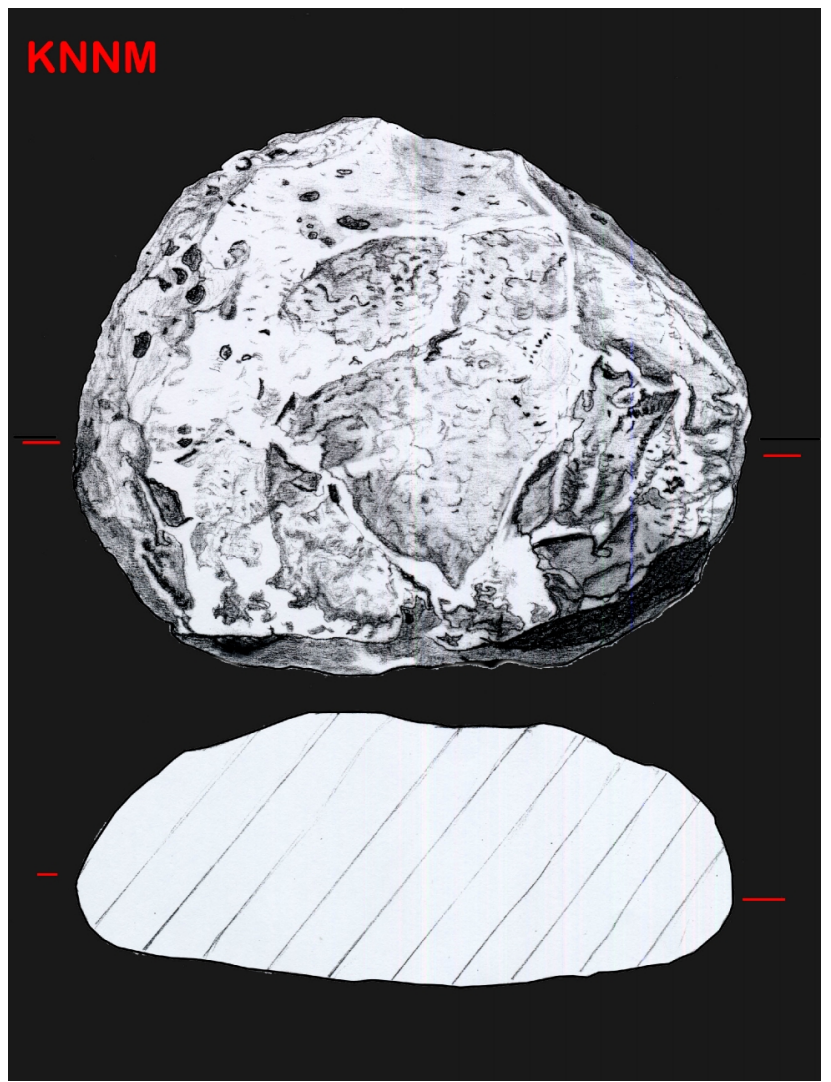

Figure 10 - Drawing of a tridacna spheroid blank from TK (King Narai Palace National Museum, no accession n.).

\section{Stage 1: Breakage of the shell}

The first stage of the manufacturing cycle, consisted in breaking the valves into large pieces. After the first breakage of the shell into pieces of variable size, the craftsman selected the ones with the thickness he envisaged suitable to be transformed into blanks. From a cognitive point of view this stage is of fundamental importance as it reveals the skill of the craftsman to imagine how he should proceed and, probably, how many pieces of finished product he could make from the selected piece, possibly with a minimum loss of base material. Therefore, in this stage the selected chunks of base material were reduced into rough blanks of spheroid or polyhedral shape (Figure 9 stages 1.2.; Figure 10). Several kilos of discarded flakes (c. 4000 primary flakes were recovered in LoRAP Op. 1 and 4) suggest a preliminary treatment of the base material to lower the natural roughness of the shell's outer surface and to prepare blanks of the desired shape. This preliminary operation consisted in chipping (probably by direct percussion with a hammer stone) and polishing with sandstone slabs the outer ridges of the T. maxima shell (characterized by 6 to 12 radial folds, intermediate riblets and scales), as well as the rough fractured edges. In some instances, pieces of discarded base material evidence linear, quite neat slits cut into their thickest part, running parallel to the shell plane (e.g. TK\# 0284, 2530) (Figure 11 A-B). Due to the smooth and even 'U-shaped' profile of the slits, we hypothesize that the tool used was a string-saw, which was one of the two basic tools used in the making of the circlets (see 'stage 4'). However, in the fragments just mentioned the slits most probably represent aborted attempts to slice pieces of base material in order to maximize its yield, or might be tests, or exercises the craftsmen performed.

Thus far, only few actual blanks have been found in the manufacturing debris at TK, indicating that in this stage the rate of waste was relatively low.

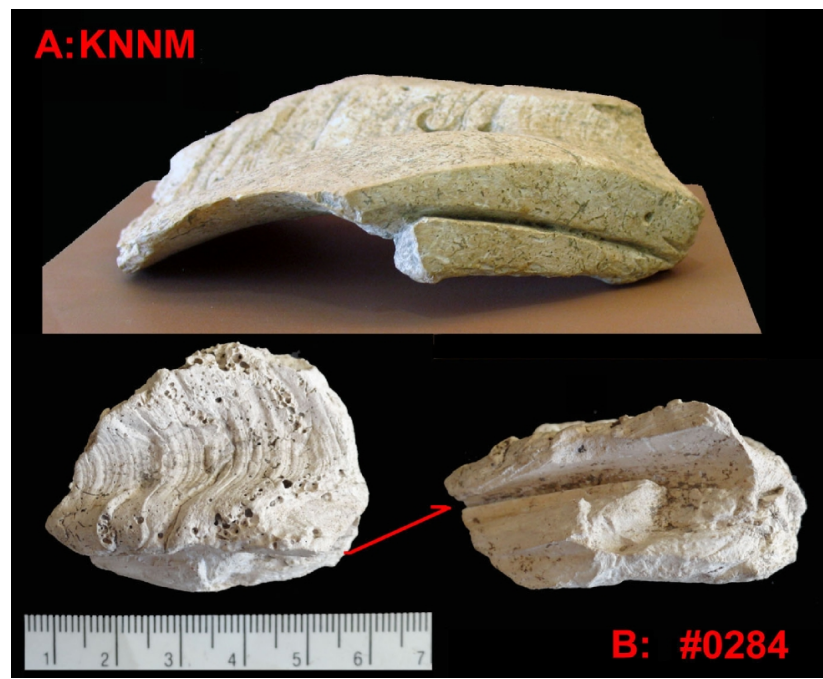

Figure 11 A-Pieces of discarded base material showing the slits cut parallel to the shell mantle plane (e.g. A: TK surface; B: TK Op.1 SqA TK\# 0284).

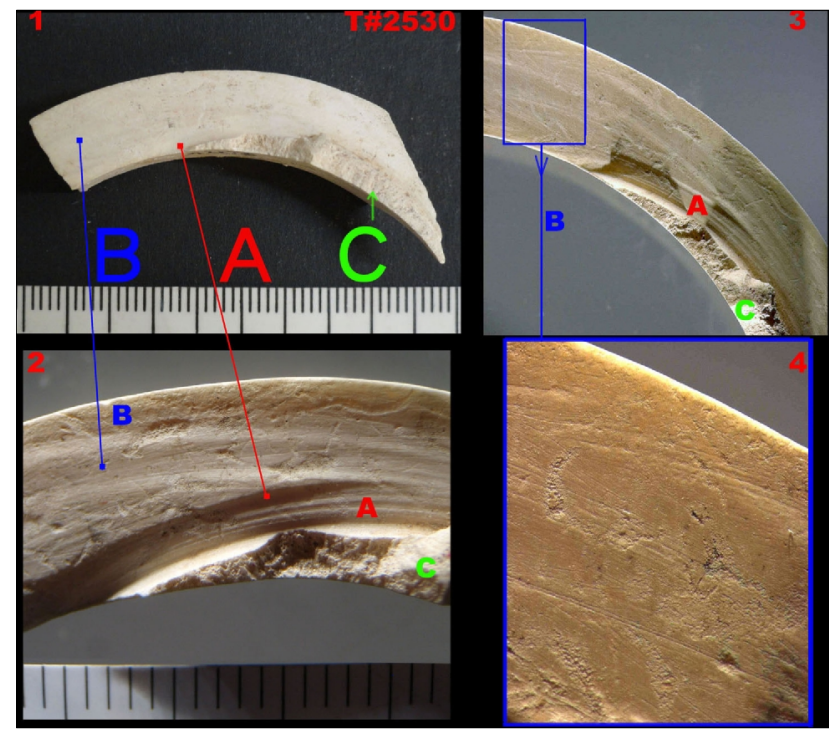

Figure 11 B-1.-2. Fragment of circlet (TK Op.1 SqA T\#2530) broken at the separation from the core (Stage 5): A. concentric traces left by the drill bit (Stage 3); B. light irregular crests and striations left by the saw (Stage 4); C. jagged ridge on the inner edge; 3. the light crests represent veins of resistance to the saw action; 4. the striations are traces of the saw cutting (under a Leica MZ 125 stereo microscope at 25x). 


\section{Stage 2: Dressing of the blank}

Although we have only indirect indication of the final blank's dressing, we can safely argue that this operation implied grinding the blank's surface to make a rough preform with two opposite flattish surfaces. On one of these surfaces the craftsman would start the perforation of the passing hole, this was achieved exploiting the partial rotary motion of a drill (Childe 1954: 189-192). The drilling, or boring, through the vertical axis of the preform would result in the production of a semi-finished artefact, formed by an external 'coat' around an internal bore core (or carrot) of cylindrical-to-truncated conical or bi-conical shape (Childe 1954:191). The bore core had to be eventually detached before the finishing stages. Typical of a 'truncated bi-conical' bore core is the eccentricity of the two halves of the solid, to be considered as unequivocal evidence of bipolar (or 'two-directional') trepanation (Figure 12).

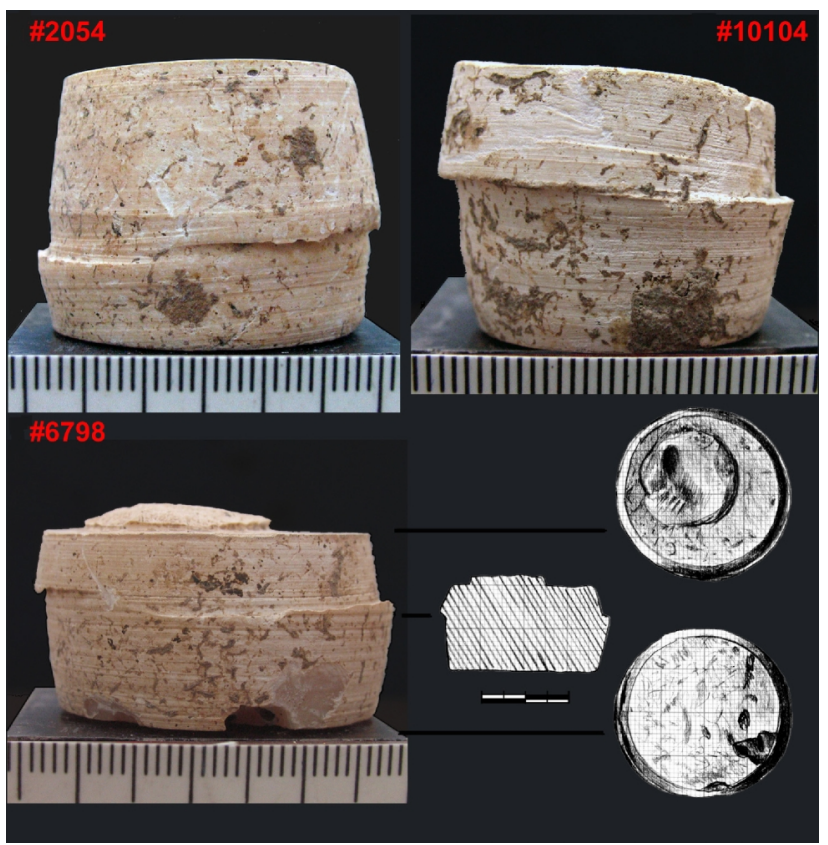

Figure 12 - Truncated bi-conical bore cores (TK\# 0254, 10104, 6798) showing the typical eccentricity of the two halves of the solid produced by bipolar (or two-directional) trepanation. Note the traces of alternate rotary motion on the surface of the cores.

\section{Stage 3: Coring of the blank}

In his discussion on rotary motion, Childe linked bi-conical bore holes to bi-polar drilling, and bore cores to the action of tubular drill bits mounted on a bow drill or a pump drill (Childe1954: 189-192). In 1957, Semenov (1964), discussing how to pierce a hole into jade artefacts, suggested that flint or agate burins might have been used to cut a groove around a circular template put on the jade preform. Once the groove was deep enough, the template was removed, keeping the burin moving inside the groove until the internal core could be detached. Semenov further developed his idea, propounding a tool that worked as a pair of compasses. This tool would consist of a simple cross-bar with holes pierced at regular distances. One end of the cross-bar would then be fixed on the piece of jade to be cut, while a burin or auger, inserted in one of the holes along the crossbar, would be rotated round, thus cutting the stone. Several studies of East Asian archaeological stone jewellery making debris and related tools, and few experimental replications, suggest that the boring methods envisaged by Childe and Semenov were both used by the craftsmen: the boring operation could have been performed either with a hollow drill-bit mounted on a bow or a pump drill, or by a rotating device armed with a stone drill bit (Nguyen 1985, 1996b; Pilditch 1993; Liu et al. 2009; Qin 2011; Tang 2000; Sun 2009; Hung 2014).

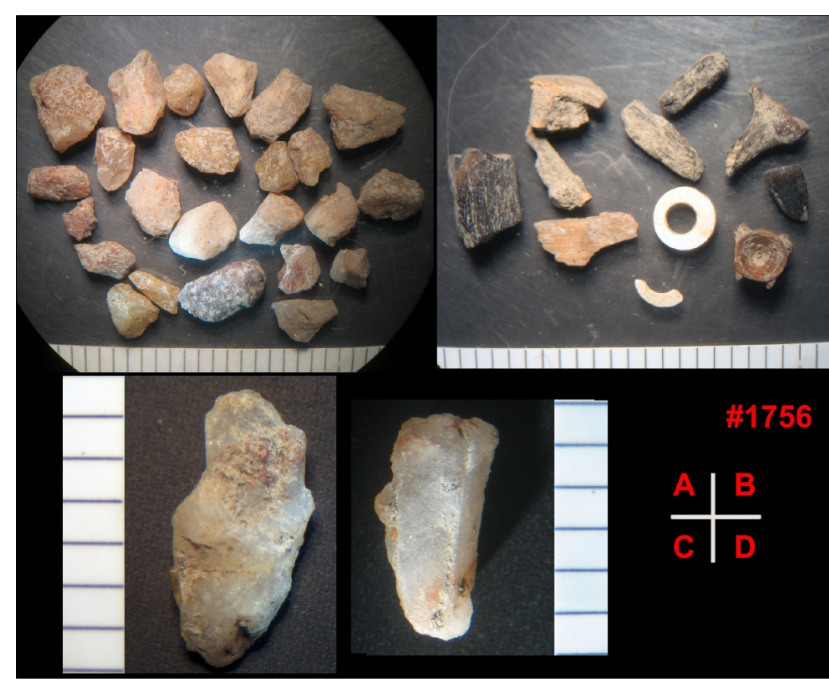

Figure 13-A. amorphous quartz chips; $B$. flakes of charred mammal bones, fish bones and a disc-shaped shell bead; C.-D. two unmodified quartz crystal fragments from a soil sample (TK\#1756 ca. $9 \mathrm{~kg}$ ) part of the filling of the Iron Age G\#16 cut into the late Neolithic-Bronze Age deposit. After sieving ( $\# 5 \mathrm{~mm}$ mash) in a solution of $5 \%$ alcohol in water.

At TK stone drill bits that could possibly be related to the boring stage of the tridacna shell jewellery have not been recognized. A sample of c. $90 \mathrm{~kg}$ of soil excavated in the main area of the shell manufacturing debris (c. $50 \mathrm{~m} 2$ in Op. 1 and c. $12,5 \mathrm{~m} 2$ in Op. 4) was carefully sieved (\#5 $\mathrm{mm}$ mash) in a solution of 5 percent alcohol in water during the 2013 study season. Beside minute flakes of potsherds, micro-faunal remains and tiny glass and shell beads, we recovered millimetric chips of quartz that under the microscope do not show any man-made modification and/or use wear compatible with a micro-drill bit (Figures 13-15). Nevertheless, four reused bore core fragments display an extremely thin circular groove (width c. $0.5 \mathrm{~mm}$ ) due to initial perforation (TK\#741; 2464; 10665; 10792) (Figure 16). A groove of this thinness could be produced only by a micro-drill of stone or by a tubular drill of copper/bronze, which thus far is not yet archaeologically documented in MSEA. Abundant evidence of stone micro-drills in late Neolithic contexts (c. 3000 BP) has been excavated at the workshop site of Bai Ben (Cat Ba Island, Vietnam) (Nguyen and Clarkson 2013). Micro-drills similar to those found at Bai Ben, which are comparable to the smallest am- 


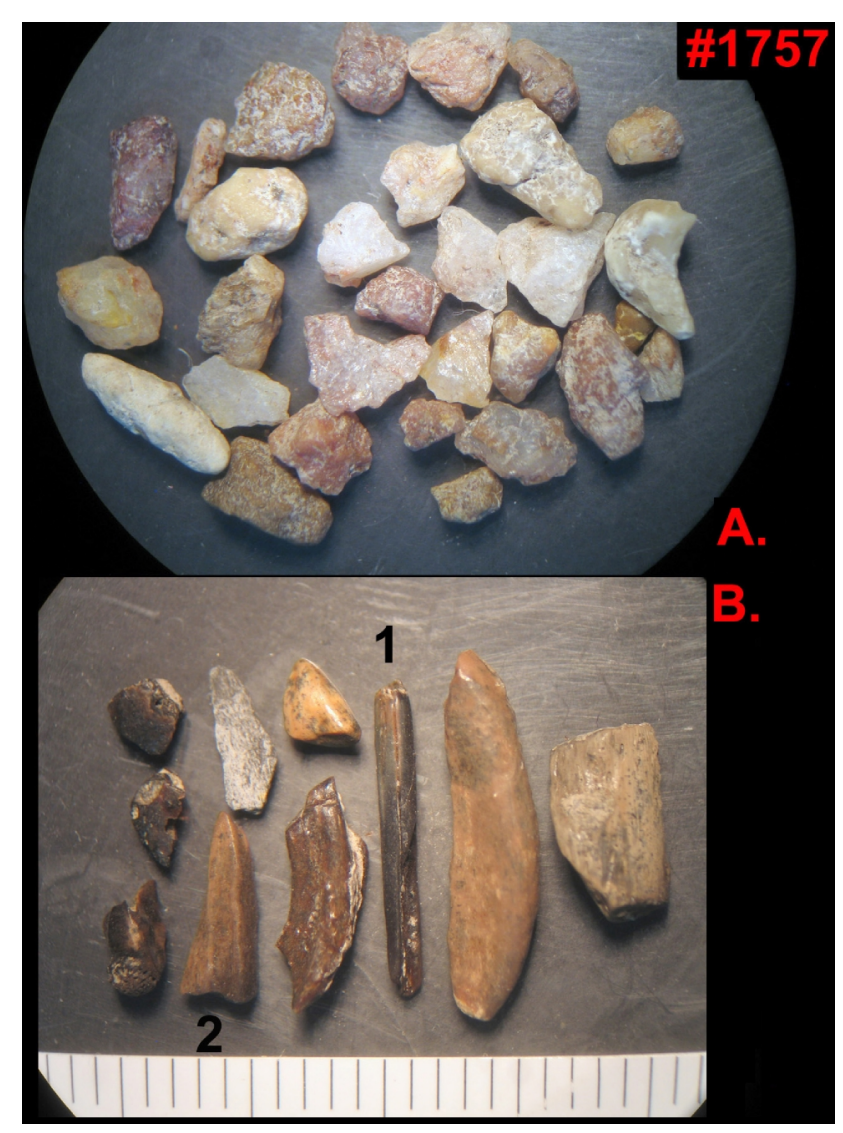

Figure 14 - A. amorphous quartz chips; B. flakes of charred animal bones (B.1 and B.2 possibly intentionally modified) and a rodent tooth. Soil sample (TK\#1756 ca. $8 \mathrm{~kg}$ ) close to a few tridacna manufacturing waste in between the Iron Age G\#16 and $\mathrm{G} \# 17$. After sieving ( $\# 5 \mathrm{~mm}$ mash) in a solution of $5 \%$ alcohol in water.

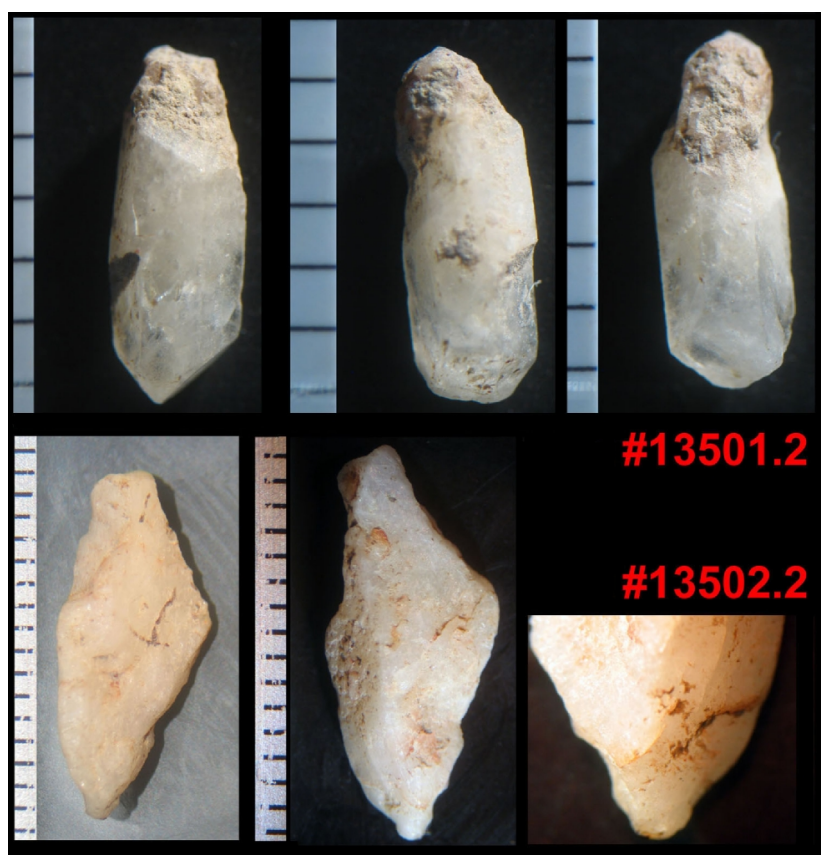

Figure 15 - Sieved from the soil matrix containing clusters of tridacna manufacturing waste in Op.1 Sq.A - Iron Age layer:
TK\#13501.2 fragment of quartz crystal compatible by size with a micro-drill bit, but without any trace of use; TK\#13502.2 fragment of quartz crystal compatible by shape with a micro-drill bit, but without any trace of use.

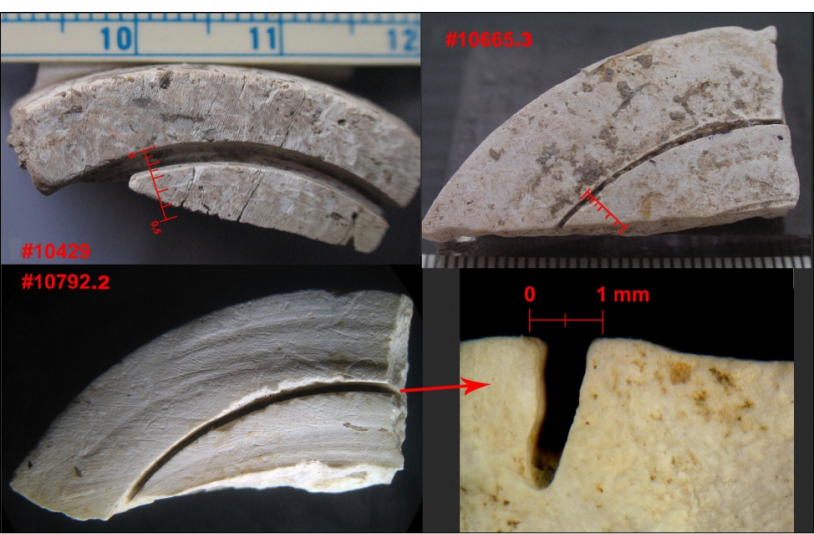

Figure 16 - Reused bore core fragments displaying the thin groove due to initial perforation: TK\#10429 from a cluster of tridacna manufacturing waste excavated (spits 29-30) in Op.1 Sq.D area a/b; TK\#10665.3 from a spread of tridacna manufacturing waste, including 465 primary flakes, excavated in Op.4.

Sq. A-B, area a/b/c; TK\#10792.2 from a spread of tridacna manufacturing waste, including 437 primary flakes, excavated in Op.4, Sq. A-B, quadrants a/b, Iron Age Layer.

ong the stone drill bits excavated at Trang Kenh (TrK) (Nguyen 1996: 93-96, Figure 25a upper row), might have been responsible for the thin grooves observed on the four wastes found at TK. Unfortunately, any attempt to test in the field the presence of micro-drills at TK is precluded for ever, due to the destruction of the site. We can only wish that other colleagues would excavate some of the many shell/stone workshop sites distributed in the Lopburi Plain, adopting an excavation technique suitable for the recovery of micro-remains.

Therefore, in absentia of stone drill bits, we hypothesize that at TK the craftsmen might have used a hollow drill bit. This tubular drill bit probably consisted of a bamboo spindle, or a sectioned animal long bone, powered with a natural abrasive (e.g. sand), which was the actual perforating agent. This kind of coring device required the use of either a bow drill or a pump drill, in both cases, the drill was driven horizontally to-and-fro by human musclepower, as evidenced by the thin, parallel traces left by the drill bit on the core and on the internal side of semi-finished artefacts; microscopic recording of these traces provides a proof of partial rotary motion (red arrows Figure 17).

The mechanical friction produced by the tubular drill against the body of the blank, induced the reduction of the sand powered drill bit, whose cutting edge grew thinner, as the progressive reduction of the space between the core and the 'coat' suggests (Figure 10, Stage 3-4). The thickness of the blank, the reduction of the drill bit and the difficulty to maintain the drill vertically in its right rotation axe, probably prompted the craftsman to adopt the bipolar drilling technique. Once the perforation “... had been driven half- 
way through the block, this was turned over and grinding began at the opposite end. The result is a very characteristic bi-conical hole." (Childe 1954:191). The main trouble with this boring method was maintaining control of the vertical axis of rotation. The typical misalignment of the two halves of the cores, and the recurring difference (from 1 to $5 \mathrm{~mm}$ ) in the width of the bangle's body, are direct evidence of this hindrance.

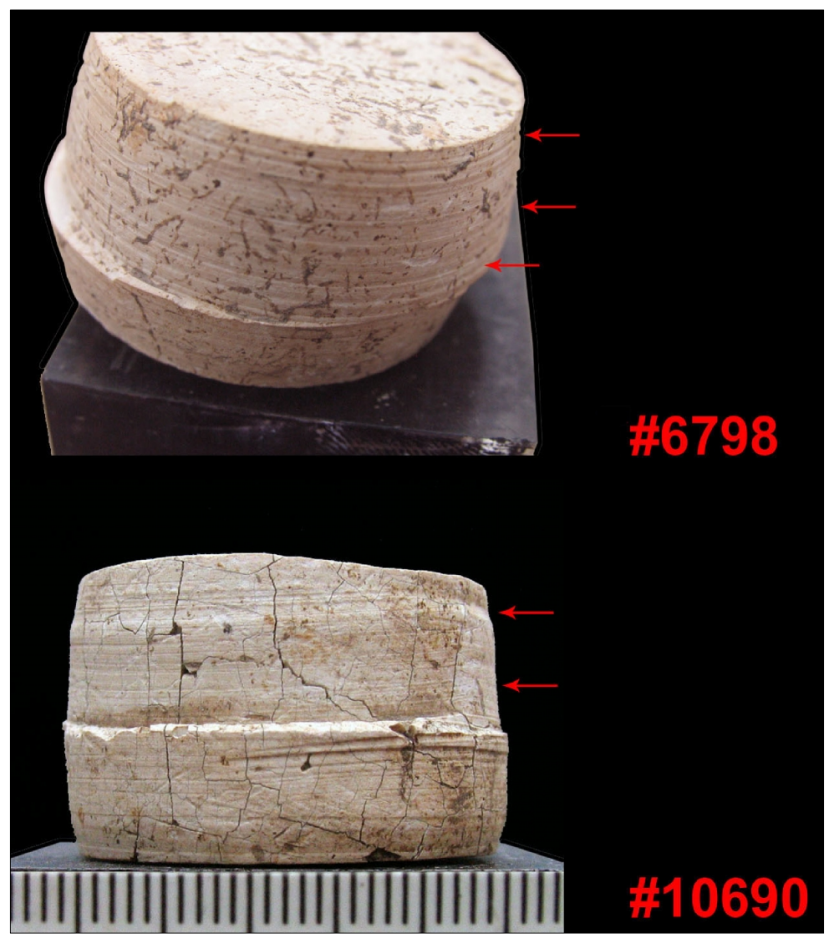

Figure 17 - Thin, parallel grooves (red arrows) left by the drill bit on the bore cores suggest the action of partial rotary motion during 'manufacturing stage 3' (e.g., TK\#6798 Op.1 TT1; TK\#10690 Op.4 Sq. A-B).

The craftsman used monopolar drilling with hollow drill bits only in the manufacturing of very thin bangles (Type D in our seriation) either made of shell or local stone (mainly marble, limestone and slate). This is demonstrated by several truncated conical bore cores found associated to shell manufacturing waste as well as by the conical hole of the stone and shell Type D circlets (Figure 6).

Several wasted blanks on display in the King Narai Palace National Museum (Figure 18 A-B), witness the craftsman's ability to foresee, from the earliest stage of the manufacturing cycle, how a blank should be treated to maximize the quantity of items that could be obtained from the dressed base material. Two wasted blanks suggest that the craftsman could choose between two boring strategies: A) use of tubular drills of decreasing diameters; B) use of a single bore drill until the desired depth into the blank was reached. In both cases the craftsman made his choice according to the quality of the base material and to a 'template' in his mind that allowed him to see the blank as sets of rings-and-core nested one inside the other (something like a Russian matrioshka nesting doll). In fact, once the rings were removed from the core, the core was sent back into the cycle again, as described later.

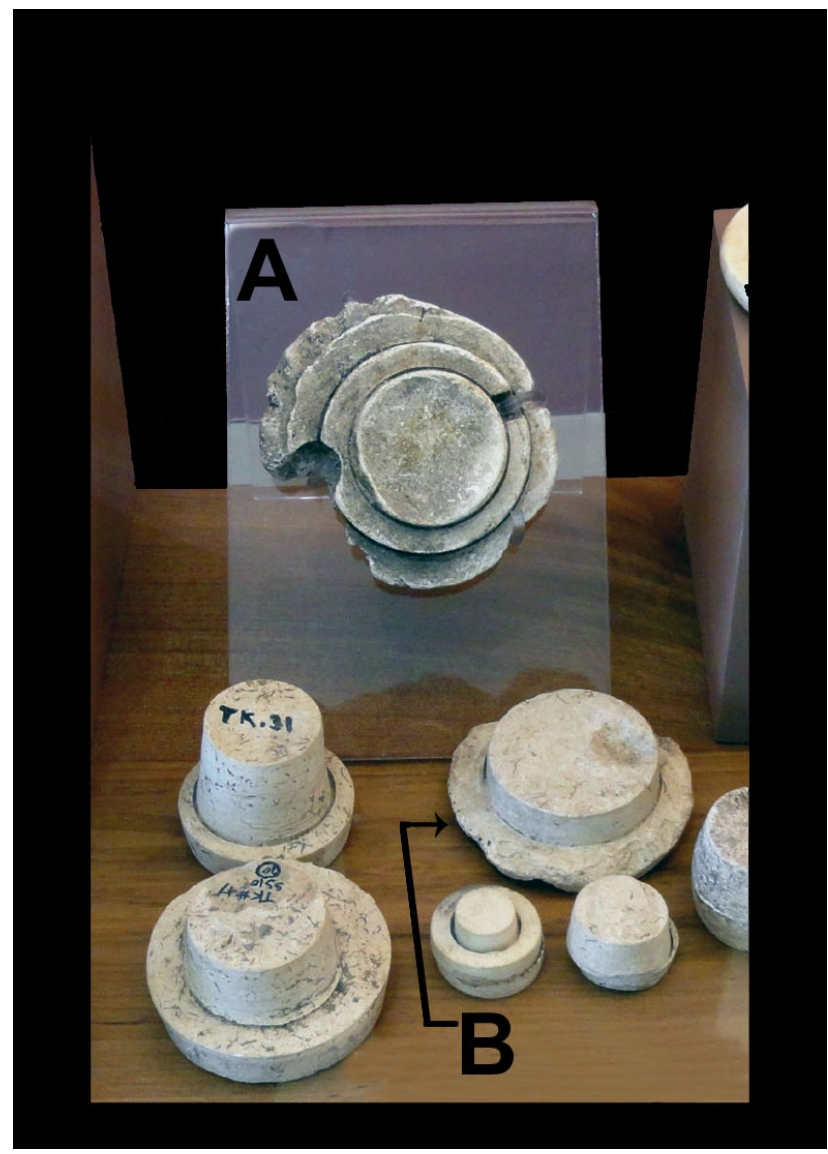

Figure 18 - Two blanks (A. Huai Yai; B. TK) wasted at different stages of the manufacturing cycle suggest two boring strategies: A) use of tubular drills of decreasing diameters; B) use of a single bore drill until the desired depth into the blank was reached (courtesy of the King Narai Palace National Museum).

Arguably after the trepanation stage, the craftsman decided how many circlets he could slice from the cylinder-shaped 'coat' still joined to the core through a 'crown', usually positioned at the point of maximum diameter of the core itself. Once the cylindrical 'coat' was cut into a sufficient number of slices (Stage 4), the following operation provided their separation from the core (Stage 5).

The sequence of these two stages is supported by the material evidence offered by fragments of circlets broken during either the cutting of the slices or their separation from the core. Actually, it has not always been possible to discriminate with certainty if a semi-finished circlet fragment belongs to one stage or to the other, in any case the manufacturing traces observed on the fragments support the actual sequence of the two phases (Figure 9, Stages 4$5)$. The sample of fragments we have measured and recorded consists of 226 items, more than 50 percent of which belong to Stages 4-5, thus suggesting that these stages were the most critical operations of the whole manufacturing cycle. 


\section{Stage 4: Slicing of the bangles/rings}

Although we cannot rely yet on the results of replication experiments, in all likelihood TK craftsmen used a sandpowered string-saw -either held by both hands or mounted onto a bow- to slice the circlets rough-outs from the core. Several parallel, barely perceptible grooves of rounded profile (height $<1-2>\mathrm{mm}$ ) observed on the lateral surface of a few cores (e.g., TK\# 0534; 1046; 1363; 1582/1) are working traces compatible with the use of a sand powered string-saw, probably made by a twisted, rather resilient fibre or sinew (Figures $11 \mathrm{~B}, 19 \mathrm{~B}$ ). A single groove deeply cut into some cores (e.g., TK\# 1661; 6794; 2516; 10057; $10101 ; 10106 ; 10287 \mathrm{e} ; 10603)$, the slits cut parallel to the shell plane in the discarded pieces mentioned under Stage 1 , as well as the groove cut in the 'band-shaped' bangles of type $\mathrm{Ba}$ (Figure $19 \mathrm{~A}, \mathrm{C}$ ) also provide indications of the use of a string-saw. In these instances, the deep groove displays the same features of profile and thickness of the very light ones. The deep grooves observed at different heights of some cores might represent a craftsman's fault in the use of the saw, or the initial stage of the cores recycling. (Figure 20).

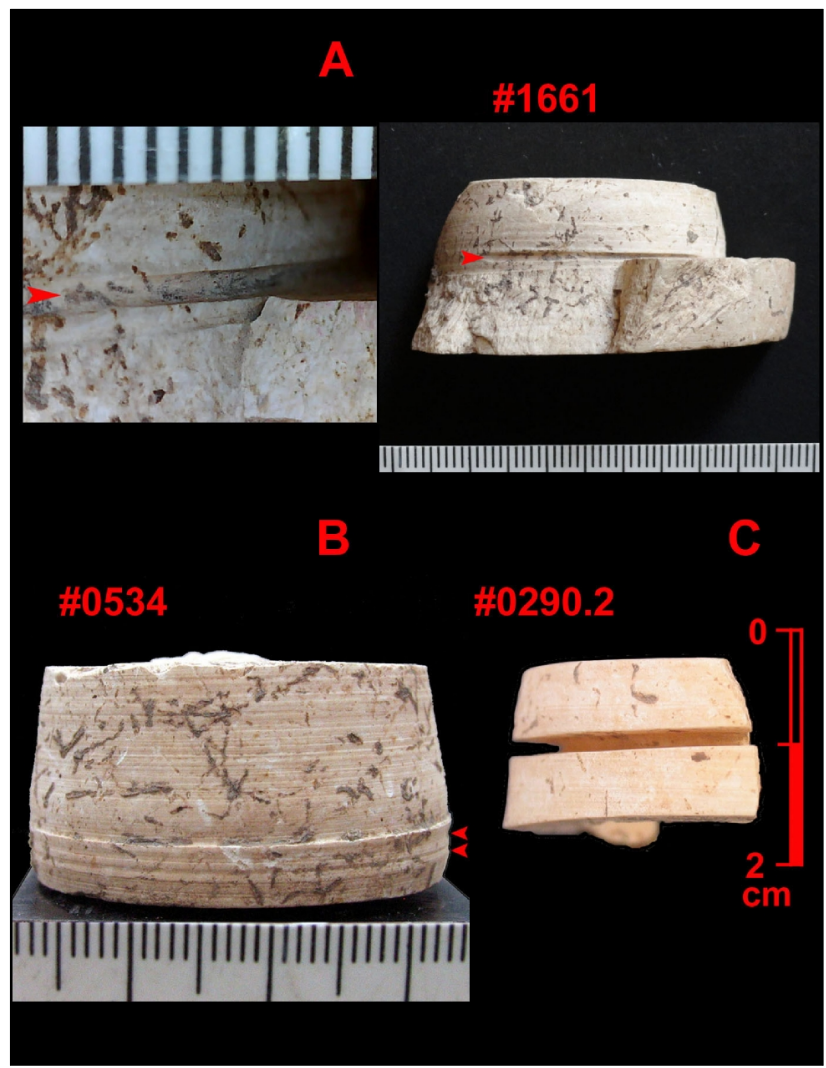

Figure 19 - Two bore cores and one bangle fragment (BNGType Ba) showing grooves compatible with the use of a sand powered string-saw.

\section{Stage 5: Separation of the circlets from the core}

The fragments of circlets broken during the slicing and separation stage can be divided according to the profiles of the radial sections into trapezoids, quadrangles and rectangles.
All originate from 'slices' cut either immediately below the flat surfaces of the cylindrical 'coat' ('apical slices') and along its lateral surface ('ventral slices') (Plate 5).

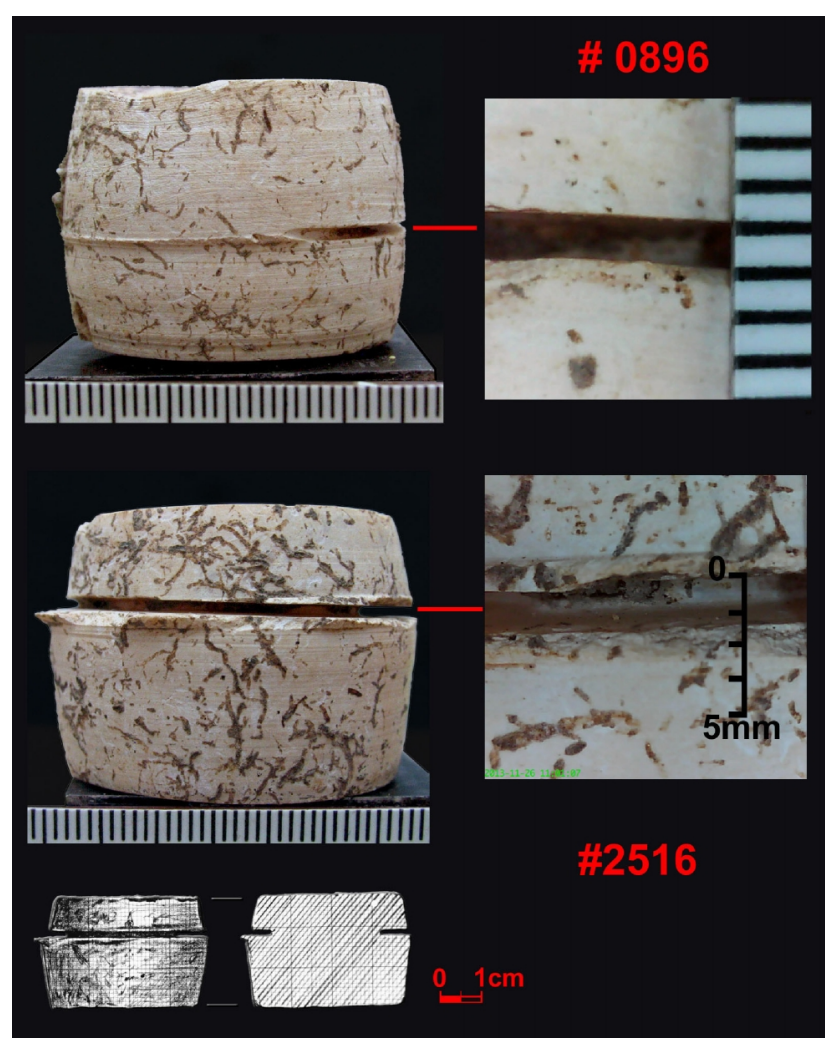

Figure 20 - Grooves at different heights of the bore cores TK\#0896 (Op.1 Sq. D Iron Age Layer) and TK\#2516 (Op.1 Sq. $D$ Neolithic/Bronze Age Layer) hint to sawing faults, or to the initial stage of the cores recycling.

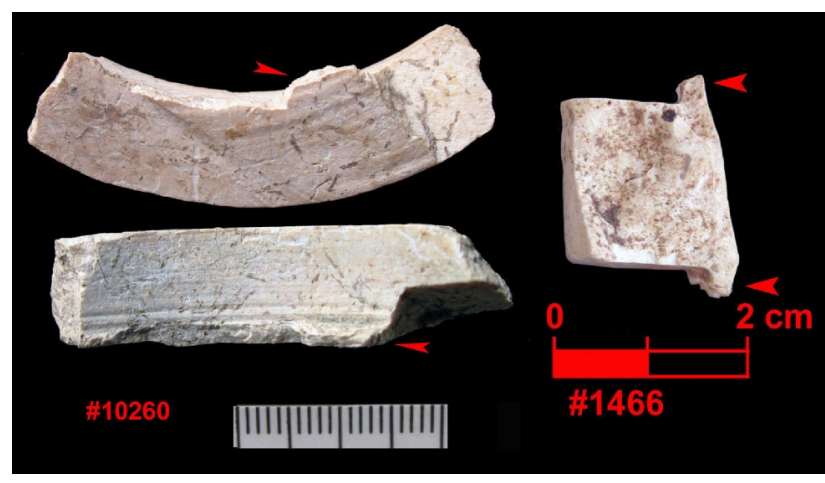

Figure 21 - View of the ridges on one or both inner edges of the circlets remnant of either the 'crown' between the core and the 'coat' (e.g., TK\#10260 Op.1 Sq. A Iron Age/proto-Dvaravati Layer) or of the joint between sliced circlets (e.g. TK\#1466 Op.1 Sq. A-B Iron Age/proto-Dvaravati Layer)

The thin ridges (from 1 to 3 ), with the lip jagged and sharp, that usually protrude from one or both inner edges of the circlets, represent the remnants of the 'crown' between the core and the 'coat', and/or of the tiny joint left by the string-saw between one slice and the next (Figures 
$11 \mathrm{~B}, 21)$. The jagged lip of these thin ridges suggest that the circlets were removed from the core and separated one from the other by percussion, probably striking either on the crowns or on the flat surface of the slice. In the separation of the central ventral slice from the core, part of the 'crown' remained on the circlet and part on the core. This was an operation of some practical difficulty, requiring a skilful hand to be accomplished, since the craftsman had to adjust the strength of the blow to the thickness of the ridges. If the blow was too powerful, or too weak, the slice circlet could easily break, as some unsuccessful attempts at separation witness (e.g., TK\# 1661, 2552, 10429, 10688).

The number and layout of the internal ridges allowed us to identify the relative position that each slice had on the original set of core and sliced 'coat' (Plate 5), thus evidencing how the craftsman addressed the string-sawing operation after a mental evaluation of the possibilities offered by the 'coat'.

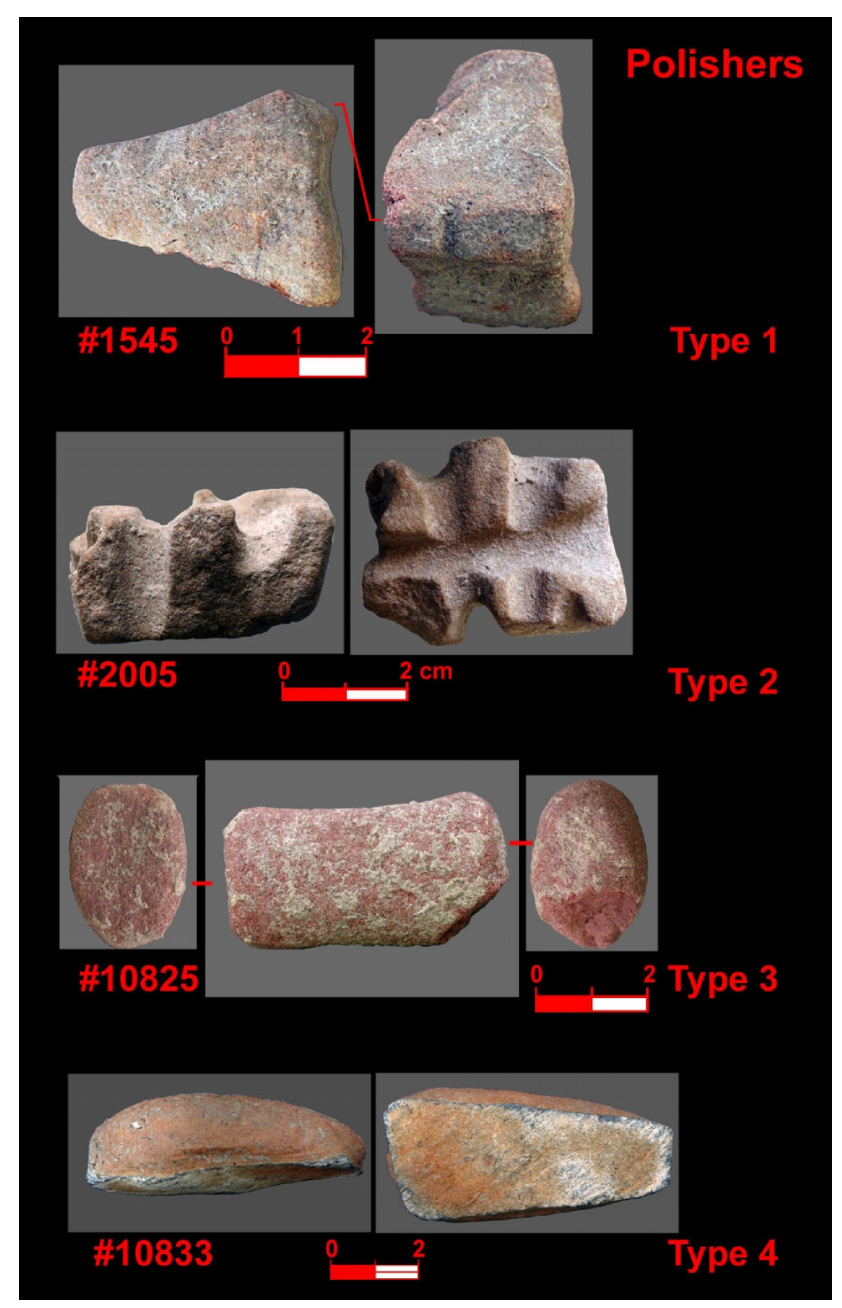

Figure 22 - TK sandstone polisher types.

\section{Stage 6: Finishing}

Once separated, the single circlets with the radial section characterized by sharp edges, at least one of which with a more or less jagged lip, were ready for the finishing stage, aimed at erasing the rough edges left by previous working

stages, as well as giving the final shape to the artefact. Four types of reddish and yellowish-buff sandstone polishers have been found at the site: slab-shaped (Type 1), polyhedral (predominantly parallelepipedal with rounded corners) (Type 2), globular/cylindrical (Type 3a/3b), and oblate ellipsoid (Type 4) (Figure 22).

Type 1 polishers were multifunctional tools, as suggested by the use wear on the flat larger faces, seldom also present on the lateral surfaces and the edges. These slabshaped polishers were possibly used also during the manufacturing Stage 2 to dress the blank and prepare it for the coring Stage 3.

Type 2 exhibit grooves within which most semi-finished and finished bangles would fit perfectly.

Type 3 polishers might have been preferentially used to smooth the internal surface of the circlets

Semi-finished circlets representative of progressive polishing steps, and the grooved type 2 polishers, provide evidence for the steps followed in the final polishing stage (Plate 6).

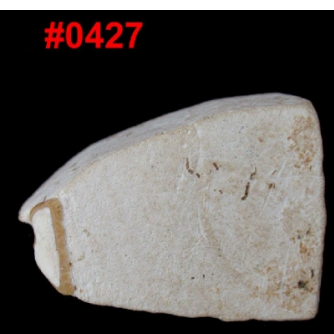

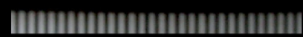
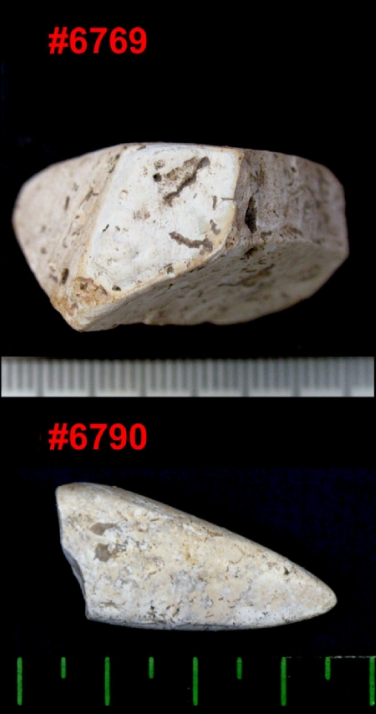

Figure 23 - TK reused circlet fragments and/or wasters; e.g., TK\#0427 Sq. D, area a, Iron Age Layer: semi-finished pendant worked from a circlet fragment; TK\#6769 TT1, area d, Iron Age Layer: Initial stage of a waste reuse, probably to make a pendant, by polishing all along its rough fracture surfaces; TK\#6790 TT1, area d, Iron Age Layer: fragment of a truncated pyramidal point made by polishing a shell bangle (?) fragment.

According to this evidence, the circlet was first ground to remove the eventual ridge(s) left by the detachment from the core and to blunt the sharp edges left by the separation 
stage (possibly by means of type 1 and 3 polishers). Then the circlet was polished all along the external surface -following planes parallel to the diameter (e.g. TK\# 1495; $2401 ; 10628 ; 13437 ; 13433)$ - in order to smooth and eventually round it in accordance to the desired final shape (Plate 6b: 1a-b, 2, 6).

Cores and wastes fragments reuse/recycling

As mentioned in the preceding chapter, the main line of the tridacna shell personal ornament production was linked with a secondary line of 'waste reuse/recycling', where for 'reuse/recycling' we mean the conversion of a waste into a reusable piece of base material, either within the production of personal ornaments, or for the production of a new artefact not necessarily intended for personal ornament (Figure 23).

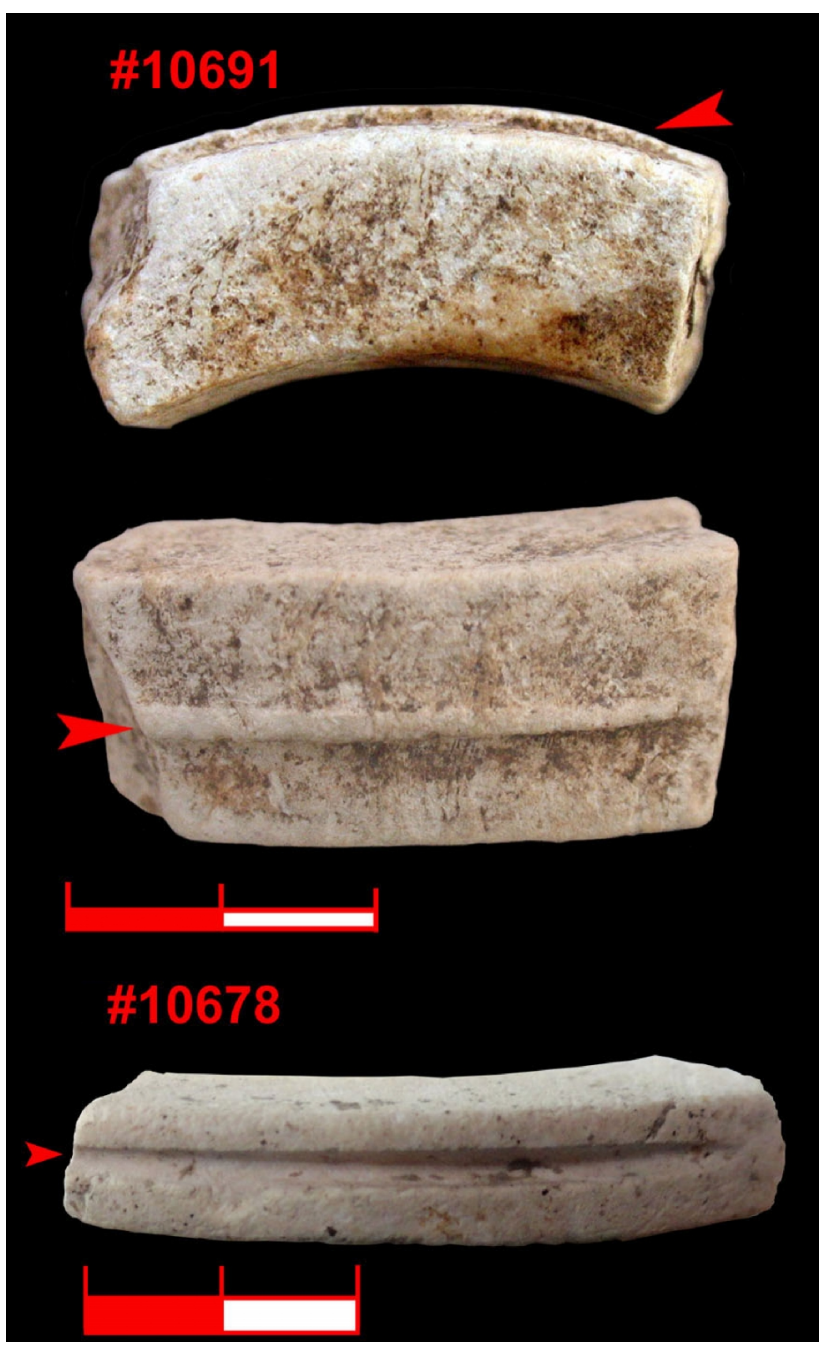

Figure 24 - Residual traces of primary manufacturing on the circlets external surface as evidence of bore core reutilization. TK\#10691 (Op. 1, Sq. A-B, Dvaravati/later Historical horizon): a ridge residue of the core-ventral slice joint; TK\#10678 (Op.4, A-B, Iron Age Level) a groove hints at a too deep sawing during the circlet slicing on the core.

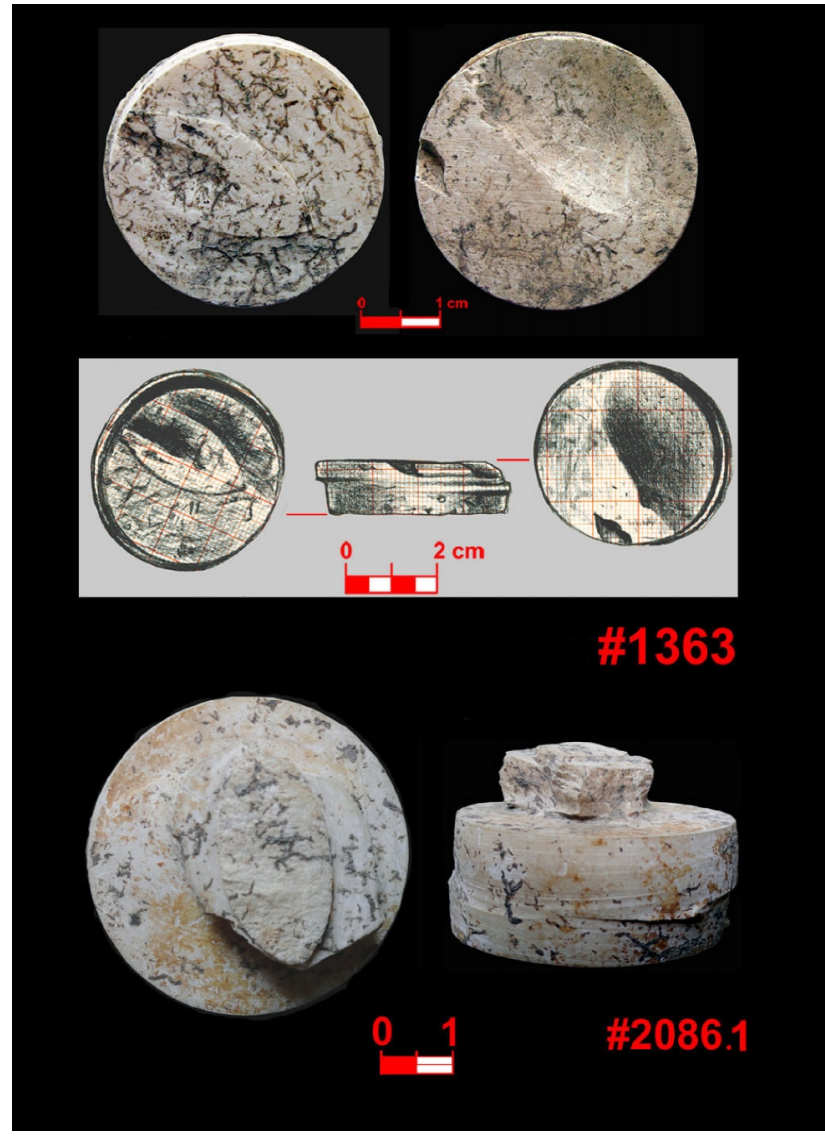

Figure 25 - Bore cores intentionally reduced for reuse: TK\#1363 (Op.1 Sq. Dc Bronze Age layer) showing both a positive and a negative ellipsoid trace of reduction on the flat faces; TK\#2086.1 (Op.1 Sect. B, cluster of shell wasters at the base of the Iron Age layer) a positive ellipsoid trace of reduction on top of a bore core evidences a failed attempt to slice a ring from the reused core.

Both bore cores and discarded fragments of circlets worked from re-used cores sustain the regular recycling of the bore cores. Several circlet fragments, broken before the finishing stage, display on the external surface a thin ridge (e.g., TK\# 10647; 10691; 10763; 13459) or a small groove (e.g., 10678) (Figure 24). We explain both the ridge and the groove as a trace of previous primary manufacturing; in particular, they represent the remnants of, respectively, the 'crown' left on the ventral slice at its separation from the core and the cut produced by the saw on the core during the slicing of the bangles. Therefore, in a set of circlets worked from a re-used core, the raised trace of the old crown or the etching of the saw on the core often remained on the external surface of new circlets. These traces would have eventually been blunt in the finishing stage.

Several cores discarded after the beginning of a secondary trepanation (e.g., TK\# 6748; 10101; 10429; 10792.2), or reduced by sawing away a slice of their apical part, witness the recycling of the bore cores. Probably the reduction was necessary to create a sufficiently wide surface to start a new coring. Most of the reduced cores show, at least on one flat face, an ellipsoid figure either positive or negative, 
or both (e.g., TK\# 0911; 1582; 1783; 2060; 2086.2; 2122; $6797 ; 6798)$ or a trace of it obliterated during subsequent stages of manufacture (e.g., TK\# 1046; 1363; 2028; 2550; $6800 ; 10453$ ) (Figure 25). This ellipsoid is the remnant of the detached section of the bore core. When it was almost completely cut (sawn from two opposite directions), the smaller section of the core was detached, probably with a sharp well-aimed blow. Once the sliced section was removed, the remaining part of the core with its ellipsoid appendage on the flat surface entered the recycling process. The severed section of the core was also recycled, being used to make rings. The circular frustum TK\# 10103 (Ø 3.6 $\mathrm{cm} ; \mathrm{H} .0 .7 \mathrm{~cm}$ ) represent in fact the type of blank reused to drill and slice rings (Figure 26), as shown by the partly drilled cores TK\# 10106 (Ø $2.62 \mathrm{~cm}$; H. $1.4 \mathrm{~cm}$ ) (Figure 27) and TK\# 2042.2 (Ø $1.8 \mathrm{~cm}$; H. $1.2 \mathrm{~cm}$ ) (Figure 28).

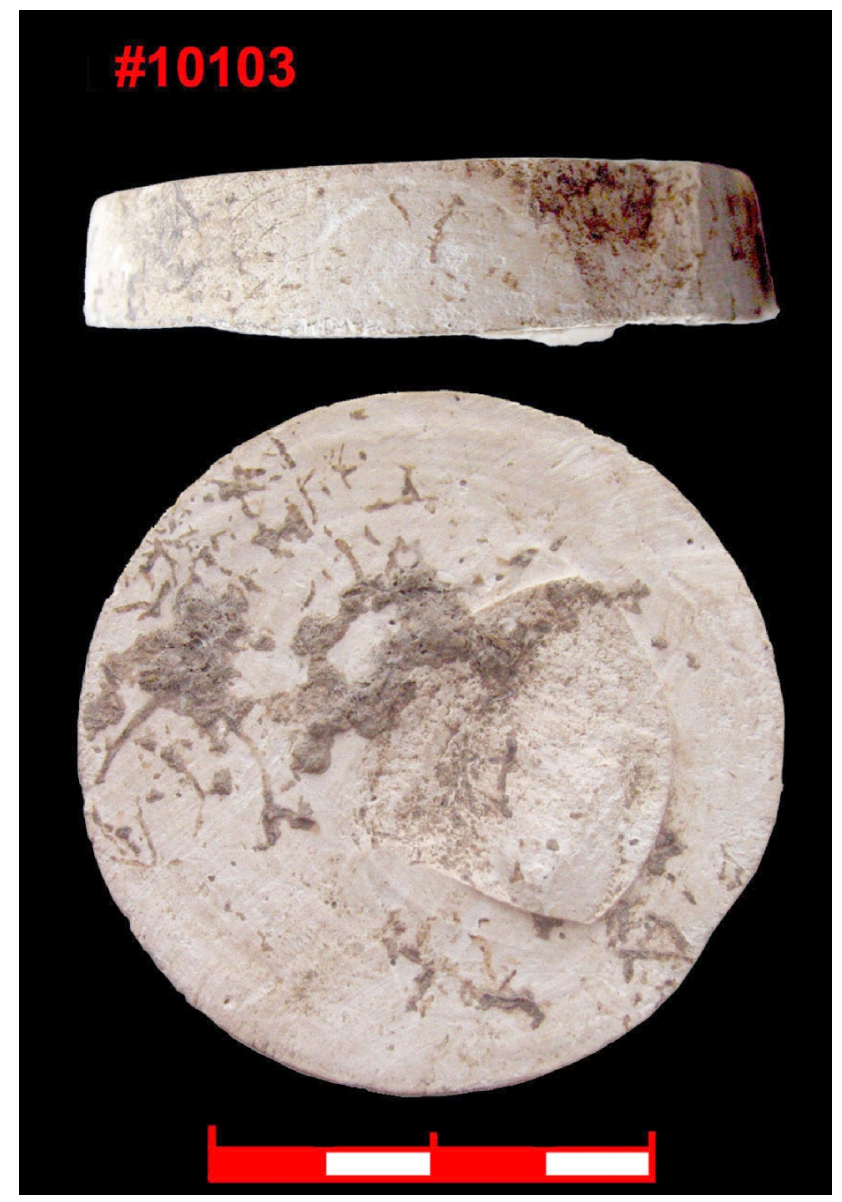

Figure 26 - TK\#10103 (Op.3 pit 1, proto-Dvaravati layer) severed section of a bore core with partly obliterated ellipsoid and, possibly, prepared to be reused as a blank for rings making.

The recycling of shell wasters is further evidenced by the micro-cores prepared for or derived from beads manufacturing. For example, we consider evidence of tridacna shell bead making the small decahedral blank TK\# 10264 (Ø $0.9 \mathrm{~cm}$; H. $1.2 \mathrm{~cm})$ and the bi-truncated conical microcore TK\# 2193 (Ø $0.5 \mathrm{~cm}$; H. $0.8 \mathrm{~cm})$, as well as the truncated conical micro-cores (Ø $0.3-1 \mathrm{~cm}$; H. 0.25-0.5 cm), of both tridacna and unidentified nacreous shells (TK\# 329;
$649 ; 1580 ; 1653 ; 10058 ; 10112 ; 10605)$ derived from mono-polar or bi-polar drilling (Figure 29 A-C).

Further support to the intensive exploitation of the base material and to the technical skill of the craftsmen is finally provided by the disc-shaped and lens-shaped micro-beads (less than $1 \mathrm{~mm}$ in diameter and thickness), of tridacna and other nacreous shells (Figure 30).

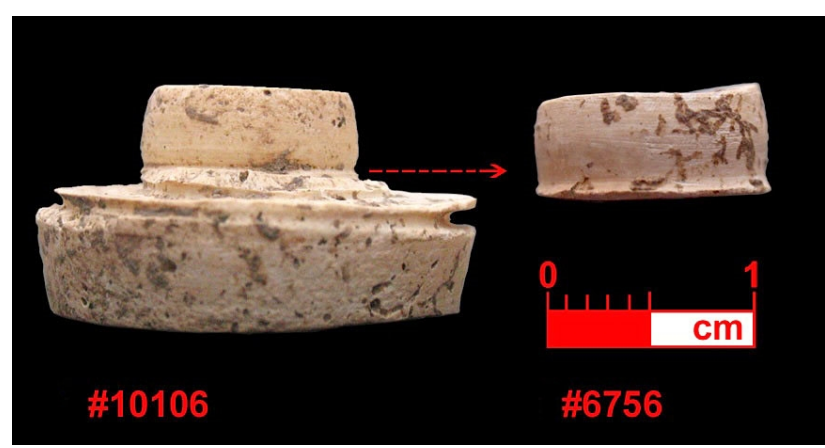

Figure 27 - TK\#10106 (Op.1 Sq. C proto-Dvaravati/Dvaravati layer) severed section of a bore core reused to make rings and TK\#6756 (Op.1 Sq. D Iron Age layer) micro-core sliced from a reused bore core (like TK\#10106), in all likelihood prepared for beads making.

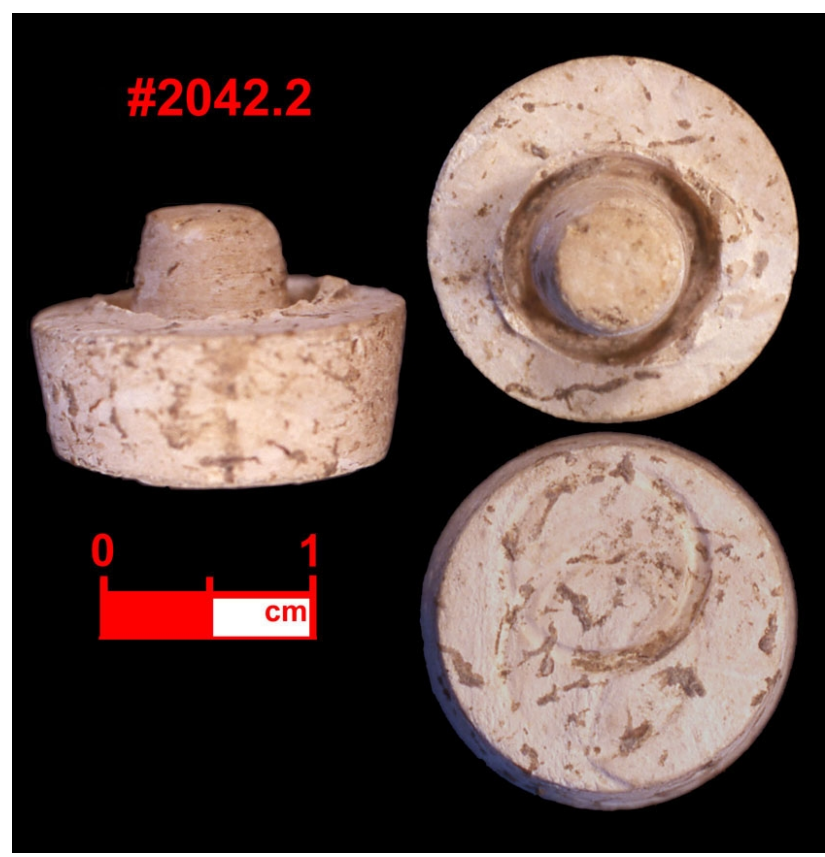

Figure 28 - TK\#2042.2 (Op.1 Sq. B Iron Age layer) severed section of a bore core showing evidence of bi-polar drilling and of sawing to slice tiny circlets.

Assessing work organization of the shell manufacture at Tha Kae

In our hypothesis, the craft under discussion can be envisaged as a sequence of physically self-contained manufacturing stages within a 'production line' of low technological investment that did not require a particularly complex division of labour. Unfortunately, the IA disturbances (e.g., 
grave pits and earth works) on the underlying deposit, precluded the archaeological recognition of discrete waste heaps, production units or working floors. Therefore, we assume that the unpatterned co-occurrence of wasters, fragments of semi-finished, working tools and domestic trash might indicate that the craft activities were not spatially and socially segregated and that each artisan had the capacity to perform the entire manufacturing cycle. In this perspective, our distinction between a main, primary 'production line' and a secondary line of 'waste-recycling' is purely epistemological, because in both cases the aim was to create luxuries, available for local use and external exchange.

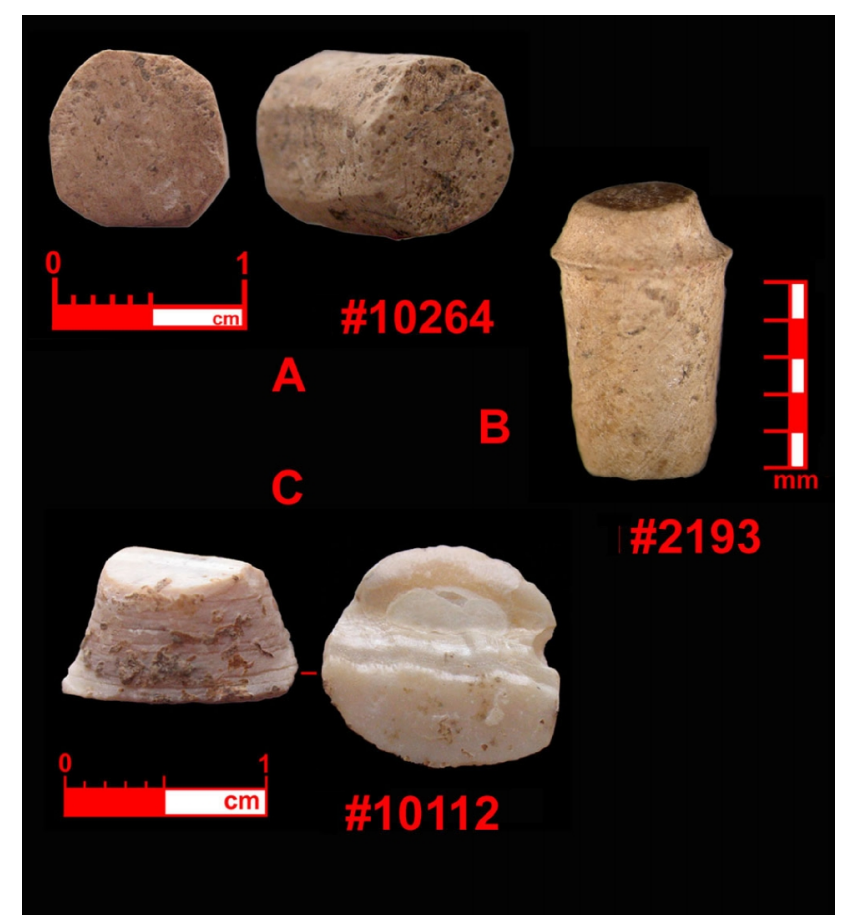

Figure 29 - A. TK\#10264 (Op.1 Sq. A, Iron Age layer) a decahedral micro-blank possibly prepared to make a cylindrical bead; B. TK\#2193 (Op.1 Sq. A proto-Dvaravati layer) bi-truncated conical micro-bore core from the bi-polar drilling on a core like TK\#2042.2; C. TK\#10112 (Op.1 Sq. A, Iron Age layer) truncated conical micro-core.

It has to be noticed also that the production of shell and stone personal adornments was not a craft exclusive of TK workshops. In the Lopburi Plain, manufacturing waste similar to that excavated at TK has been recorded at several other sites, all of them presumably dated between the Neolithic and the IA: e.g., Huai Yai in the Khao Wong Prachan valley excavated by S. Natapintu (1988; 1995); Ban Na Yao on the Lopburi-Saraburi border kindly signalled by $\mathrm{P}$. Bhumadhon (pers. comm., 2002) and the stone and shell ornaments working site $2 \mathrm{~km}$ southwest of the Sab Champa moat (Lertrit et al. 2002; Lertrit 2004a, 2004b; Lertcharnrit 2005).

This evidence suggests that shell/stone jewellery production might have been a specialized craft at a regional level. The quantity of stone/shell debris at all these sites compared to the small number of finished ornaments found, particularly in mortuary contexts, hints at a semispecialized production for exchange, "even though the production unit was the household." (Trubbit 2003: 256), or many households distributed in several villages within a region favoured by the relatively easy access to raw materials. In all likelihood, although we admit that much more in depth analyses at the regional level are needed, the consumers of this production of the Lopburi Plain has to be sought at some distance from the Plain, possibly on the Khorat Plateau, as the abundance of shell bangles in the wealthy graves of BNW suggests: here from 47 burials ascribed to the BA 2 and 3A mortuary periods (1000-800 $\mathrm{BCE}), 772$ shell bangles (tridacna and trochus shell) and 159,135 shell beads have been recovered (Higham and Kijngam 2012). (Figure 31)

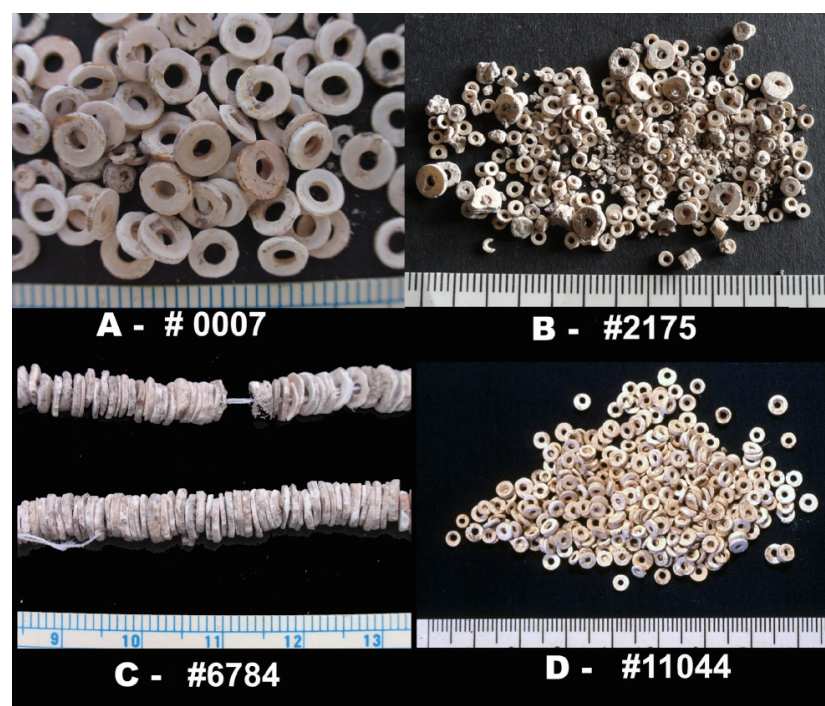

Figure 30 -Disc-shaped shell beads: A - TK\#0007 Op.1 Sect. $D$, ca. 125 Tridacna shell beads recovered from the looted Grave 1 (Neolithic); B - TK\#2175 Op.1 cluster of Tridacna shell beads recovered nearby a row of looted graves; $C$ - TK\#6784 Op.1, 153 chipped beads and polished beads of Anadara and Tridacna shells recovered from the looted Grave 3 (Neolithic); D - TK\#11044 Op.1 Sq. A Grave 10 (Neolithic), 310 Tridacna shell beads part of the mortuary furniture in association with the valve of a mussel.

In our proposition as it is evidenced by the presence of shell bangles in Neolithic contexts, shell and stone manufacturing technology, including bipolar boring methods, might have entered the Lopburi Plain as part of the customary practices (including technical and ideological aspects) accompanying the agricultural dispersal on the routes from Lingnan into MSEA at the onset of the interregional exchange network of goods and information that Rispoli envisaged as the Southeast Asian interaction sphere (SEAIS) (Rispoli 2007:280-281). However, the florescence of this craft occurred in the late second -early first millennium $\mathrm{BCE}$, sparked by new incoming technological innovations (e.g. copper-base metallurgy) and by the demand for luxuries on the inter-regional exchange circuits of the SEAIS within the general process of social complexity growth that 


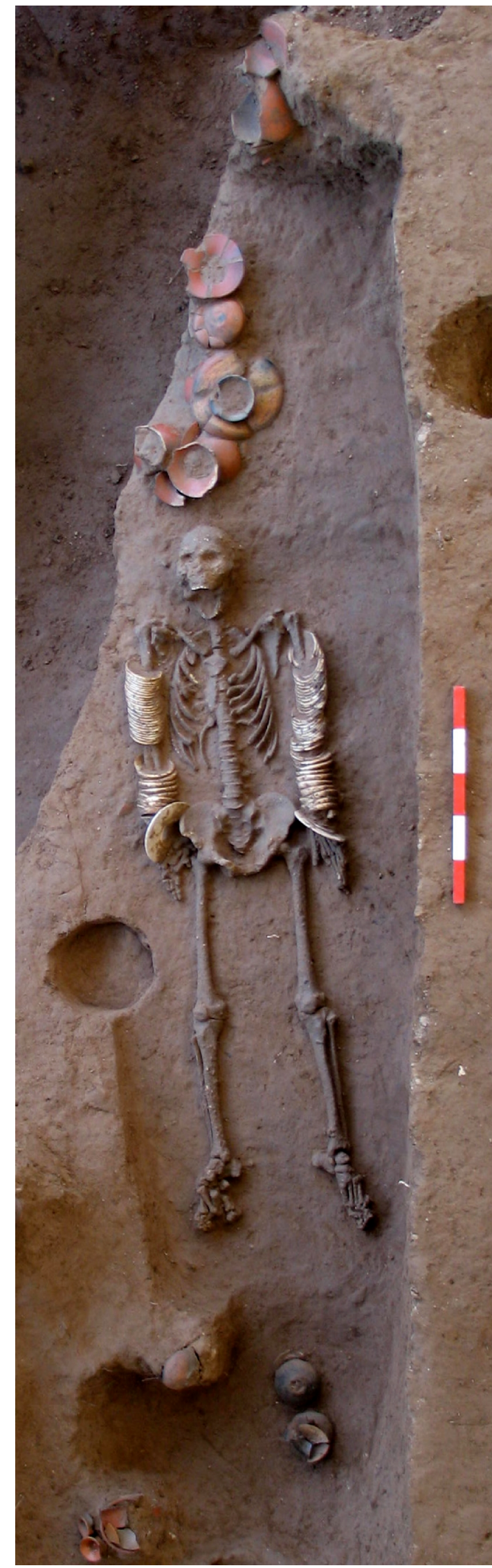

Figure 31 - Ban Non Wat (Sq. D7) Burial 260 (Bronze Age 3A, ca. 900-800 BCE), partly disturbed by Burial 631, of a mid- adult man accompanied by 24 pots, 76 exotic bangles (including

18 made of tridacna shell) wore from the wrists to the upper arms and 1425 shell disc beads (courtesy C. Higham).

led to the formation of the IA regional polities (Pigott and Ciarla 2007; Higham et al. 2011; Rispoli et al. 2013; Ciarla forthcoming; Rispoli forthcoming B).

\section{THE DISPERSAL OF BIPOLAR DRILLING TECHNIQUE INTO MAINLAND SOUTHEAST ASIA}

We suggest that the inception of shell technology was linked with the early dispersal of agriculturalists into MSEA from the north, and that it blossomed with the social, cultural and technological growth sparked by the strengthening of agricultural practices in the river valleys of the region. In order to test this hypothesis, we have attempted to identify relevant technological similarities between the shell craft evidence at TK and the jewellery workshop sites along the agricultural dispersal path from the Yangtze valley to MSEA (Zhang and Hung 2010; Rispoli forthcoming A).

Several authors have offered well-reasoned explanatory hypotheses for the widespread occurrence of similar forms of jade ornaments in pre- protohistoric East Asian sites between the third and the late first millennium BCE (Tang 2000; Qin 2011; Hung 2014). The relevance of jade and its natural sources in the pre- and protohistory of East Asia justify the particular emphasis placed, since the nineteenth century (e.g. Damour 1846), on the petrographic and mineralogical characterization of 'jades', and in particular of Chinese 'jades' (e.g., West 1963; Wen and Jing 1992; Middleton and Freestone 1995; Sun et al. 2002; Wang 2011; Zhang et al. 2011; Yin et al. 2014). However, with jade not being the focus of our research, we will use here 'jade' as a surrogate for any kind of stone hard enough to make ornaments, e.g. circlets of varying size and shape, suitable to be polished to the state of lustre.

As for China and Southeast Asia, several authors, either on typological or geo-mineralogical bases, start to trace the relationship of similar personal ornaments found in diverse, geographically distant, cultural environments with raw materials geo-chemically diagnostic to specific sources (e.g., Hetian jade from Xinjiang or Fengtian jade from Taiwan), thus providing fundamental information for the reconstruction of prehistoric networks of cultural interactions and trading that extended beyond regional circuits (Loofs-Wissowa 1982; Tang 2003; Hung et al. 2007; Yan 2010; Bellwood et al. 2011; Dai and Long 2011; Zhao 2011; Hung and Bellwood 2010).

In comparison, less attention has been paid to the implications of the widespread occurrence of the bore cores discovered at several prehistoric production centres distributed from China, to Japan to Mainland and Island Southeast Asia. The formal identity of these cores mirrors a widely shared technology aimed at making a passing hole, by means of a rotating device, into more or less thick and solid materials (e.g jade and shell), to be eventually shaped 
into not utilitarian artefacts: personal/ritual ornaments and paraphernalia.

The widespread dispersal of the drilling technique to make circlets used for ear lobe ornaments, namely the open rings or slit-rings (also known as jue 玦), and cylindrical beads possibly start from the early Neolithic Xinlongwa culture of the Liao River Valley (NE China) during the sixth millennium BCE (Tang 2000, 2003; Yu et al. 2007).

In the fifth millennium BCE, drilling is attested in the lower Yangtze Valley at Hemudu. From the first period (c. late sixth-early fifth millennium BCE) of this early rice cultivators' village, the use of monopolar and bipolar drilling is attested by the passing holes of slit-rings and cylindrical beads, although not accompanied by evidence of in situ manufacturing (Zhejiangsheng WWKGYJS 2003:78-79).

Direct evidence of manufacturing debris in the form of (cylindrical-to-truncated bi-conical) cores suggestive of bipolar drilling, have been excavated at Lingjiatan (Hanshan county, Anhui province), a Neolithic settlement dated c. 3600-3300 BCE (Zhang 1999; Anhui 1989, 2000, 2006, 2008). At this site, several burials grouped into three distinct clusters were found on a large, rammed earth ritual platform $(1200 \mathrm{~m} 2)$. The burials were diverse in size and the wealth of mortuary offerings. The larger and richest burials probably represent highly-ranked individuals who may well have been connected with sacral, ritual or political activities. Such activities are reflected in the sophisticated, not utilitarian goods that accompanied the deceased. Lingjiatan craftsmen exploited several probably local metamorphic rocks, including chalcedony, rock crystal, nephrite, and tremolite (Sun et al. 2002). According to the size and wealth of the graves, reasonably the cluster of Level II burials, in an ideal hierarchy, lay between the well-to-do (Level I) and the burials almost devoid of offerings (Level III). They would thus represent a group of individuals who enjoyed an intermediate prestigious position between the richest and poorest in the community.

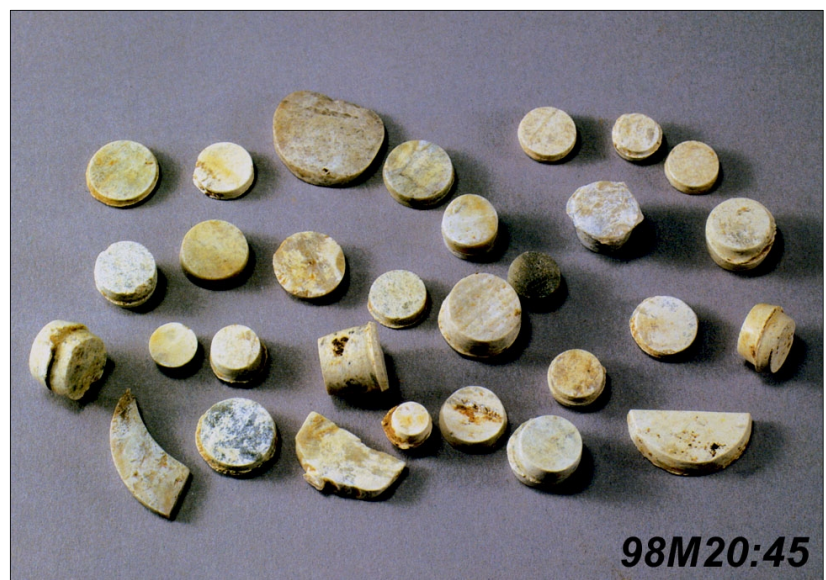

Figure 32 - Lingjiatan (Hanshan, Anhui prov., PRC) ca. 36003300 BCE. Grave 20: jade bore cores derived from mono- and bi-polar drilling disposed in the grave furniture.
The social position of these individuals might derive from the lapidary craft they had practiced in life, represented by the 'tools of the trade' and jade debris placed in their funerary furniture. These individuals arguably "... might represent 'embedded' specialists who work within elite households or who are themselves elite" (Trubbit 2003:257).

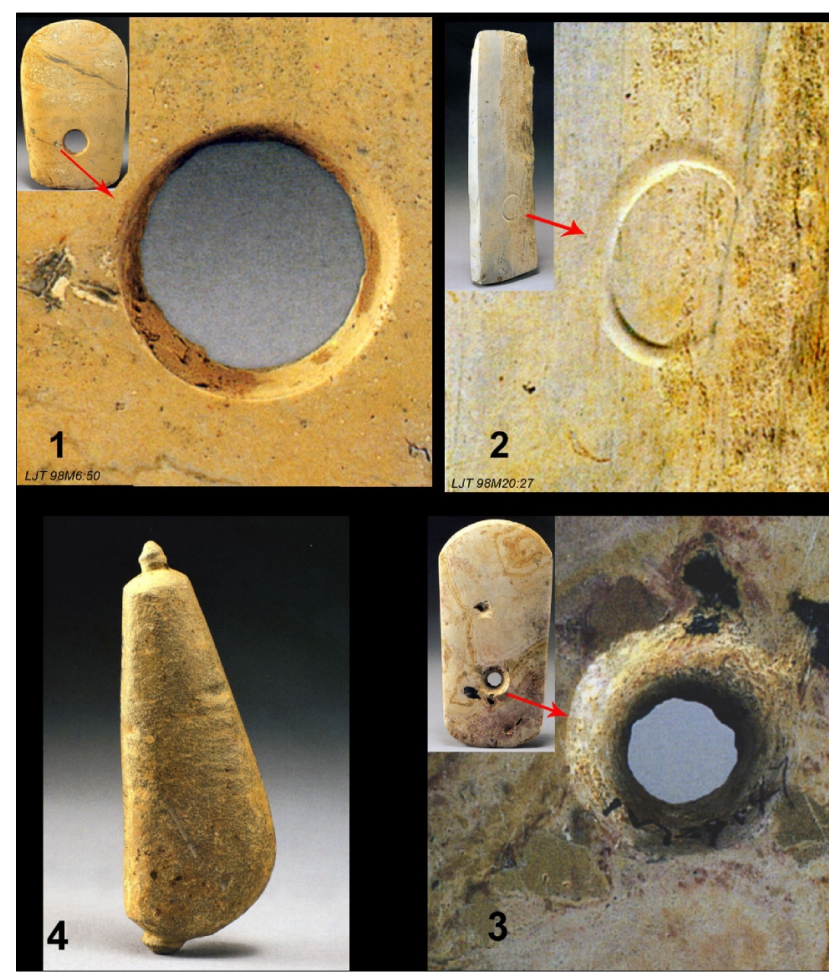

Figure 33 - Lingjiatan (Hanshan, Anhui prov., PRC) ca. 36003300 BCE. 1-2: traces of monopolar drilling possibly made by means of hollow drill bits; 3: traces of monopolar boring possibly left by a sandstone borer/whetstone similar to the one in Fig. 33.4 .

The highly formal refinement of the jade artefacts found in Level I graves (Anhui 2000) reflects the complexity of both their symbolic/ritual functions and their manufacturing technique. This latter is well documented by the jade wasters found in Level II graves, including bi-conical bore cores, derived from bipolar boring, and truncated conical cores produced by monopolar boring (Figure 32). The shape of the cores, the sharp edge of the passing holes as well as their radial sections of quadrangular, trapezoidal or pentagonal shape (e.g. the hole on the heel of the ritual axe M6:50) (Figure 33.1) and the circular groove left by an initial perforation on the heel of the chisel n. 27 from burial M20 (Figure 33.2), all hint at the use of hollow drill bits. The presence in burial 98 of a sandstone tool (M98:6) of irregular ellipsoid shape that also displays two small quasiglobular projections on the opposite poles is particularly relevant (Anhui 2000:120, 132) (Figure 33.4). These projections suggest the tool's use as a whetstone, perhaps a kind of hand driven boring bit. A tool of this kind might have been used, instead of a tubular drill, to pierce conical 
holes of trapezoidal section characterized by a rather irregular rim of the passing hole (e.g., on the heel of the ritual axe M29:47) (Figure 33.3). Crescent-shaped furrows on the flat faces of many ritual axes are also traces of working tools used at Lingjiatan. These furrows in fact evidence the use of a string-saw to slice from a jade boulder, the slab required to work the artefact.

Summing up, manufacturing traces and waste at Lingjiatan, in particular string sawing traces and bore cores, provide comparisons with the manufacturing traces and waste described for the shell craft at TK. Meanwhile, the presence of a sandstone borer/whetstone suggests that two different boring devices were in use within the same technological tradition: hollow (or tubular) drill bits and solid drill bits. It seems reasonable to argue that Lingjiatan represents a stage in the southward dispersal of the boring/drilling technology.

To the South of Lingjiatan, in the lower Yangtze Delta region, mono and bipolar boring technique are evidenced in the manufacturing of the jade artefacts (e.g., bi flat discs, cong cuboid tubes, jue slit-rings, yue large axes) that best characterize the lapidary craft of the Liangzhu Culture (3300-2300/2000 BCE).

In the third millennium BCE, Liangzhu cultural area was the main centre south of the Yellow River for the production of jade personal/ritual ornaments and status paraphernalia, as demonstrated by the number and quality of the jade items discovered in Liangzhu graves (Mou 1989; Nanjing 2001; Liu 2003:9-12; Liu et al. 2009). The typological variety and the generally high craftsmanship of Liangzhu jade artefacts must have required adequately varied tool kits and techniques as revealed by at least five Liangzhu lapidary workshops (Qin 2015:157). At Dingshadi, associated with jades that show traces of stringsawing and sandstone bore bits (or whetstones), both cylindrical and truncated-conical cores (H. $<1.5-9 \mathrm{~cm}>$ ) attest to the use of monopolar and bipolar drilling (Nanjing 2001:26-27, 33, figures 6-7). Further evidence of bore cores, tubular drill bits and string-sawing in Liangzhu jade craft have been discussed by Liu Weidong and colleagues, who also put forward the reconstruction of a jade boring operation with a sand tipped bamboo drill (2009: Figure 8). We consider this sound hypothesis as the most appropriate to explain the shell boring evidence at TK.

Although less frequent than the findings in the Liangzhu core area, Liangzhu style ritual tools have been found at several other late third-second millennium BCE locations outside the Yangtze Delta region, including the ritual cong found at sites of the Shixia culture, in the northern belt of Lingnan (Ciarla 2013: XI-XIV, 137-143). These latter findings would be of direct interest in tracing the southward dispersal of string-sawing and boring techniques, but, as argued elsewhere (Ciarla 2013:144-150), although the Shixia cong have a strong local flavour, any Shixia workshop directly related to the production of Liangzhu style ritual artefacts was found thus far.

Several manufacturing sites for the production of stone jewellery, in particular jue slit-rings, bracelets and cylindrical beads, have been discovered in southeast China
(Plate 7). In southern Zhejiang (in the upper Feiyun River valley), the Niutougang site yielded the remains of an atelier (over $600 \mathrm{~m}^{2}$ ) for the manufacturing of stone hoes, axeadzes, knives and spear points (Wang et al. 1999). Among the stone wasters, a few truncated conical bore cores, possibly derived from bracelets and jue making, hint at a onedirection (monopolar) boring technique, although no boring tools had been recognized in the published materials (Plate 7). According to the excavators, the site represents a local late Neolithic cultural type of the mid-to-late second millennium BCE (and later?) (Wang et al. 1999:46).

Workshop sites related to stone cylindrical beads, circlets and slit-rings are densely distributed along the continental coast and in the islands of the Zhujiang Delta Region (ZDR). Probably one of the earliest evidence of hollow drill bits in this part of Lingnan was discovered at the coastal Yunglong site in the New Territories (Hong Kong) (HKGW 1997). Here indirect evidence of hollow drill bits is provided by at least one bi-conical bore core, two semifinished jue with the typical circular groove suggestive of initial perforation and by the slit-rings with bi-conical radial section, diagnostic of bipolar boring (HKGW 1997:4546) (Plate 7).

Two uncalibrated ${ }^{14} \mathrm{C}$ dates set a chronological terminus post quem in the second millennium BCE for this late Neolithic site (HKGW 1997:52). Similar remains related to slit-ring making are known from contexts of period I (late Neolithic) and period II (Bronze age), dated between the late second and the first half of the first millennium BCE, at Baimang/Pakmong on Lantau Island (Hong Kong) (Tang et al. 1997). In the late Neolithic layer only two truncated conical cores were found, but in the following period these increased to 228 pieces, including two jue pre-forms with the typical circular groove of an initial perforation, again suggestive of a hollow drill bit (Tang et al. 1997:60, figures 8.1, 8.5) (Figure 37). The truncated conical and truncated bi-conical cores, from bracelets and slit-rings making, excavated from the upper cultural layer at the Chengjiayuan dune site (Yuanlang county, Hong Kong) point in the same direction (Ou and Mo 2002: 346-47, Figure 15) (Figure 37).

At Chengjiayuan the upper layer, characterized by a noticeable increase of craft activities (mainly pottery and stone/jade industries), represents a cultural assemblage of the local early BA that finds comparisons, among other sites, at Tangxiahuan (Zhuhai city). In the 4th layer of this site, the earliest sandstone casting mould in the region (late second -early first millennium BCE) was associated with evidence of stone slit-rings making (Guangdong and Zhuhai 1998:13-15, figures 13-14; Ciarla 2013:185-190) (Plate 7). In the above-mentioned contexts however no evidence of the actual tools used to pierce the raw material was found.

Several other late second -early first millennium BCE stone workshops for the manufacturing of slit-rings and bracelets, in addition to other tool types, are known in the ZDR, among which Suochiwan on Hebao Island (Zhuhai 1999), Baojingwan on Gaolan Island (Guangdong et al. 2004) and Hac Sa on Coloane Island (Macau) are probably 
the most representative (Tang 2013). At these sites, globular, ellipsoid and cylindrical sandstone whetstones (used either as borers or solid drill bits), with the actual grinding portion on one or both poles of the tools (Plate 8), are associated to grooved polishers, blanks and semi-finished slit-rings/bracelets, as well as to bore cores of truncated conical and truncated bi-conical shape.

Tang Chung considers the boring tools found at $\mathrm{Hac} \mathrm{Sa}$ as the main component of an elaborate boring machine that provided both centring and downward pressure on the spindle, this latter actually formed by the boring whetstone itself (Tang 2013:337). Although this boring machine is logically plausible, it needs more experimental procedures to be proven. For the time being, we consider the solid drill bits found in the stone workshops of the ZDR, homologous with the Lingjiatan sandstone tool (M98:6), and with the drill bits associated to other relevant tools and wasters in the stone workshops discovered at Qijiacun (QJ) (c. 1000$800 \mathrm{BCE}$ ), in the Zhouyuan archaeological area (Shaanxi prov.) (Sun 2007, 2009) (Plate 8).

This site is rather distant from the coast of eastern Guangdong to imply any direct contact, but is worth mentioning for the close functional/technological similarities with the lapidary evidence of Southeastern Lingnan and of MSEA. Sun Zhouyong has proposed a convincing reconstruction of the QJ jue manufacturing cycle based on the study of 35,993 wasters, on the analyses of the associated tools, of working traces observed on semi-finished and finished artefacts and on replication exercises. According to Sun, most of the jue preforms at QJ were chiselled in the centre to make a steep depression until the stone was pierced; after this stage the passing hole was enlarged and smoothed with a hand driven whetstone (Sun 2009: figures 3, 5.A upper row). The discovery of elongated drill bits [or s.c. 'prismatic drill bits', Ø 1 cm c., H. 3-6 cm] (Sun 2009: figure 5.A lower row) also suggests the use of either a bowdrill or a pump-drill (Sun 2009:56), possibly used to pierce the passing holes of the beads. Besides the piercing methods based on the chiselling of a small hole enlarged and/or smoothed with a whetstone or by means of 'prismatic drill bits', a third method is evidenced at QJ. A semi-finished jade circlet with central circular groove (H29:36) broken in the initial stage of the boring operation, witnesses the use of a hollow drill bit, possibly a bamboo or bone bit powered with sand, as Sun also suggested (Sun 2009:57-58) (Plates 7-8). The striking formal comparability of the semi-finished jade circlet H29:36, the semi-finished stone circlets from Yunglong and Pakmong (Plate 7), the ones from TrK and Hong Da (Plate 9) and the semi-finished and/or reused bore cores from TK (e.g. Figure 28) hints at similar boring devices (e.g., hollow drill bits), rather than to an accidental coincidence of ancient technology.

In the workshops of the ZDR, arguably depending on the mineralogical nature of the raw materials locally available, two boring methods were preferentially used: hollow drill bits and solid drill bits (or whetstones), both used in a monopolar and bipolar way. Hollow drill bits are indirectly witnessed by widespread truncated conical and truncated bi-conical bore cores and by the bi-conical radial section of the finished artefacts. The boring method with solid drill bits is directly evidenced by the finding of actual whetstones, as well as indirectly by semi-finished circlets that display the radial section similar to a rounded "8-shaped" figure (e.g., Guangdong et al. 2004: figures 96.13, 99.9) (Plate 7, Baojingwan lower left).

In the ZDR the truncated bi-conical stone cores found at Man Kok Tsui on Lantau Island (Hong Kong) (Davies and Tregear 1960) document the continuity of the bipolar coring method with hollow drill bits until around the sixthfifth centuries BCE. After the fifth century the making of stone circlets -jue slit-rings, in particular- suffered a slow decline due to changes in the local rituals sparked by the contact with the expanding Qin state (Xiao 2004:50-51).

Also two jade bore cores (one truncated conical and one truncated bi-conical) associated with bracelets and jue slitrings of various types in contexts of the mid/late first millennium BCE at the multi-period Batatai graveyard (Qujing prefecture, eastern Yunnan) are relevant to this discussion. These bore cores, of which the bi-conical one (M96:2) was part of Burial 96 furniture (Yunnansheng 2003: 117, plate 101.7, figure 10.1), were not accompanied by other manufacturing debris, therefore they could be hardly considered evidence of a local workshop. Nevertheless, they might signal a westward stage of the tubular drilling technology dispersal. The site in fact is located on the east-west route that, running along the watershed between the Yangtze and the Zhujiang, links the Yunnan-Guizhou Plateau with coastal Lingnan, where the majority of the workshops so far mentioned are located.

Archaeological data indicate that the stone jewellery craft centres of coastal Lingnan shared the main bulk of their technological behaviour with the lapidary workshops discovered in the region of the Song Hong Delta in northern Vietnam. Over twenty ateliers investigated by Vietnamese archaeologists since the early 1960s yielded finished stone bracelets/rings, slit rings and tools of varied types (mainly axes/adzes and chisels) associated to semifinished items and wasters (Nguyen 1996a:21-41). The data excavated at the workshops found at Bai Tu (BT) (Tu Son district, Bac Ninh prov.), TrK (Thuy Nguyen district, Haiphong city), Dau Ram (Quang Ninh prov.) and Hong Da (Tam Nong district, Phu Tho prov.), the first three sites assigned to the late Phung Nguyen-Dong Dau cultures (second millennium BCE), and the fourth one to the Dong Dau culture (early first millennium BCE) (Nguyen 1996a: 29, 31; 1996b:161 and note 1). Nguyen Kim Dung submitted the manufacturing debris from these sites to in-depth study and analysis, in particular the jasper augers (or drill bits) that characterize the lapidary tool kit at BT and TrK (Nguyen 1985, 1990, 1996a-b) (Plate 8). Based on her experimental replications, Nguyen (1985) rightly argued these drill bits -locally made, as shown by those at different stages of manufacture (Nguyen 1996b:162)- were mounted either on a pump-drill [probably similar to the wooden one found at the Dong Son site of Dung Du (Nguyen 1996b: Figure 7)], or on a bow-drill in order to pierce the passing hole of cylindrical beads. Nguyen also set forth an elaborate mechanical device for stone circlets making where the 
drill would have been fixed on a static crossbar exerting a certain vertical pressure on the blank mounted on a turntable. In this way the drill bit would cut a groove around the centre of the blank, forming the circular core that was extracted before the eventual finishing of the circlet (Nguyen 1996a:138-40, figure 31; Hung 2014: Figure 8d).

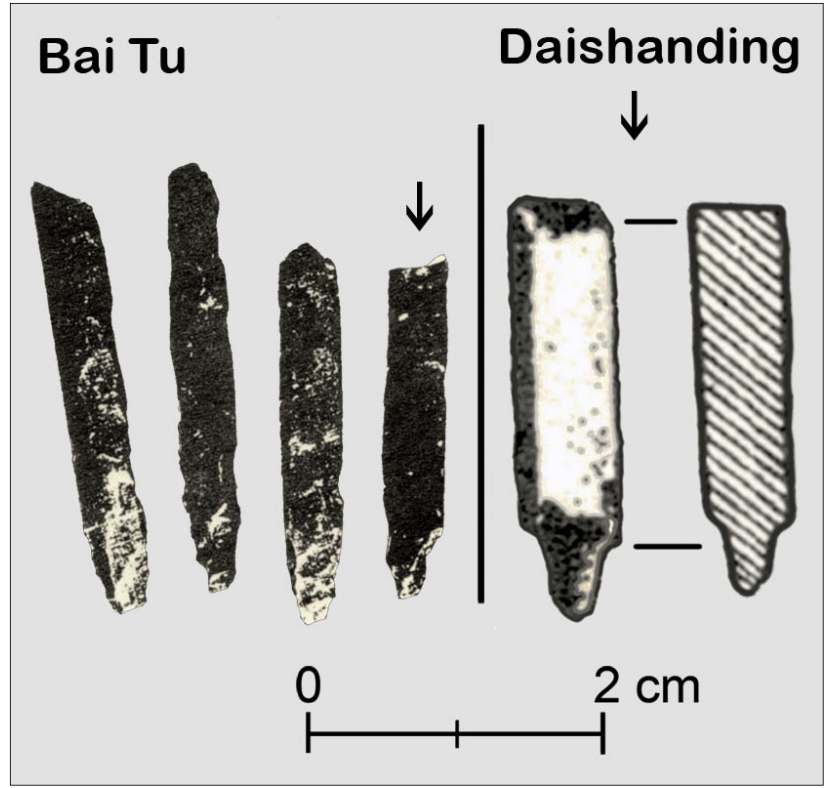

Figure 34: (left, black arrow) A jasper drill bit excavated at Bai Tu (Bac Ninh prov., Vietnam) and (right) a possibly comparable stone tool excavated at Daishangding (Guangdong prov., China).

Although this mechanical borer, inspired by Semenov (1964), remains hypothetical and in need of further experimental testing, the jasper drill bits of northern Vietnam workshops might well have entered the production cycle of stone circlets, but in a way still to be clarified. Moreover, the jasper drill bits might not be specific to the northern Vietnamese lapidary tradition. Although shaky, being based on rather old published drawings, one morphological comparison could be advanced between a drill bit from BT and a similar tool from the late Neolithic site of Daishanding in the ZDR (Mo and Yang 2003: Figure 3.6) (Figure 34) while, from the functional point of view, the jasper drill bits of the northern Vietnamese ateliers compare with the 'prismatic drill bits' excavated at Qijia (Sun 2007: figure 11.11-.13) (Plate 8). As for all the other evidence related to stone circlets making, the data yielded by the northern Vietnamese workshops exhibit close typological and functional comparisons with the stone jewellery workshops of the Zhujiang Delta/Hong Kong region (Plates 7 and 9). This general picture, with the occurrence of similar sets of working tools, wasters and semi-finished products, does not change when analysing the relevant data recovered from the stone jewellery workshop sites of southern Vietnam (e.g., Bung Bac in Dong Nai prov.) (Nguyen 1996:33-41), that, at least by 500 BCE, participated to a network of jade base material exchange that stretched from the sources in Taiwan to the coasts of Southeast Asia overlooking the 'Mediterranean' waters of the South China Sea (Hung and Bellwood 2010).

\section{CONCLUSIONS}

As we have recurrently mentioned in the preceding pages, three main boring methods were used in the lapidary workshops distributed from the Yangtze valley to the Lopburi Plain to make a passing hole in the centre of preformed, mostly round-shaped, solid pieces of stone/jade or shell. Out of these three methods, two -namely drilling by means of whetstone/borers and by means of drill bits- have direct archaeological evidence in the workshops excavated in China and Vietnam. The third method -namely, mono- and bipolar drilling by means of a hollow drill bit of organic nature- found indirect evidence in the semi-finished circlets, biconical bore cores and working traces on semi-finished and finished artefacts excavated at several ateliers from the Yangtze valley to the Lopburi Plain of Central Thailand. Our reconstruction is based on the limited material published so far in several languages and on the first hand data excavated at TK. However, we are aware that more fieldwork, laboratory research (including the most welcomed http://media.uow.edu.au/news/UOW 189914.html), and experimental replications are required to finally prove the use and the nature of the hollow drill bits in the stone/shell jewellery craft of MSEA during the late second-early first millennium BCE.

The data analysed indicate that the southward dispersal of the bipolar drilling technique followed the long wave of the down-the-line contacts along the river valleys and/or the coasts of Southern China reaching MSEA around the mid-late second millennium BCE. However, the outburst of the jade/stone craft, significantly associated with innovative craft production techniques such as copper-base metallurgy, only occurred since the late second -early first millennium BCE.

The findings from the workshops mentioned in the preceding pages, even located quite far from each other, witness the skills of the late second -early first millennium BCE craftsmen to resort to basically similar suit of techniques and tools according to type, hardness and/or thickness of the raw materials locally available. Of particular significance is a behavioural trait common to all the workshops so far mentioned: production efficiency, that is maximizing the yield of the raw material through the reuse of the wasters, in particular of the bore cores, to make circlets of progressively smaller diameters (Tang 2000:37-38, Figure1, 2003: 42-43; Nguyen 1996a: Figures 23-24, 1996b:163). This typical artisanal tradition further highlights the technological continuity of the ring-shaped ornaments handicraft from the Yangtze valley to the Lopburi Plain.

At the same time, these findings demonstrate that by the mid-late second millennium BCE, different stone workshops had adopted and adapted the same technological package to the production of widely demanded luxuries for the mere satisfaction of customary practices linked to ideological models of social display. During the second 
half of the first millennium BCE (IA) new jewellery types and glamorous materials replaced the customary use of stone and shell ornaments as a consequence of the contact with new ideational sources unsettling the ancient ritual practices: the expanding Chinese empire in Lingnan and Song Hong regions, the more reciprocal/interactive Indian markets and religions in the river plains of MSEA.

\section{ACKNOWLEDGEMENTS}

We gratefully acknowledge the American Philosophical Society of Philadelphia for having supported us with a Franklin Research Grant that made possible the conclusion of the present study in Lopburi.

We also wish to acknowledge the Fine Arts Department of Thailand for its continuing assistance, and the National Research Council of Thailand for having granted permission to our multiyear research in the Lopburi Province.

Our research in Thailand would never had been possible without the continuous support, both in the field and post-excavation, of the Italian Ministry of Foreign Affairs and International Cooperation, of the Italian Embassy in Bangkok, and the International Association for Mediterranean and Oriental Studies-ISMEO. To the Museum of Civilizations-'G. Tucci' National Museum of Oriental Art also go our sincere thanks for having provided scientific facilities and, above all, the collaboration of the laboratory assistant, Mr. Fabrizio Pica.

In Lopburi, the Directors of the King Narai Palace National Museum and of the 4th Regional Office of the Fine Arts Department graciously gave us their time and working space. A special thanks is owed to them.

In closing, our grateful thanks go to Thomas Higham, Deputy Director of the Radiocarbon Accelerator Unit (University of Oxford), for having kindly provided the radiocarbon AMS dates of the TK tridacna samples, whose result not only shed light on the chronology, but contributed to the understanding of the procurement cycle of the raw material.

Any remaining mistakes are our responsibility.

\section{GLOSSARY}

$\mathrm{AP}=$ Asian Perspective

BIPPA= Bulletin of the Indo-Pacific Prehistory Association

BSPI= Bollettino della Società Paleontologica Italiana

$\mathrm{BWG}=$ Bowuguan

BWY= Bowuyuan

DNKGYJ= Dongnan Kaogu Yanjiu

$\mathrm{DNWH}=$ Dongnan Wenhua

$\mathrm{E} \& \mathrm{~W}=$ East and West

$\mathrm{JAR}=$ Journal of Archaeological Research

JHKAS $=$ Journal of the Hong Kong Archaeological Society

JWP $=$ Journal of World Prehistory

HKGWGJBSJ= Hong Kong Guwu Guji Banshiju

$\mathrm{HXKG}=$ Huaxia Kaogu

$\mathrm{KCH}=$ Khao Co Hoc

$\mathrm{KG}=\mathrm{Kaogu}$

$\mathrm{KGXB}=$ Kaogu Xuebao
KGyWW= Kaogu yu Wenwu

PNAS $=$ Proceedings of the National Academy of Sciences

$\mathrm{WW}=\mathrm{Wenwu}$

WWKGYJS=Wenwu Kaogu Yanjiusuo

ZYWW = Zhongyuan Wenwu

\section{BIBLIOGRAPHY}

Anhui sheng WWKGYJS. 1989. Short report on the excavation at the Neolithic cemetery of Lingjiatan, Hanshan, Anhui. $W W, 4: 1-9,30$. (In Chinese).

Anhui sheng WWKGYJS. 2000. The Jades of Lingjiatan. Beijing: Wenwu chubanshe. (In Chinese).

Anhui sheng WWKGYJS. 2006. Lingjiatan: excavation report $n$. 1. Beijing: Wenwu chubanshe. (In Chinese).

Anhui sheng. 2008. New discoveries of the 5th excavation at Lingjiatan in Hanshan county, Anhui. $K G, 3: 7-17$. (In Chinese).

Bhumadhon, Phuthorn. 1984. Some archaeological finds from the excavation at Ban Tha Khae, 1983. In Archaeological Site: Ban Tha Khae, pp 13-19. The Fine Arts Department for the special exhibition 'Archaeological Site: Ban Tha Khae'. (In Thai).

Bellwood, P., Hung, H.c. and Y. Iizuka. 2011. Taiwan jade in the Philippines: 3000 years of trade and long-distance interaction. In P. Benitez-Johannot (ed.) Paths of Origins: Austronesia in the Collections of the National Museum of the Philippines. The Museum Nasional Indonesia, and the Netherlands Rijksmuseum voor Volkenkunde, pp. 30-41. Manila: ArtPostAsia.

Chang, N. 2001. Personal Ornaments in Thai Prehistory: Nong Nor, Ban Lum Khao and Noen U-Loke. Unpublished PhD Thesis. University of Otago, Dunedin, New Zealand.

Chang, N. J. (2004). IX The Personal Ornaments. In Higham, C.F.W. and Thosarat, R. (eds), The origins of the civilization of Angkor. Volume I. The excavation Ban Non Wat: the Bronze Age, pp. 217-237. Bangkok: The Fine Arts Department of Thailand.

Childe, V. G. 1954. Rotary Motion. In Singer C., E.J. Holmyard and A.R. Hall, A History of Technology, Vol. 1, pp. 187215. Oxford: Oxford University Press.

Ciarla R. 1992. The Thai-Italian Lopburi regional archaeological project: Preliminary results. In I. C. Glover (Ed.), Southeast Asian Archaeology 1990, pp. 11-128. Hull: Centre for Southeast Asian Studies, University of Hull.

Ciarla, R. 1994. La città delle scimmie. Archeo, 11 (117):42-53.

Ciarla, R. 2013. Cultural and technological interactions between Southern China and Mainland Southeast Asia in the late 2nd - early 1st millennium BCE: the southern dispersal of copper base metallurgy, Vol. I, pp. 1-356. Unpublished PhD Thesis. Venice: University of Venice Ca' Foscari. (In Italian)

Ciarla, R. (forthcoming). The origins of the Bronze Age in Mainland Southeast Asia. In C. F. W. Higham and Nam, K. (Eds), The Oxford Handbook of Southeast Asian Archaeology. Oxford: Oxford University Press.

Ciarla, R., Rispoli, F. 2016. A Thai Gentleman, a Thai Archaeological site and We: 1988-1993 Thai-Italian Archaeological Investigations at Tha Kae-Lopburi. In Wanna Navigamune (Ed.), Multidisciplinary Studies on Lopburi, pp. 
582-618. Lopburi: Faculty of Management, Rajabhat Thepsatri University College. (In English and Thai).

Ciarla, R., Natapintu, S. 1992. Towards a definition of site formation processes in monsoonal-tropical environments: Preliminary considerations. In G. Leonardi (Ed.), Formation processes and excavation methods in archaeology: Perspectives, pp. 173-198. Padova: Saltuarie dal Laboratorio del Piovego 3.

Ciarla, R., Cremaschi, M., Weiss, A.D. 1989. Community growth and changes at Tha Kae. Paper Presented at the 54th Annual Meeting of the Society for American Archaeology, Atlanta, GA, USA, April 5-9.

Cremaschi, M. 1990. Le strutture del sito di Tha Kae. LoRAP Internal Report to the Italian Ministry of Foreign Affairs. (In Italian).

Cremaschi, M., Ciarla, R., Pigott, V. C. 1992. Palaeoenvironment and late prehistoric sites in the Lopburi Region of Central Thailand. In I. C. Glover (Ed.), Southeast Asian Archaeology 1990, pp. 167-177. Hull: Centre for Southeast Asian Studies, University of Hull.

Dai, J.C., Long, Y. 2011. On the chrono-geographic distribution of the sites of the mid-late Neolithic Jade culture in the central and eastern regions of China. $H X K G, 2: 54-61$. (In Chinese).

Damour, A. 1846. Analyse du jade orientale, réunion de cette substance à la trémolite. Annales de Chimie et Physica, Series 3, 16:469-474.

Davis, S.G. and Tregear, M. 1960. Man Kok Tsui, archaeological site 30, Lantau Island, Hong Kong. AP 4:183-212.

Deng, C. (Tang, C.), Shang, Zhitan, Huang, Yunzhang. 1997. Short report on the excavations at Baimang/Pakmong site in Dayushan, Hong Kong. $K G$, 6:54-64. (In Chinese).

Fengxiang xian BWG. 2005. Artefacts of the Spring and Autumn period excavated at Shangguodiancun in Fengxiang county, Shaanxi. $W W, 1: 3-6$. (In Chinese).

Guangdongsheng WWKGYJS, Zhuhai shi Pingsha Wenhuake. 1998. A short report on the excavation at Tangxiahuan near Pingsha, Zhuhai. $W W 7: 4-16$. (In Chinese).

Hanwong, Thanongsak (1985/2528). Artifacts Analysis from the Excavation at Ban Tha Kae, Amphoe Muang, Changwat Lopburi. Unpublished MA Thesis, Department of Archaeology, Silpakorn University, Bangkok. (In Thai)

Higham, C.F.W. 2012a. III The Male Burials Of Bronze Age Period 2. In Higham C.F.W., Kijngam, A. (Eds.), The origins of the civilization of Angkor. Volume $V$. The excavation Ban Lum Khao, pp. 23-86. Bangkok: The Fine Arts Department of Thailand.

Higham, C.F.W. 2012b. IV The Female Burials of Bronze Age Period 2. In Higham C.F.W., Kijngam, A. (Eds.), The origins of the civilization of Angkor. Volume $V$. The excavation Ban Non Wat: the Bronze Age, pp. 87-116. Bangkok: The Fine Arts Department of Thailand.

Higham, C.F.W. 2012c. VI Bronze Age 3A Burials. In Higham C.F.W., Kijngam, A. (Eds.), The origins of the civilization of Angkor. Volume V. The excavation Ban Non Wat: the Bronze Age, pp. 149-196. Bangkok: The Fine Arts Department of Thailand.

Higham, C.F.W. 2012d. VIII The Male Burials of Bronze Age Period 4 Group A. In Higham C.F.W., Kijngam, A. (Eds.), The origins of the civilization of Angkor. Volume V. The excavation Ban Non Wat: the Bronze Age, pp. 227-247. Bangkok: The Fine Arts Department of Thailand.
Higham, C.F.W. 2012e. XI The Burials of Bronze Age Period 4 Group B. In Higham C.F.W., Kijngam, A. (Eds.), The origins of the civilization of Angkor. Volume V. The excavation Ban Non Wat: the Bronze Age, pp. 285-318. Bangkok: The Fine Arts Department of Thailand.

Higham, C.F.W. 2012f. XVI The Male, Adult, Infant and Child Burials of Bronze Age Period 5. In Higham C.F.W., Kijngam, A. (Eds.), The origins of the civilization of Angkor. Volume V. The excavation Ban Non Wat: the Bronze Age, pp. 417-443. Bangkok: The Fine Arts Department of Thailand.

Higham, C.F.W. 2012g. XIII The Male Burials of Iron Age Period 1: the Southern Group. In Higham C.F.W., Kijngam, A. (Eds.), The origins of the civilization of Angkor. Volume VI. The excavation Ban Non Wat: the Iron Age, Summary and Conclusions, pp. 227-273. Bangkok: The Fine Arts Department of Thailand.

Higham, C.F.W. 2012h. XV The Infant Burials of Iron Age Period 1, Southern Group. In Higham C.F.W., Kijngam, A. (Eds.), The origins of the civilization of Angkor. Volume VI. The excavation Ban Non Wat: the Iron Age, Summary and Conclusions, pp. 299-312. Bangkok: The Fine Arts Department of Thailand.

Higham, C.F.W., R. Bannanurag (eds.). 1990. The Excavation at Khok Phanom Di, Vol. I: The Excavation, Chronology and Human Burials. London: Society of Antiquaries.

Higham, C.F.W., R. Thosarat (eds.). 1998. The Excavation of Nong Nor, a Prehistoric Site in Central Thailand. University of Otago Studies in Prehistoric Anthropology No. 18. Otago: Department of Anthropology, University of Otago.

Higham, C.F.W., R. Thosarat (eds.). 2004. The Origins of Civilization of Angkor. Vol. I. The Excavation of Ban Lum Khao. Bangkok: Thai Fine Arts Department.

Higham, C., Higham, T., Ciarla, R., Douka, K., Kijngam, A., Rispoli, F. (2011). The Origins of the Bronze Age of Southeast Asia. JWP, 24 (4):227-274.

Higham, C.F.W., A. Kijngam (eds.). 2012. The Origins of Civilization of Angkor. Vol. V. The Excavation of Ban Non Wat, Part III: The Bronze Age. Bangkok: The Thai Fine Arts Department.

Ho, C.m. W. (1984). The Pottery of Khok Charoen and Its Further Context. Unpublished PhD Thesis. London: University of London.

HKGWGJBSJ. 1997. A short report on the excavation of the Neolithic site at Yunglong in Hong Kong, $K G, 6: 35-53$. (In Chinese)

Huang, T.M. 1992. Liangzhu - A Late Neolithic Jade-Yielding Culture in Southeastern Coastal China. Antiquity, LXVI:75-83.

Hung, H.C. 2014. Jade in Southeast Asia. In Selin, H. (ed.) Encyclopaedia of the History of Science, Technology, and Medicine in Non-Western Cultures, pp. 1-8. Springer Netherland.

Hung, H.C., Iizuka, Y., Bellwood, P. , Nguyen, T.K.D., Bellina, B., Silapanth, P., Dizon, E., Santiago, R., Datan, I., Manton, J.M. 2007. Ancient jades map 3,000 years of prehistoric exchange in Southeast Asia. PNAS, USA 104(50):19745-19750.

Hung, H.C., Bellwood, P. 2010. Movement of raw materials and manufactured goods across the South China sea after 500 BCE: From Taiwan to Thailand, and back. In Bellina, B., Bacus, E.A., Pryce, T.O., Wisseman Christie, J., eds., 50 
Years of Archaeology in Southeast Asia. Essays in Honour of Ian Glover, pp. 234-243. Bangkok: River Books.

Hutangkura, T. 2014. Reconsidering the Palaeo-shoreline in the Lower Central Plain of Thailand. In Revine, N. and Murphy, S. A. (eds.) Before Siam, pp. 32-67. Bangkok: River Books and The Siam Society.

Hviding, E. 1993. The Rural Context of Giant Clam Mariculture in Solomon Islands: An Anthropological Study, ICLARM Tech. Rep. 39.93.

Kenoyer, J. M. 1991. Ornament Styles of the Indus Valley Tradition: evidence from recent excavations at Harappa, Pakistan. Paleorient, Vol. 17/2:79-98.

Kittiwattanawong, K. 2011. Record of extinct Tridacna gigas in Thailand. Tropical Marine Molluscs Programme (TMMP), Phuket Marine Biological Center, Smaller Research Contributions, pp. 461-463.

Kobayashi, I. 1969. Internal microstructure of the shell of bivalve mollusks. American Zoologist, 9:663-672.

Lertcharnrit, T. 2005. Late Prehistoric and Early Historic Archaeology in Thailand: Recent Evidence from Central Highland. Silpakorn University Journal, 5(1-2), pp. 55-72.

Lertcharnrit, T. 2009 (2552). Ancient Ornaments at Phromthin Tai. Sarawadee 298, pp. 26-30. (In Thai).

Lertcharnrit, T. 2010 (2553). Beads: Life Accessories. Prateep 3, pp. 2-9. (In Thai).

Lertcharnrit, T. 2014. Phromthin Tai: An Archaeological Perspective on Its Societal Transition. In Revine, N. and Murphy, S. A. (eds.) Before Siam. Bangkok, River Books and The Siam Society, pp- 118-131.

Lertrit, S., Preeyanuch, J., Anan K. 2002. The 2000 archaeological excavation at Sab Champa: Results and speculations. Muang Boran Journal 27(3) : 117-133. (In Thai).

Lertrit, S. 2004a. Sab Champa Revisited: Results of Recent Archaeological Field Investigations. In Paz, V. (ed.), Southeast Asian Archaeology: Wilhelm G. Solheim II Festschrift, pp. 504-521. Quezon City: University of the Philippines Press.

Lertrit, S. 2004b. Late prehistoric and early historic archaeology in the Central Highland of Thailand: excavation at the site of Sab Champa. Antiquity 78, No 299, March 2004, pp. 5472 .

Liu, L., 2003. The products of minds as well as of hands: production of prestige goods in the Neolithic and early state periods of China. $A P, 42: 1-40$.

Liu, W.D., Lu, W.B., Qi, S.G. 2009. A preliminary investigation on the jade bi-disc making of the Liangzhu culture. $D N W H$, 6:47-53. (In Chinese).

Loofs-Wissowa, H. H. E. 1982. Prehistoric and protohistoric links between the Indochinese Peninsula and the Philippines' JHKAS, IX:57-76.

Middleton A., I. Freestone, 1995. The Mineralogy and Occurrence of Jade. In Rawson J. (ed.) Chinese Jade from the Neolithic to the Qing, pp. 413-423. London: The British Museum Press.

Mo, Z., Yang, H. 2003. Neolithic sites in Eastern Guangdong. In Mo, Z. (ed.) Nan Ao Wenwu Kaogu Ji (1955-2002), pp. 112-129. Beijing: Wenwu chubanshe. (first published in KG 1961,12). (In Chinese).

Mou, Y.K. 1989. Three arguments on Liangzhu jades. $W W$, 5:6468,74 . (In Chinese).
Nanjing BWY KGYJS, 2001. A short report on the 2nd excavation at Dingshadi near Jurong, Jiangsu province. $W W, 5: 22$ 36. (In Chinese).

Natapintu, S. 1984a/2527. Ancient Settlement at Ban Tha Kae. Muang Boran 10(4):20-27. (In Thai).

Natapintu, S. 1984b/2527. Evidences from Ban Tha Khae and some aspects about an old settlement in the lower central Thailand. The Fine Arts Department for the special exhibition 'Archaeological Site: Ban Tha Khae', pp. 1-12. (In Thai).

Natapintu, S. (1988). Current Research on Ancient Copper-Base Metallurgy in Thailand. In P. Charoenwongsa and B. Bronson (Eds.), Prehistoric Studies: Stone and Metal Ages in Thailand, pp. 107-124. Bangkok: Thai Antiquity Working Group.

Natapintu, S. 1995. Les changements culturels de la préhistoire tardive en Thailande centrale. In 3e Symposium francothaï: Les apports de l'archéologie à la connaissance des anciens Etats en Thailand, pp. 146-170. Bangkok: Université Silpakorn.

Negri, M. P. 2009. An experimental mapping method by means of fossil mollusc faunas: the Holocene Thai palaeogulf. BSPI, 48 (1):41-50.

Nguyễn, Thị Kim Dung. 1985. Research on stone augers and ancient drilling techniques. $\mathrm{KCH}, 2: 63-80$. (In Vietnamese).

Nguyễn, Thị Kim Dung.1990). Two excavations at the lithic workshop site of Trang Kenh (Hai Phong). $\mathrm{KCH}, 3: 64-82$ (In Vietnamese).

Nguyễn, Thị Kim Dung, 1996a. Workshop sites and stone jewellery manufacturing techniques in the Bronze Age of Viet Nam. Hanoi: Nha Xuat Ban Khoa Hoc Xa Hoi. (In Vietnamese).

Nguyễn, Thị Kim Dung. 1996b. The Trang Kenh Jewellery Workshop Site: an experimental and microwear study. BIPPA, 14:161-165.

Ou, J.F., Mo, Z. 2002. The excavation of the dune site at Chenjiayuan, Xiacun township, Yuanlang, Hongkong), KGXB, 3:335-358. (In Chinese).

Pigott, V.C., R. Ciarla. 2007. On the Origins of Metallurgy in Prehistoric Southeast Asia: The View from Thailand. In S. La Niece, D. Hook, P. Craddock, Metals and Mines. Studies in Archaeometallurgy, pp. 76-88. London: British Museum.

Pilditch, J.S. 1993. The Personal Ornaments. Higham, C.F.W. and Thosarat, R. (eds), The Excavation of Khok Phanom Di: a prehistoric site in Central Thailand, Volume III: the material culture (part 1), pp. 119-176. London: The Society of Antiquaries of London, Research Report No. L.

Qin, X.1. 2011. A research on the annular ornaments in the Neolithic period. $K G X B, 2: 151-182$. (In Chinese).

Qin, X.1. 2015. Relationship between South China and Vietnam: Technology, Function and Distribution of Jade Ornaments. Archaeological Bulletin of Kanazawa University, 36:155165.

Rispoli, F. 1992. Preliminary report on the pottery from the 1989 excavation season at Tha Kae, Op. 1 Square A. In I. C. Glover (Ed.), Southeast Asian Archaeology 1990, pp. 129142. Hull: Centre for Southeast Asian Studies, University of Hull.

Rispoli, F. 1997a. Ad Occidente è l'India. Alla ricerca delle radici del processo di indianizzazione nella Thailandia Centrale. 
[To the West and India. Tracing the roots of the Indianization process in central Thailand]. Upublished Ph.D. Thesis, Istituto Universitario Orientale, Naples. (In Italian).

Rispoli, F. (1997b). Late-third/early second millennium BC pottery traditions in central Thailand: Some preliminary observations in a wider perspective. In R. Ciarla, F. Rispoli (Eds.), Southeast Asian archaeology 1992, pp. 59-97. S.O.R. 77, Istituto Italiano per l'Africa e l'Oriente, Rome.

Rispoli, F. 2004. Gli skin rubbers della Valle del Chao Phraya (Thailandia centrale) [The skin rubbers of the Chao Phraya Valley (Central Thailand)]. In Fontana, M. V., Genito, B. (Eds.), Studi in onore di Umberto Scerrato per il suo settantacinquesimo compleanno, pp. 669-680. Naples: Istituto Universitario Orientale. (In Italian).

Rispoli, F., 2005. To the West and India. In Callieri, P. and Filigenzi, A. (Eds.), Studi in onore di Maurizio Taddei, E\&W, 55:243-264.

Rispoli, F. 2006. Terracotta Ear-studs and Skin-rubbers: looking for the Roots of Indianization in Central Thailand. In I. Piovano (a cura di), La Cultura Thailandese e le Relazioni Italo-Thai, pp 45-76. Torino: CESMEO. (In Italian).

Rispoli, F. (forthcoming A). The expansion of rice and millet farmers into Southeast Asia. In C. F. W. Higham and Nam, K. (Eds), The Oxford Handbook of Southeast Asian Archaeology. Oxford: Oxford Univ. Press.

Rispoli, F. (forthcoming B). The Iron Age in Central Thailand. In C. F. W. Higham and Nam, K. (Eds), The Oxford Handbook of Southeast Asian Archaeology. Oxford: Oxford University Press.

Rispoli, F., Ciarla, R., Pigott, V.C. 2013. Establishing the Prehistoric Cultural Sequence for the Lopburi Region, Central Thailand. JWP, 26:101-171.

Ross, K. W., Oxenham, M. F. 2017. The distribution of unworked molluscs, with special reference to Unionidae (freshwater mussels), in Mainland Southeast Asian mortuary contexts. Journal of Indo-Pacific Archaeology, 41, pp. 1-12. http://dx.doi.org/10.7152/jipa.v41i0.15016

Shang Y.S. 1999. A survey at the Suochiwan site on Hebao Island, Zhuhai, Guangdong. In Tang C. and Wu C.m. (ed.s), $D N K G Y J$, 2, pp. 71-82. Xiamen: Xiamen Daxue Chubanshe. (In Chinese).

Schiffer, M.B. 1972. Archaeological context and systemic context. American Antiquity, 37 (2):156-165.

Semenov, S. A. 1964. Prehistoric Technology: on experimental study of the oldest tools and artifacts from traces of manufacture and wear. M.W. Thompson transl. from Russian edition 1957. London: Cory, Adams and Mackay.

Siripanish, Sunee. 1985. An Analythical Study on Pottery from the Excavation at Ban Tha Kae, Muang District, Lopburi Province. Unpublished MA Thesis, Department of Archaeology, Silpakorn University, Bangkok. (In Thai).

Siripong, Absornsuda. 2010. Detect the Coastline Changes in Thailand by Remote Sensing. International Archives of the Photogrammetry, Remote Sensing and Spatial Information Science, Volume XXXVIII, Part 8:992-995.

Somboon, J.R.P.. 1990. Geomorphology of the Chao Phraya Delta, Thailand. Ph.D. Dissertation, Kyoto Uiversity, Kyoto.

Sraffa, P. 1963. Production of Commodities by means of Commodities: Prelude to a Critique of Economic Theory. Bombay: Vora \& Co., Publishers PVT. Ltd.
Sun, G.P., Wang, H.M., Tian, Z.B., Wang, T.J. 1999. Cultural remains of the Bronze age in the Feiyun River valley of Southern Zhejiang, pp. 1-51. In Tang C. and Wu C.m. (ed.s), DNKGYJ, 2. Xiamen: Xiamen Daxue Chubanshe. (In Chinese).

Sun, X.R., Zhang, J.G., Wang, H.R., Sun, H., Jiang, X.P., Xu, Q. 2002. On the Jades of Tremolite type from the Neolithic site at Lingjiatan in Hanshan county, Anhui province. Yan Shi Kuang Wuxue Zazhi - Acta Petrologica et Mineralogica, 9:124-128. (In Chinese).

Sun, Z.Y. 2009. Production pattern of stone slit-rings in the Western Zhou; a discussion on the raw materials, technology and work organization. $K G y W W, 3: 49-63$. (In Chinese).

Tang, C. (Deng, C,). 2000. Some remark on the jue ornaments in East Asia. $W W, 2: 35-45$. (In Chinese).

Tang, C. (Deng, C,). 2003. The Road of the jade slit-rings in East Asia. In Li J.j. (ed.), Renlei Wenhua Yichan Baohu-Human Culture Heritage Preservation 1, pp. 41-44. Xi'an: Jaotong University. (In Chinese).

Trubitt, M. B. D. 2003. The production and exchange of marine shell prestige goods. JAR, 11 (3):243-277.

Wang, R. 2011. Progress Review of the Scientific Study of Chinese Ancient Jade. Archaeometry, 53 (4):674-692.

Wen, G., Jing, Z.C. 1992. Chinese Neolithic Jade - a preliminary geoarchaeological study. Geoarchaeology, an International Journal, 7 (3):251-255.

West, E. H. 1963. Jade. Its Character and Occurrence. Expedition, 5 (2):2-11.

Wilem, R. N. 1989. Excavation at Non Pa Kluay, Northeast Thailand. Oxford: BAR International Series 517.

Xiao, Y.T.. 2004. On the slit-rings and round whetstone excavated form sand dune sites. In Guangdongsheng WWKGYJS, Guangzhoushi WWKGYJS, Shenzhen BWG (ed.s), Huanan Kaogu 1, pp. 38-52. Beijing, Wenwu Chubanshe. (In Chinese).

Yan, Y.L.. 2010. On the question of the "Jade Road". $K G y W W$, 3:38-41. (In Chinese).

Yang, J.F. 2009. On wire cutting, wheel cutting and wheel carving - a discussion on the earliest use of wheel tools. $W W$, 7:52-67. (In Chinese).

Yin, Z.W., Jiang, C., M. Santosh, Chen Y.M., Bao Y., Chen Q.1. 2014. Nephrite Jade from Guangxi province, China. Gems and Gemology, 50 (3). http://www.gia.edu/gems-gemology/fall-2014-nephrite-jade-guangxi-province-china

Yu, H., Liu, G.X., Tang, C. 2007. On the origin of jade objects: researches and illustrations of the jades of the Xinlongwa culture. The Origin of Jade in East Asia: Jades of the Xinglongwa Culture. Hong Kong: Chinese University Press. (In Chinese).

Yunnansheng WWKGYJS (2003). Batati and Hengdalu in Qujing. Beijing: Kexue chubanshe. (In Chinese).

Zhang, C., Hung, H.C. 2010. The emergence of agriculture in southern China. Antiquity 84: 11-25.

Zhang, J.G. 1999. Main achievements of the 3rd archaeological excavation at Lingjiatan, Hanshan. DNWH, 5:14-17. (In Chinese).

Zhang, J.G., Yang, Z.Y., Chen, Q.X. 2002. Microscopy researches and observations of micro-traces on Lingjiatan jades: the discovery of the Chinese tuo (emery wheel). DNWH, 5: 16-28. (In Chinese). 
CIARLA ET AL.: SHELL PERSONAL ORNAMENTS CRAFT AT THE SITE OF THA KAE, LOPBURI PROVINCE, CENTRAL THAILAND. TRACING THE SOUTHWARD DISPERSAL OF THE DRILLING TECHNIQUE

Zhang, Z.W., Gan, F.X., Cheng, H.S. 2011. PIXE analysis of nephrite minerals from different deposits. Nuclear Instruments and Methods in Physics Research, vol. 269 (4):460465. (In Chinese).

Zhao, L. 2011. The regional traits of Chinese jades in the Neolithic period. $Z Y W W, 6: 27-36$. (In Chinese).
Zhejiangsheng WWKGYJS. 2003. Hemudu - Archaeological excavation report of a Neolithic period site, voll. I-II. Beijing, Wenwu Chubanshe. (In Chinese). 
PLATES

Plate 1-4 - Personal Ornament types made from Tridacna shell represented at Tha Kae.

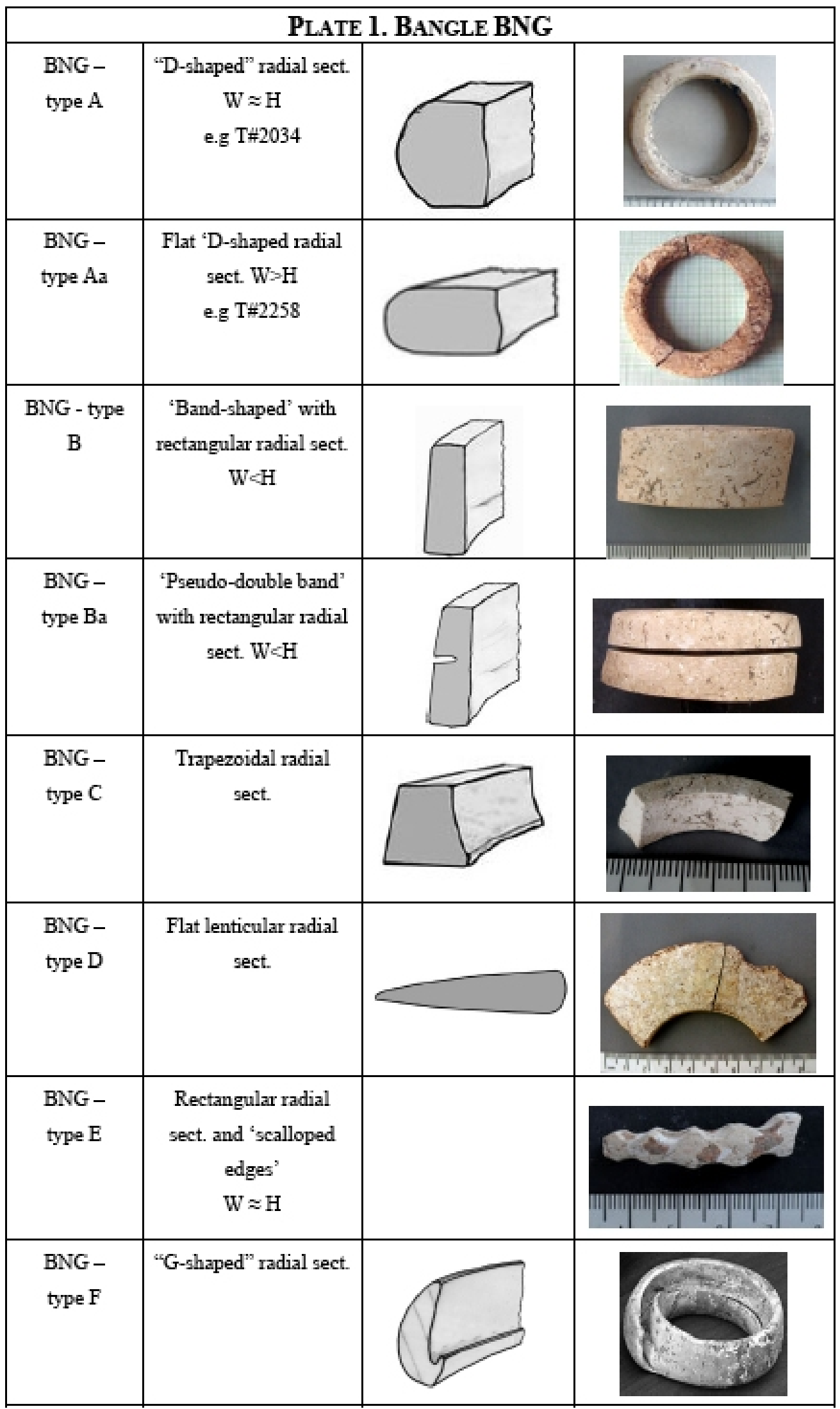




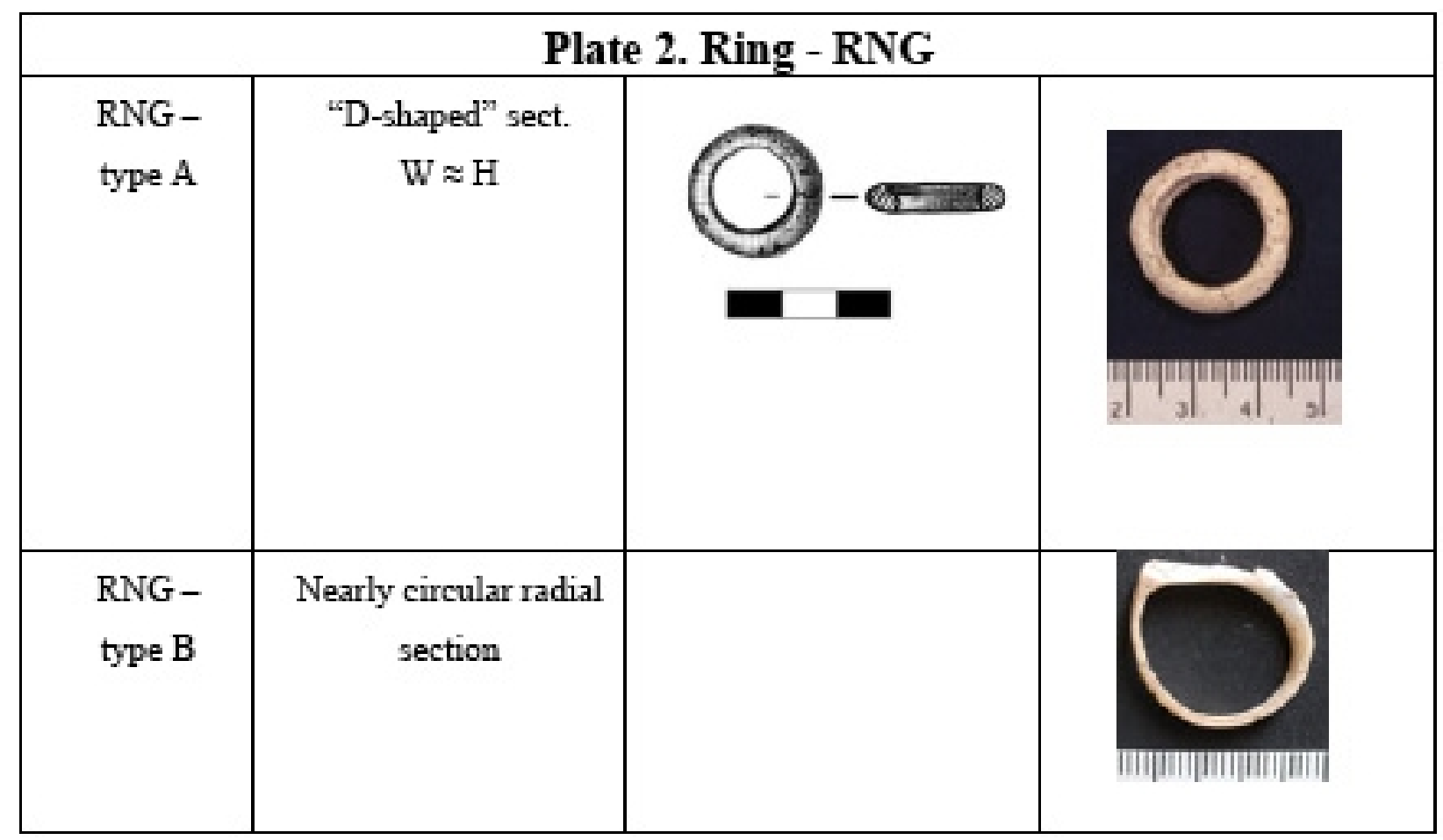

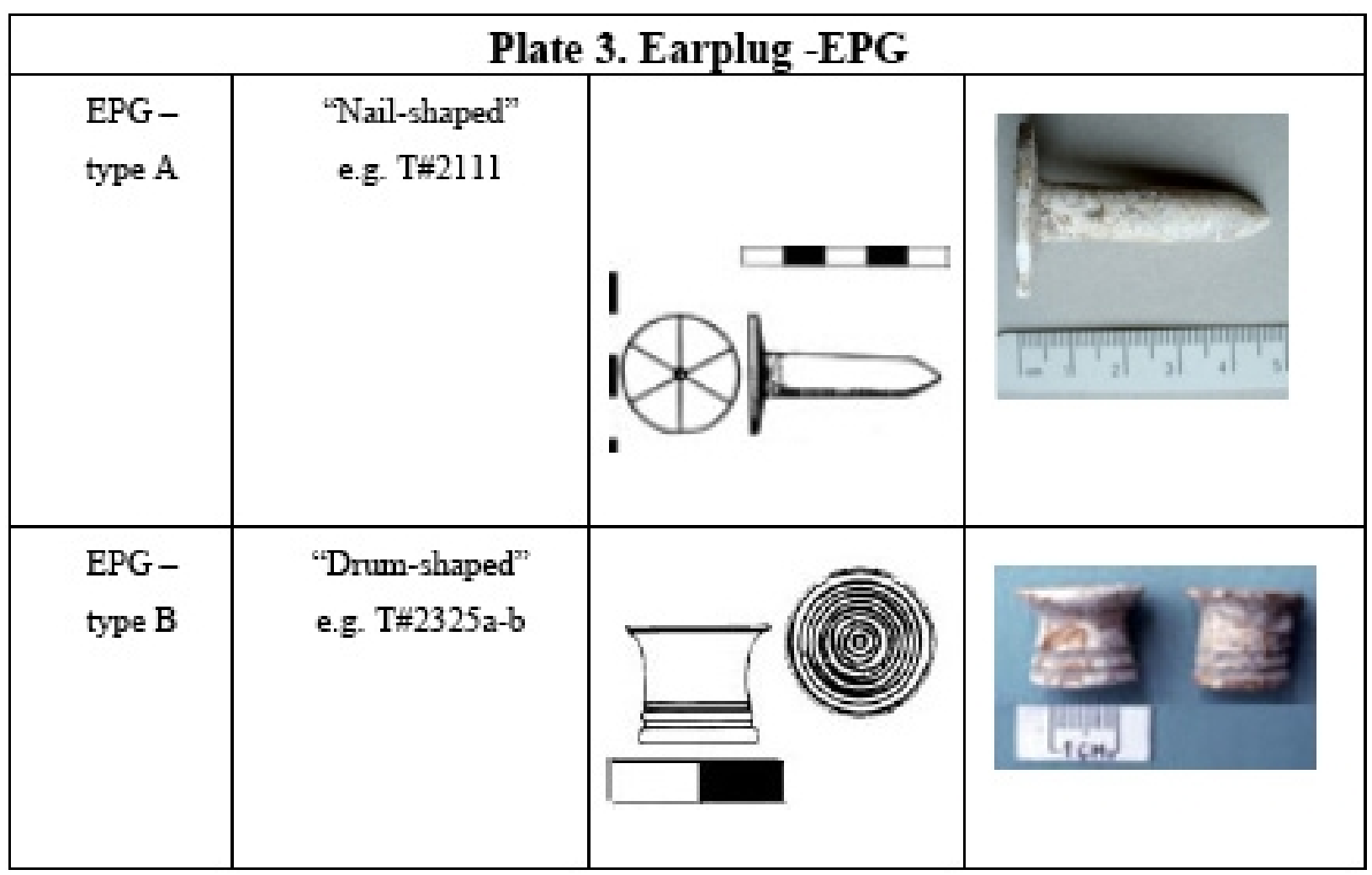




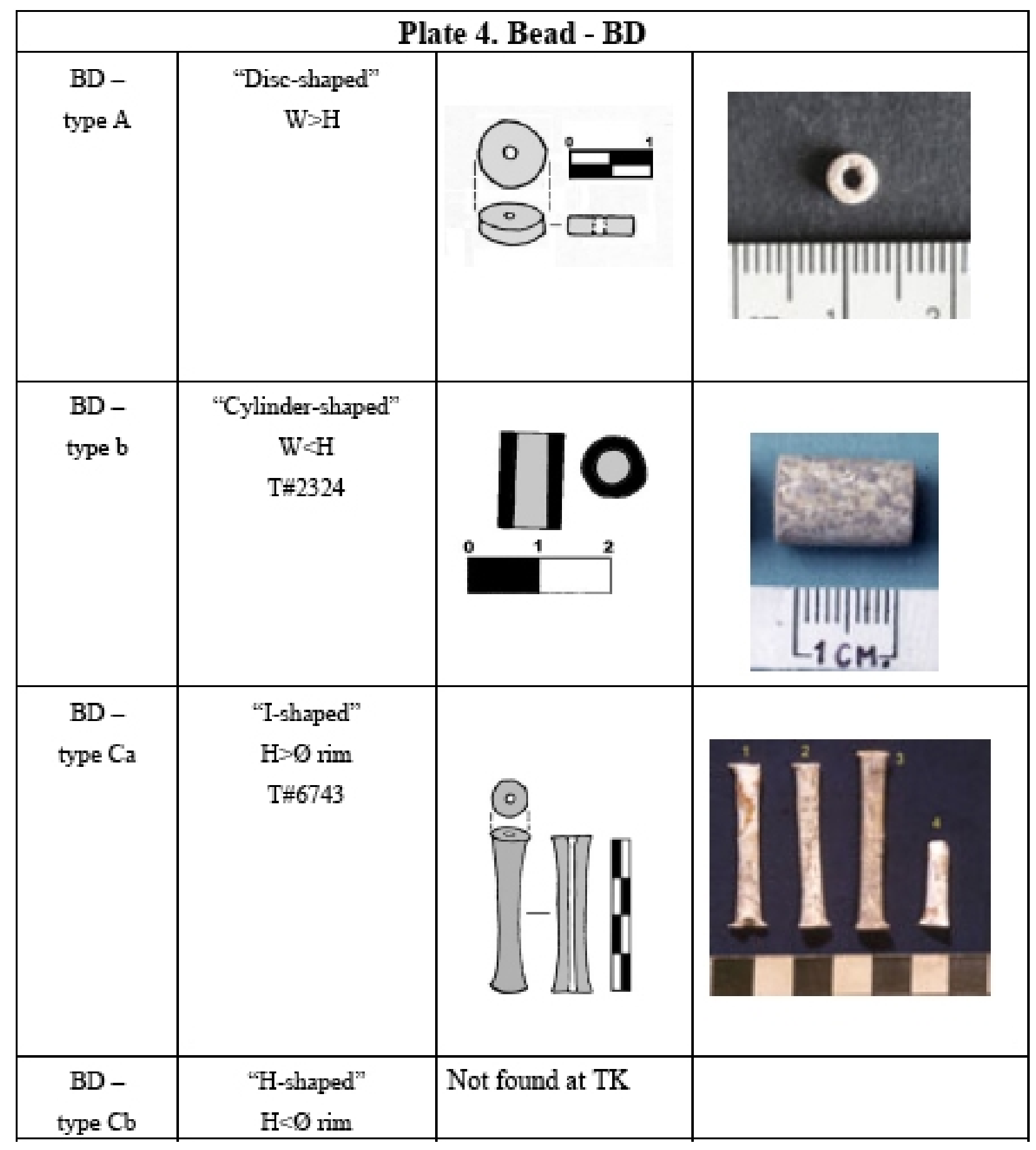


Plate 5 - Circlet fragments of quadrangular radial section broken during the manufacturing stages 4-5. A: Relative position of the 'apical' and 'ventral' slices (the external 'coat') in relation to the core at the moment of the separation stage; B. fragments of semifinished circlets with: (1) one, (2) two and (3) three jagged ridges remnants of the 'crown' between the core and the 'coat' and/or of the joints between one sliced circlet and the other.

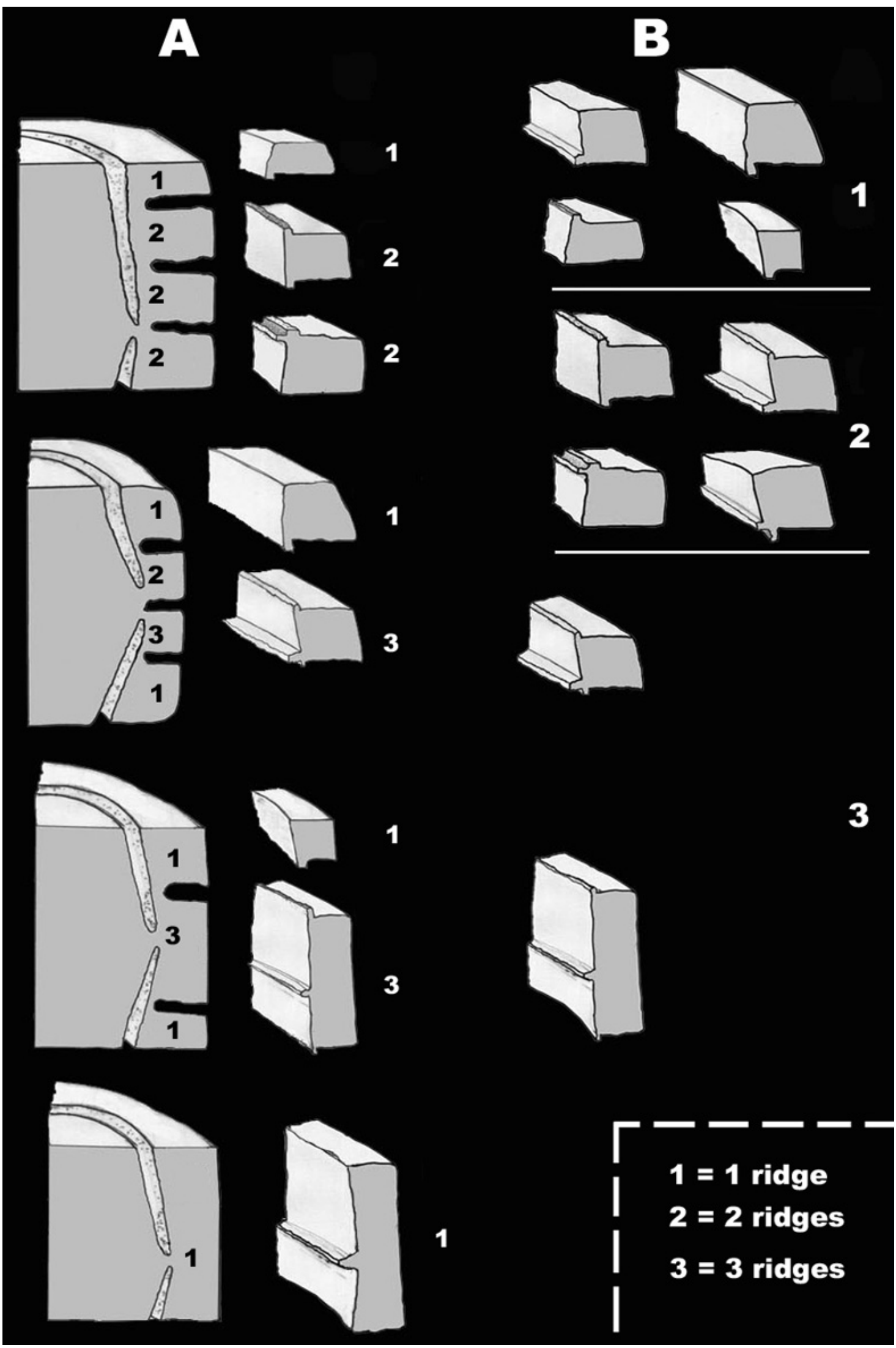


Plate 6-Progressive finishing steps of the main bracelet/ring types documented by the circlet fragments analyzed in the present study.

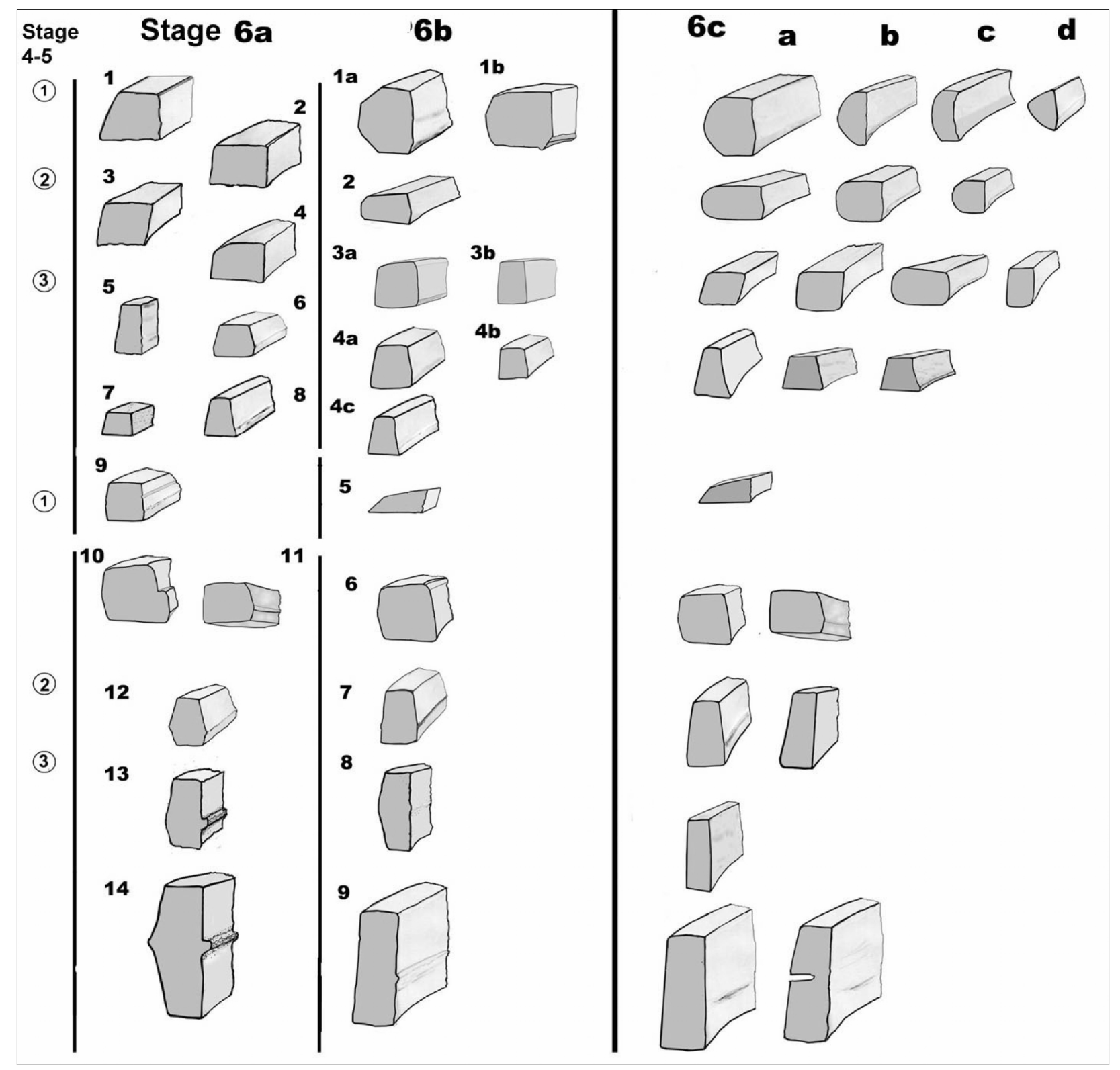


Plate 7 - Bore cores and semi-finished stone circlets evidencing the use of hollow drill bits and of solid stone borers (Baojingwan lower left) from Fujian-Guangdong sites and (lower central part) Qijia stone workshops (Shaanxi province).

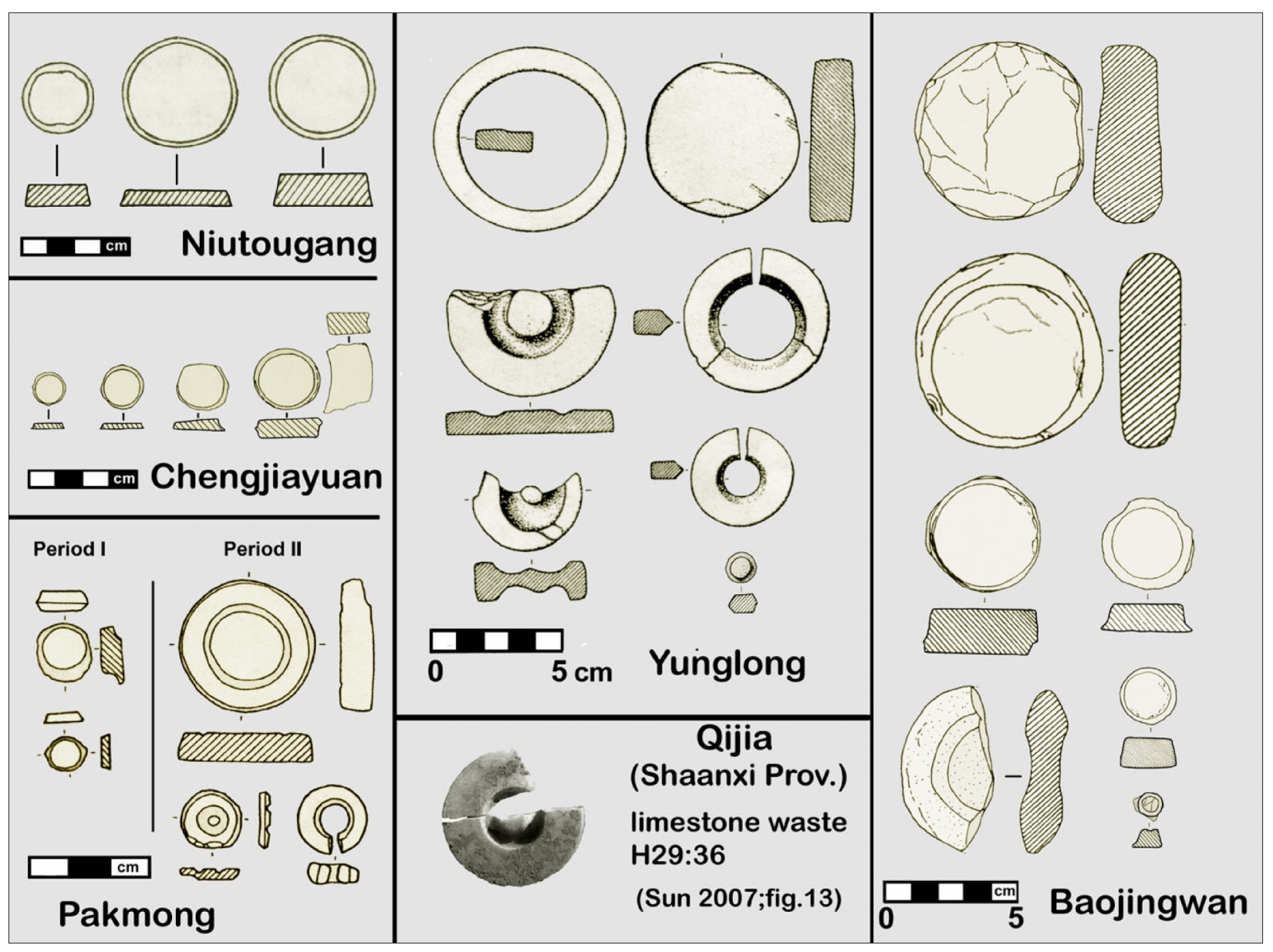


Plate 8 - A. ellipsoid and cylindrical sandstone whetstones/borers; B. (elongated/prismatic) stone drill bits, possibly to be gripped on a bow- or pump-drill, from Baojingwan, Suochiwan, Qijia and Trang Kenh.

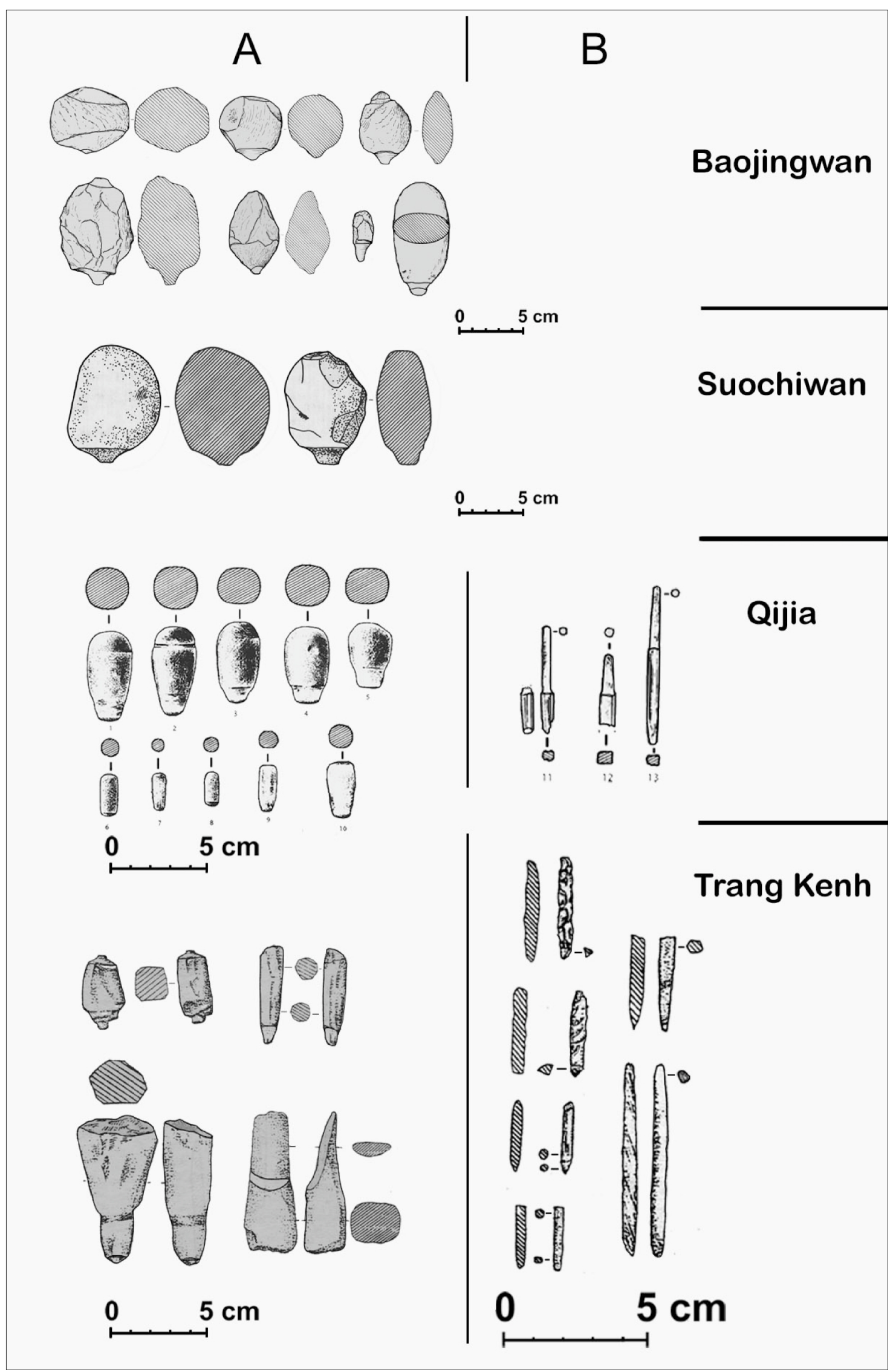


Plate 9 - Vietnam: bore cores and semifinished stone circlets comparable to the manufacturing wasters shown in Plate 7.

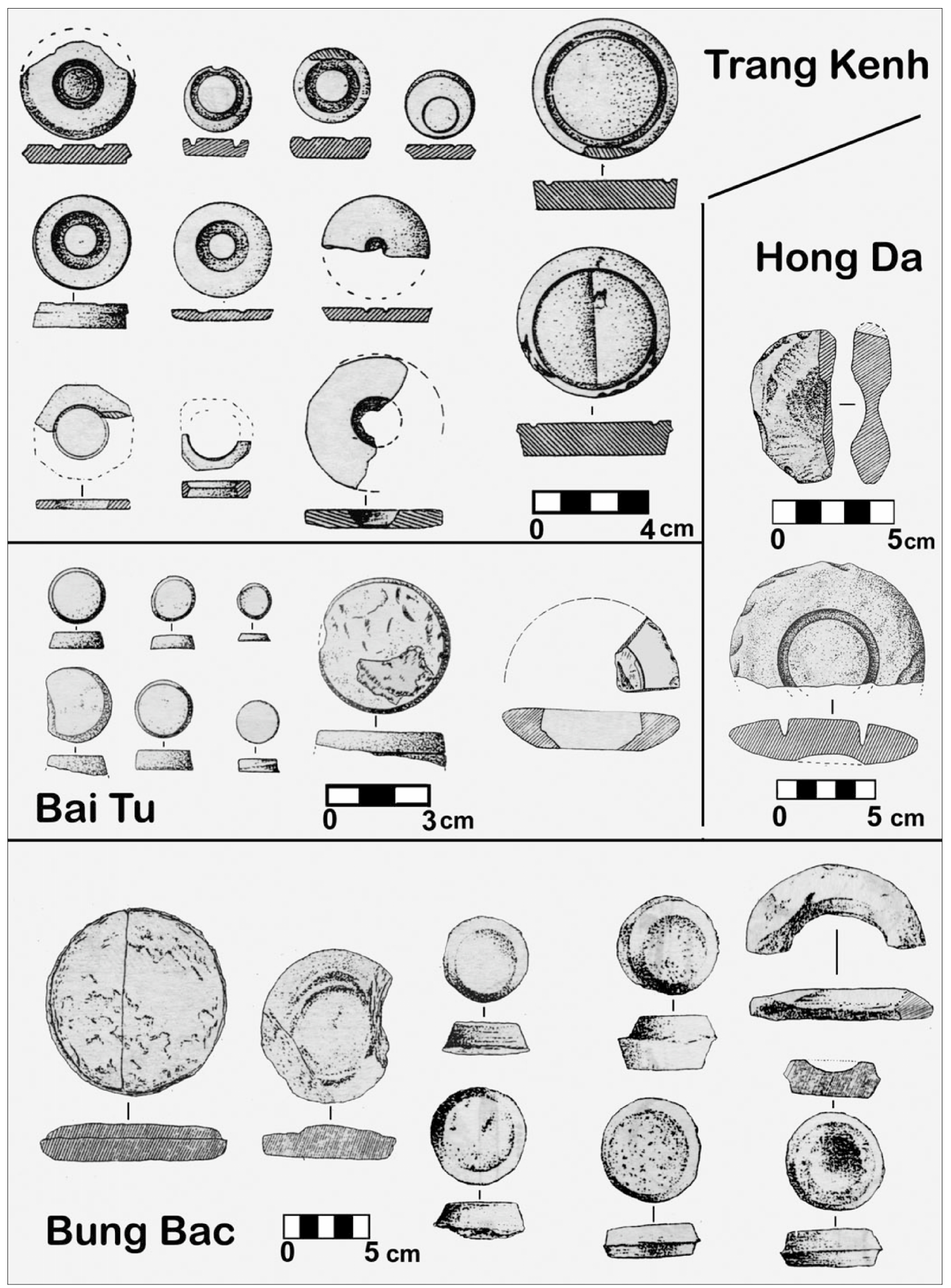

